\title{
Review \\ Putative Anticancer Compounds from Plant-Derived Endophytic Fungi: A Review
}

\author{
Md. Hridoy ${ }^{1,2}{ }^{D}$, Md. Zobayer Hossain Gorapi ${ }^{3}$, Sadia Noor ${ }^{3,4}$, Nargis Sultana Chowdhury ${ }^{5}$, \\ Md. Mustafizur Rahman ${ }^{6}{ }^{(D}$, Isabella Muscari ${ }^{7}$, Francesco Masia ${ }^{7}$, Sabrina Adorisio ${ }^{8}$, Domenico V. Delfino ${ }^{8, *}$ (D) \\ and Md. Abdul Mazid 1,4,*iD
}

check for updates

Citation: Hridoy, M.; Gorapi, M.Z.H.; Noor, S.; Chowdhury, N.S.;

Rahman, M.M.; Muscari, I.; Masia, F.; Adorisio, S.; Delfino, D.V.;

Mazid, M.A. Putative Anticancer Compounds from Plant-Derived Endophytic Fungi: A Review. Molecules 2022, 27, 296. https:// doi.org/10.3390/molecules27010296

Academic Editor: Josphat Matasyoh

Received: 22 November 2021

Accepted: 28 December 2021

Published: 4 January 2022

Publisher's Note: MDPI stays neutral with regard to jurisdictional claims in published maps and institutional affiliations.

Copyright: (C) 2022 by the authors. Licensee MDPI, Basel, Switzerland. This article is an open access article distributed under the terms and conditions of the Creative Commons Attribution (CC BY) license (https:// creativecommons.org/licenses/by/ $4.0 /)$.
Department of Pharmacy, University of Dhaka, Dhaka 1000, Bangladesh; md.hridoy@temple.edu

2 Department of Pharmaceutical Sciences, School of Pharmacy, Temple University, Philadelphia, PA 19140, USA

3 Department of Pharmacy, University of Asia Pacific, Dhaka 1215, Bangladesh; mdzobayerhossain14@gmail.com (M.Z.H.G.); noorsadia.du@uap-bd.edu (S.N.)

4 Department of Pharmaceutical Chemistry, Faculty of Pharmacy, University of Dhaka, Dhaka 1000, Bangladesh 5 Department of Pharmacy, Manarat International University, Dhaka 1343, Bangladesh; nargis@manarat.ac.bd

6 Pharmacy Discipline, Khulna University, Khulna 9208, Bangladesh; mmrahman0103@pharm.ku.ac.bd

7 Department of Medicine and Surgery, University of Perugia, 06132 Perugia, Italy; isa.muscari2@gmail.com (I.M.); francesco.masia@unipg.it (F.M.)

8 Department of Medicine and Surgery, Foligno Nursing School and Section of Pharmacology, University of Perugia, Piazzale Severi, S. Andrea delle Fratte, 06129 Perugia, Italy; adorisiosabrina@libero.it

* Correspondence: domenico.delfino@unipg.it (D.V.D.); ma.mazid@du.ac.bd (M.A.M.)

\begin{abstract}
Endophytic fungi are microorganisms that exist almost ubiquitously inside the various tissues of living plants where they act as an important reservoir of diverse bioactive compounds. Recently, endophytic fungi have drawn tremendous attention from researchers; their isolation, culture, purification, and characterization have revealed the presence of around 200 important and diverse compounds including anticancer agents, antibiotics, antifungals, antivirals, immunosuppressants, and antimycotics. Many of these anticancer compounds, such as paclitaxel, camptothecin, vinblastine, vincristine, podophyllotoxin, and their derivatives, are currently being used clinically for the treatment of various cancers (e.g., ovarian, breast, prostate, lung cancers, and leukemias). By increasing the yield of specific compounds with genetic engineering and other biotechnologies, endophytic fungi could be a promising, prolific source of anticancer drugs. In the future, compounds derived from endophytic fungi could increase treatment availability and cost effectiveness. This comprehensive review includes the putative anticancer compounds from plant-derived endophytic fungi discovered from 1990 to 2020 with their source endophytic fungi and host plants as well as their antitumor activity against various cell lines.
\end{abstract}

Keywords: endophytic fungi; anticancer compounds; living plants

\section{Introduction}

In 1866, de Bary introduced the term "endophyte" [1]. An endophyte may be a fungal or bacterial microorganism that colonizes various interior parts of plants causing no apparent pathogenic effects on its host plants. The endophytes, most commonly endophytic fungi, are believed to help plants adapt to abiotic factors (high temperature and salinity, drought, metal toxicity, and harmful effects of light) as well as biotic factors (herbivores, insects, nematodes, and pathogens). This is mainly achieved by the secondary bioactive metabolites produced by the endophytic fungi. In their symbiotic relation, the endophytes are fed and protected by the host plant, and in return, these microorganisms produce bioactive secondary metabolites, enhancing the growth of the host plant and protecting the plant from pathogens and herbivores [2]. Therefore, endophytic fungal metabolites can also be exploited as drugs for the treatment of various types of human diseases, including cancer [3]. 
This group of microorganisms has drawn tremendous attention from researchers since the isolation, culture, purification, and characterization of this fascinating group of microorganisms revealed the presence of hundreds of important and diverse chemical classes of compounds. The interest of scientists in endophytes is also growing as they are a good reservoir of bioactive metabolites [4,5]. Until now, many cytotoxic agents including paclitaxel (also known as Taxol) [6] have been isolated from endophytes. Secondary metabolites with cytotoxic properties have the potential to be explored as anticancer drugs.

Recent studies revealed that naphthoquinone derivatives fusarubins including anhydrofusarubin and fusarubin (FUS) produced by endophytic fungi Cladosporium species [7] and Fusarium species [8] showed promising cytotoxicity against cancer cells. Although FUS was reported earlier to have antibacterial activity, its cytotoxic activity was reported recently. Very recently, for the first time, we have revealed the molecular mechanism of cytotoxic action of fusarubin isolated from a Cladosporium species inhabiting the leaves of Rauwolfia serpentina. We have reported that fusarubin and anhydrofusarubin inhibit proliferation and increase apoptosis in leukemia and other hematological tumor cells lines in different manners through the p21/p53-mediated pathway [9]. Our findings urge us to write this review on endophytic fungal metabolites as a fascinating group of bioactives or putative anticancer compounds. Many of these putative anticancer compounds have very promising cytotoxicity against a broad spectrum of cancer cell lines; some compounds are already used as treatments for different cancer types such as breast, bladder, colorectal, esophageal, lung, ovarian, prostate, melanoma, testicular, leukemia, and lymphoma.

\section{Anticancer Activity of Endophytic Fungi}

Endophytic fungi have been a known source of anticancer agents since the discovery of the valuable drug Taxol (also known as paclitaxel, a diterpenoid) isolated for the first time from an endophytic fungus Taxomyces andreanae obtained from the Pacific Yew bark (Taxus brevifolia) [6]. Since then, other anticancer drugs have been isolated from endophytic fungi, and among these 9-methoxycamptothecin and 10-hydroxycamptothecin from Fusarium solani [10], camptothecin from Entrophospora infrequens [11]; the anticancer lead compounds podophyllotoxin from Phialocephala fortinii [12] and deoxypodophyllotoxin from Aspergillus fumigatus [13] fueled further research on endophytic fungi to discover many other important known and novel anticancer compounds. According to this review, until now, more than 100 different fungal species have been identified to produce more than two hundred putative anticancer compounds (Figures 1 and 2) reported to possess antiproliferative and/or cytotoxic properties against more than 60 different cell lines (Tables 1-3). Figure 1 indicates that endophytic fungal-derived anticancer agents gained attention from scientists over the past three decades. Meanwhile, Figure 2 represents the abundance of different chemical classes and diversity of fungal metabolites. The anticancer compounds isolated from endophytic fungi are effective against diverse cell lines that could be helpful in combating any particular type of cancer (Table 1).

Table 1. Different cell lines against which endophytic fungal derived metabolites showed cytotoxicity.

\begin{tabular}{cccc}
\hline & Cell Lines & & Cell Lines \\
\hline A2780S & Ovarian tumor cell line & Int-407 & Human intestine cancer \\
A2058 & Human melanoma & Jurkat & Tuman nasopharyngeal leukemia \\
A549 & Lung carcinoma epithelial & KB & epidermoid tumor \\
A431 & Skin carcinoma & K562 & Mouman leukemia cells \\
ACHN & Renal cells & L5178Y & Pancreatic carcinoma cells \\
AsPC-1 & Human pancreatic cancer cells & MIA Pa Ca-2 & Pancreatic cancer \\
B16F10 & Skin carcinoma & MiaPaka-2 & Breast cancer cell line \\
BC & Human breast cancer cell line & MDA-MB-231 & Human breast cancer cell line \\
BC-1 & Breast cancer & MDA-MB-435 &
\end{tabular}


Table 1. Cont.

\begin{tabular}{|c|c|c|c|}
\hline \multicolumn{2}{|r|}{ Cell Lines } & \multicolumn{2}{|c|}{ Cell Lines } \\
\hline BEL-7402 & $\begin{array}{l}\text { Human hepatocellular } \\
\text { carcinoma/human hepatoma cell line }\end{array}$ & MFC & Gastric cancer cells in mice \\
\hline BEL-7404 & $\begin{array}{l}\text { Human hepatocellular } \\
\text { carcinoma/human hepatoma cell line }\end{array}$ & MCF-7 & Breast cancer cell line \\
\hline BGC-823 & Gastric carcinoma & MOLT-4 & Lymphoblastic leukemia \\
\hline BT-220 & Breast cancer cell line & MRC-5 & Fibroblast-like fetal lung cells \\
\hline BT474 & Human breast cancer & MV4-11 & $\begin{array}{l}\text { Human FLT3-ITD mutant AML } \\
\text { cell line }\end{array}$ \\
\hline CHO & Chinese hamster ovary & NCI-H187 & Human small-cell lung cancer \\
\hline DU145 & Human prostate carcinoma & NCI-H460 & Non-small-cell lung cancer \\
\hline EAC & Ehrlich ascites carcinoma & NEC & $\begin{array}{l}\text { Colorectal neuroendocrine } \\
\text { cell carcinoma }\end{array}$ \\
\hline H116 & Human colon adenocarcinoma & OVCAR-5 & Human ovarian cancer \\
\hline HeLa & Cervical cancer & PANC-1 & Human pancreatic carcinoma \\
\hline HEp-2 & Human liver cancer & P388 & Murine leukemia cells \\
\hline HepG2 & $\begin{array}{l}\text { Human hepatocellular } \\
\text { liver carcinoma }\end{array}$ & PC-3 & Prostate cancer \\
\hline Hep3B & Human hepatoma cell line & PC-3 M & Metastatic prostate cancer \\
\hline HM02 & Human gastric carcinoma & RAW264.7 & Mouse macrophage cell \\
\hline HL-60 & $\begin{array}{l}\text { Human promyelocytic leukemia } \\
\text { cell line }\end{array}$ & SF-268 & CNS glioma \\
\hline HL251 & Human lung cancer & SW480 & Human colon cancer cells \\
\hline HL-7702 & Normal hepatocyte & SW-620 & Colon tumor cell line \\
\hline HLK 210 & Human leukemia & SW1116 & Human colon cancer cell line \\
\hline НСТ-8 & Human colorectal adenocarcinoma & SW1990 & Human pancreatic cancer cells \\
\hline НСТ-116 & Colon tumor cell line & T24 & Bladder carcinoma \\
\hline H22 & Hepatic cancer cells in mice & T47D & Breast cancer \\
\hline H1975 & $\begin{array}{l}\text { Non-small-cell lung cancer } \\
\text { cells/human lung adenocarcinoma }\end{array}$ & THP-1 & Human monocytic cell line \\
\hline H522-T1 & Non-small cell lung cancer & WI-38 & Normal human fibroblast cells \\
\hline HT-29 & Human colon cancer line & U2OS & Human osteosarcoma cells \\
\hline
\end{tabular}

Table 2. Anticancer compounds from plant-derived endophytic fungi.

\begin{tabular}{|c|c|c|c|c|c|c|}
\hline Compounds & Chemical Class & $\begin{array}{c}\text { Fungal } \\
\text { Endophytes }\end{array}$ & Host Medicinal Plant & $\begin{array}{l}\text { Activity Against } \\
\text { Cell Lines }\end{array}$ & IC50 Values & Ref. \\
\hline Leucinostatin A & Peptide & \multirow{2}{*}{$\begin{array}{l}\text { Acremonium spp. } \\
\text { Allantophomopsis } l \text {. } \\
\text { KS-97 }\end{array}$} & \multirow[t]{2}{*}{ Taxus baccata twig } & BT-20 & $2 \mathrm{nM}(\mathrm{LD} 50)$ & {$[14]$} \\
\hline Allantopyrone A & $\alpha$-Pyrone & & & A549 cells, HL-60 & $>32,0.32 \mu \mathrm{M}$ & {$[15]$} \\
\hline $\begin{array}{c}\text { Alternariol, } \\
\text { Altenusin, } \\
\text { Alternariol } \\
\text { 5-O-sulfate, } \\
\text { Alternariol } \\
\text { 5-O-methyl ether, } \\
\text { Desmethylaltenusin }\end{array}$ & Polyketide & Alternaria spp & $\begin{array}{c}\text { Polygonum senegalense } \\
\text { leaves }\end{array}$ & L5178Y & $\begin{array}{c}<1 \times 10^{-6} \\
1 \times 10^{-5}, 1 \times 10^{-5} \\
1 \times 10^{-5}, 1 \times 10^{-5} \\
\mathrm{~g} / \mathrm{mL}\end{array}$ & [16] \\
\hline Lapachol & $\begin{array}{l}\text { Naphtho- } \\
\text { quinone }\end{array}$ & Alternaria spp. & Tabebuia argentea leaf & $\begin{array}{l}\text { DU145, HepG2, } \\
\text { Hep3B \& MCF-7 } \\
\text { ( } \beta \text {-Lapachone) }\end{array}$ & $3.5,3.5,3.5 \& 5 \mu \mathrm{M}$ & [17-22] \\
\hline $\begin{array}{c}\text { Resveratrodehydes } \\
\text { A \& B }\end{array}$ & $\begin{array}{l}\text { Stilbenoid } \\
\text { (Resveratrol } \\
\text { dervatives) }\end{array}$ & Alternaria spp. R6 & $\begin{array}{c}\text { Myoporum bontioides } \\
\text { root }\end{array}$ & $\begin{array}{l}\text { MDA-MB-435, } \\
\text { HCT-116 }\end{array}$ & $<10 \mu \mathrm{M}$ & [23] \\
\hline $\begin{array}{l}\text { Alterporriol K, } \\
\text { Alterporriol L }\end{array}$ & Quinones & $\begin{array}{l}\text { Alternaria spp. } \\
\text { ZJ9-6B }\end{array}$ & Aegiceras corniculatum & $\begin{array}{l}\text { MDA-MB-435, } \\
\text { MCF-7 }\end{array}$ & $\begin{array}{c}26.97,29.11 \& 13.11 \\
20.04 \mu \mathrm{M}\end{array}$ & {$[24]$} \\
\hline $\begin{array}{l}\text { Alternariol-10- } \\
\text { methyl ether }\end{array}$ & Polyketide & Alternaria a. & Capsicum annum & $\begin{array}{c}\text { HL-60, A549, } \\
\text { PC-3, HeLa, A431, } \\
\text { MiaPaka-2 and } \\
\text { T47D }\end{array}$ & $\begin{array}{c}85,>100,>100,>100 \\
95,>100 \text { and }>100 \\
\mu \mathrm{M}\end{array}$ & [25] \\
\hline
\end{tabular}


Table 2. Cont.

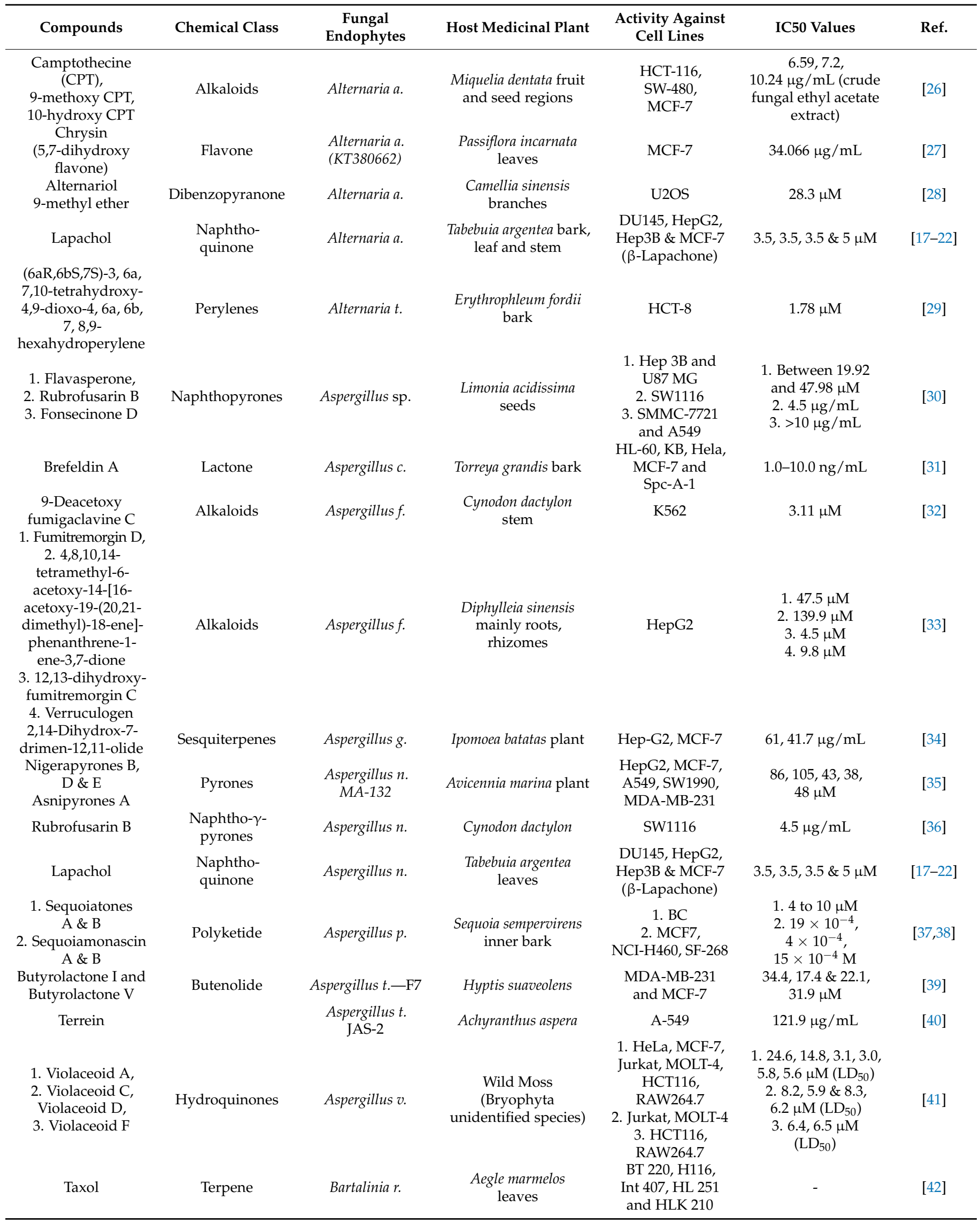


Table 2. Cont.

\begin{tabular}{|c|c|c|c|c|c|c|}
\hline Compounds & Chemical Class & $\begin{array}{c}\text { Fungal } \\
\text { Endophytes }\end{array}$ & Host Medicinal Plant & $\begin{array}{l}\text { Activity Against } \\
\text { Cell Lines }\end{array}$ & IC50 Values & Ref. \\
\hline Depsidone 1 & Depsidone & $\begin{array}{c}\text { Pleosporales (BCC } \\
8616)\end{array}$ & $\begin{array}{c}\text { unidentified plant leaf } \\
\text { of the Hala-Bala forest } \\
\text { origin }\end{array}$ & $\mathrm{KB}, \mathrm{BC}$ & $6.5,4.1 \mu \mathrm{g} / \mathrm{mL}$ & [43] \\
\hline $\begin{array}{l}\text { 1. Diepoxin } \delta, \\
\text { Palmarumycin } C 8 \\
\text { 2. Diepoxins } \kappa \& \zeta\end{array}$ & $\begin{array}{l}\text { Spirobis- } \\
\text { naphthalenes }\end{array}$ & Berkleasmium spp. & Dioscorea zingiberensis & $\begin{array}{c}\text { 1. HCT-8, } \\
\text { Bel-7402, } \\
\text { BGC-823, A } \\
\text { 549, A2780 } \\
\text { 2. Bel-7402 and } \\
\text { A } 549\end{array}$ & $\begin{array}{c}\text { 1. } 1.7,3.3,3.3,3.2 \\
\text { 5.8 \& } 4.2,2.5,2.6 \\
1.6,1.3 \mu \mathrm{M} \\
\text { 2. } 6.4,8.7 \& 5.1 \\
8.8 \mu \mathrm{M}\end{array}$ & {$[44]$} \\
\hline Verticillin D & Peptide & Bionectria o. & $\begin{array}{l}\text { Sonneratia caseolaris } \\
\text { Inner leaf tissues }\end{array}$ & L5178Y & $<0.1 \mu \mathrm{g} / \mathrm{mL}(\mathrm{EC} 50)$ & {$[45]$} \\
\hline Ophiobolin A & Sesterterpenoid & Bipolaris s. & Unidentified & MDA-MB-231 & $0.4-4.3 \mu \mathrm{M}$ & [46] \\
\hline $\begin{array}{c}1 . \\
\text { Stemphyperylenol } \\
\text { 2. Altenuene }\end{array}$ & $\begin{array}{l}\text { 1. Polyketide } \\
\text { 2. Mycotoxin }\end{array}$ & $\begin{array}{l}\text { Botryosphaeria d. } \\
\text { KJ-1 }\end{array}$ & $\begin{array}{c}\text { Melia azedarach stem } \\
\text { bark }\end{array}$ & HCT116 & $3.13 \mu \mathrm{M}$ & [47] \\
\hline $\begin{array}{c}\text { Botryorhodine A } \\
\text { and B }\end{array}$ & Depsidone & Botryosphaeria $r$. & Bidens pilosa stem & HeLa, K-562 & $\begin{array}{c}96.97,36.41 \& 0.84 \\
0.003 \mu \mathrm{M}\left(\mathrm{CC}_{50}\right)\end{array}$ & [48] \\
\hline Cercosporene F & $\begin{array}{l}\text { Guanacastane } \\
\text { Diterpenes }\end{array}$ & Cercospora spp. & Fallopia japonica leaves & $\begin{array}{l}\text { HeLa, A549, } \\
\text { MCF-7, HCT116 } \\
\text { and T24 }\end{array}$ & $\begin{array}{c}19.3,29.7,46.1,21.3 \\
\& 8.16 \mu \mathrm{M}\end{array}$ & [49] \\
\hline $\begin{array}{l}\text { Ceriponol F, } \\
\text { Ceriponol G, } \\
\text { Ceriponol K }\end{array}$ & Sesquiterpenes & Ceriporia 1. & Huperzia serrata & $\begin{array}{l}\text { HeLa, HepG2, } \\
\text { SGC7901 }\end{array}$ & $\begin{array}{c}173.2,32.3,77.5 \\
185.1,>500.0,>500.0 \\
\& 47.8,35.8 \\
60.2 \mu \mathrm{M}\end{array}$ & {$[50]$} \\
\hline $\begin{array}{l}\text { Cochliodinol, } \\
\text { Isocochliodinol }\end{array}$ & Quinones & Chaetomium spp. & $\begin{array}{c}\text { Salvia } \\
\text { officinalis Stem }\end{array}$ & L5178Y & $\begin{array}{c}7.0,71.5 \mu \mathrm{g} / \mathrm{mL} \\
(\mathrm{EC} 50)\end{array}$ & {$[51]$} \\
\hline Chaetocochin C & Diketopiperazine & Chaetomium spp. & $\begin{array}{c}\text { Cymbidium goeringii } \\
\text { root }\end{array}$ & SW-480 & $0.63 \mu \mathrm{M}$ & {$[52]$} \\
\hline Chaetocochin G & $\begin{array}{l}\text { Indole diketo- } \\
\text { piperazines }\end{array}$ & $\begin{array}{l}\text { Chaetomium spp. } \\
88194\end{array}$ & Cymbidium goeringii & MCF-7 & $8.3 \mathrm{mg} / \mathrm{mL}$ & {$[53]$} \\
\hline Chaetominine & Alkaloids & $\begin{array}{l}\text { Chaetomium spp. } \\
\text { IFB-E015 }\end{array}$ & $\begin{array}{c}\text { Adenophora } \\
\text { axilliflora leaves }\end{array}$ & K562, SW1116 & $21.0,28.0 \mathrm{nM}$ & {$[54]$} \\
\hline Radicicol & Lactone & Chaetomium c. & $\begin{array}{c}\text { Ephedra fasciculate } \\
\text { stem }\end{array}$ & MCF-7 & $0.03 \mu \mathrm{M}$ & {$[55]$} \\
\hline Chaetoglobosin X & Alkaloids & $\begin{array}{l}\text { Chaetomium g. } \\
\text { L18 }\end{array}$ & Curcuma wenyujin & $\mathrm{H} 22, \mathrm{MFC}$ & $3.125,6.25 \mu \mathrm{g} / \mathrm{mL}$ & {$[56]$} \\
\hline $\begin{array}{c}\text { Chaetoglobosin C, } \\
\text { E, F \& U, } \\
\text { Penochalasin A }\end{array}$ & Alkaloids & $\begin{array}{l}\text { Chaetomium g. } \\
\text { IFB-E019 }\end{array}$ & $\begin{array}{c}\text { Imperata cylindrica } \\
\text { stem }\end{array}$ & KB cell line & $\begin{array}{c}34.0,40.0,48.0 \& \\
16.0,48.0 \mu \mathrm{M}\end{array}$ & [57] \\
\hline $\begin{array}{l}\text { Globosumone } \\
\text { A \& B }\end{array}$ & Ester & Chaetomium g. & Ephedra fasciculata & $\begin{array}{l}\text { NCI-H460, } \\
\text { MCF-7, SF-268, } \\
\text { MIA Pa Ca-2, } \\
\text { WI-38 }\end{array}$ & $\begin{array}{c}6.50,21.30,8.80, \\
10.60,13.00 \& 24.80, \\
21.90,29.10,30.20 \\
14.20 \mu \mathrm{M}\end{array}$ & [58] \\
\hline $\begin{array}{l}\text { Chaetoglobosins A, } \\
\mathrm{F}_{\mathrm{ex}}, \mathrm{F}_{\mathrm{a}} \text { \& } 20- \\
\text { dihydrochaetoglobosin }\end{array}$ & $\begin{array}{l}\text { Alkaloids } \\
\text { (cytochalasan } \\
\text { mycotoxins) }\end{array}$ & Chaetomium g. & Ginkgo biloba leaves & HCT116 & $\begin{array}{c}3.15,4.43,5.85 \\
8.44 \mu \mathrm{M}\end{array}$ & [59] \\
\hline $\begin{array}{l}\text { Annydrofusarubin } \\
\text { and } \\
\text { methyl ether of } \\
\text { Fusarubin }\end{array}$ & $\begin{array}{l}\text { Naphtho- } \\
\text { quinones }\end{array}$ & Cladosporium spp. & $\begin{array}{c}\text { Rauwolfia serpentina } \\
\text { leaves }\end{array}$ & $\mathrm{K}-562$ & $3.97 \& 3.58 \mu \mathrm{g} / \mathrm{mL}$ & [7] \\
\hline Taxol & Diterpene & Cladosporium c. & Taxus media inner bark & $\begin{array}{l}\text { MCF-7, BT220, } \\
\text { H116, INT-407, } \\
\text { HL251, HLK210 }\end{array}$ & 0.005 to $5 \mu \mathrm{M}$ & {$[60,61]$} \\
\hline Taxol & Diterpene & Cladosporium o. & $\begin{array}{c}\text { Aegle marmelos, } \\
\text { Coccinia indica and } \\
\text { Moringa oleifera }\end{array}$ & HCT 15, T47D & $3.5,2.5 \mu \mathrm{M}$ & {$[62,63]$} \\
\hline Taxol & Diterpene & Colletotrichum c. & Capsicum annuum fruit & $\begin{array}{l}\text { MCF-7, HL 251, } \\
\text { HLK 210, } \\
\text { BEL7402 }\end{array}$ & 0.005 to $5 \mu \mathrm{M}$ & {$[64,65]$} \\
\hline Tyrosol C & \# & Colletotrichum g. & $\begin{array}{l}\text { Pandanus } \\
\text { amaryllifolius } \\
\text { leaves }\end{array}$ & $\begin{array}{l}\text { A549, HT29, } \\
\text { HCT116 }\end{array}$ & - & {$[66]$} \\
\hline $\begin{array}{l}\text { Deacetylcytochalasin } \\
\text { C and } \\
\text { Zygosporin D }\end{array}$ & Cytochalasins & Cordyceps $t$. & unidentified & 95-D & $3.67 \& 4.04 \mu \mathrm{M}$ & {$[67]$} \\
\hline
\end{tabular}


Table 2. Cont.

\begin{tabular}{|c|c|c|c|c|c|c|}
\hline Compounds & Chemical Class & $\begin{array}{c}\text { Fungal } \\
\text { Endophytes }\end{array}$ & Host Medicinal Plant & $\begin{array}{l}\text { Activity Against } \\
\text { Cell Lines }\end{array}$ & IC50 Values & Ref. \\
\hline $\begin{array}{l}\text { 1. Cytospolide } \mathrm{P} \text {, } \\
\text { 2. Cytospolide Q }\end{array}$ & Lactones & Cytospora spp. & Ilex canariensis & $\begin{array}{c}\text { 1. A-549, QGY, } \\
\text { U973 } \\
\text { 2. A-549 }\end{array}$ & $\begin{array}{c}\text { 1. } 2.05,15.82,28.26 \\
\mu \mathrm{g} / \mathrm{mL} \\
\text { 2. } 10.55 \mu \mathrm{g} / \mathrm{mL}\end{array}$ & [68] \\
\hline Xylarolide & \# & $\begin{array}{l}\text { Diaporthe } t . \\
\text { GG3F6. }\end{array}$ & $\begin{array}{l}\text { Glycyrrhiza glabra } \\
\text { rhizomes }\end{array}$ & T47D & $7 \mu \mathrm{M}$ & {$[69]$} \\
\hline Taxol & Diterpenes & Didymostilbe spp. & $\begin{array}{l}\text { Taxus chinensis var. } \\
\text { mairei old inner bark }\end{array}$ & $\begin{array}{c}\text { MCF-7, HL 251, } \\
\text { HLK 210, } \\
\text { BEL7402 }\end{array}$ & 0.005 to $5 \mu \mathrm{M}$ & {$[64,65]$} \\
\hline Camptothecin & Alkaloids & Entrophospora i. & $\begin{array}{l}\text { Nothapodytes foetida } \\
\text { inner bark }\end{array}$ & $\begin{array}{l}\text { A-549, HEP-2, } \\
\text { OVCAR-5 }\end{array}$ & - & [11] \\
\hline $\begin{array}{l}\text { 1. Eutypellin A, } \\
\text { 2. ent-4(15)- } \\
\text { eudesmen-11-ol-1- } \\
\text { one }\end{array}$ & $\begin{array}{l}\text { 1. } \gamma \text {-Lactone } \\
\text { 2. Sesquiterpene }\end{array}$ & $\begin{array}{l}\text { Eutypella sp. BCC } \\
13199\end{array}$ & Etlingera littoralis & $\begin{array}{l}\text { NCI-H187, MCF7, } \\
\text { KB, Vero cells }\end{array}$ & $\begin{array}{l}\text { 1. } 12,84,38,88 \mu \mathrm{M} \\
\text { 2. } 11,20,32,32 \mu \mathrm{M}\end{array}$ & [70] \\
\hline $\begin{array}{c}\text { Camptothecine } \\
\text { (CPT), } \\
\text { 9-methoxy CPT, } \\
\text { 10-hydroxy CPT }\end{array}$ & Alkaloids & Fomitopsis spp. & $\begin{array}{l}\text { Miquelia dentata fruit } \\
\text { and seed regions }\end{array}$ & $\begin{array}{l}\text { HCT-116, } \\
\text { SW-480, } \\
\text { MCF-7 }\end{array}$ & $\begin{array}{c}5.63,23.5, \\
10.32 \mu \mathrm{g} / \mathrm{mL} \text { (crude } \\
\text { fungal ethyl acetate } \\
\text { extract) }\end{array}$ & [26] \\
\hline Beauvericin & Depsipeptide & Fusarium o. & $\begin{array}{l}\text { Cinnamomum } \\
\text { kanehirae bark }\end{array}$ & $\begin{array}{c}\text { PC-3, PANC-1, } \\
\text { A549 }\end{array}$ & $49.5,47.2,10.4 \mu \mathrm{M}$ & {$[71]$} \\
\hline Taxol & Diterpenes & Fusarium o. & $\begin{array}{c}\text { Rhizomphora } \\
\text { annamalayana leaves }\end{array}$ & $\begin{array}{l}\text { BT220, HL251, } \\
\text { HLK } 210\end{array}$ & 0.005 to $5 \mu \mathrm{M}$ & {$[72,73]$} \\
\hline Vincristine & Alkaloids & Fusarium o. & $\begin{array}{c}\text { Catharanthus roseus } \\
\text { inner bark }\end{array}$ & $\begin{array}{c}\text { HeLa, MCF7, } \\
\text { A549, U251, A431 } \\
\text { \& HEK293 }\end{array}$ & $\begin{array}{l}4.2,4.5,5.5,5.5 \\
\quad 5.8 \mu \mathrm{g} / \mathrm{mL}\end{array}$ & {$[74,75]$} \\
\hline Beauvericin & Depsipeptide & Fusarium o. & $\begin{array}{l}\text { Cinnamomum } \\
\text { kanehirae bark }\end{array}$ & $\begin{array}{c}\text { PC-3, PANC-1, } \\
\text { A549 } \\
\text { NCI-H460, MIA }\end{array}$ & $49.5,47.2,10.4 \mu \mathrm{M}$ & [71] \\
\hline Beauvercin & Depsipeptide & Fusarium o. & Ephedra fasciculata root & $\begin{array}{l}\text { Pa Ca-2, MCF-7, } \\
\text { SF-268, PC-3 M, } \\
\text { MDA-MB-231, } \\
\text { MRC-5, Hep-G2 }\end{array}$ & $\begin{array}{c}1.41,1.66,1.81,2.29 \\
3.0,5.0,4.7-5.0 \\
8.8-22.2 \mu \mathrm{M}\end{array}$ & {$[76,77]$} \\
\hline Beauvercin & Depsipeptide & $\begin{array}{l}\text { Fusarium o. } \\
\text { EPH2RAA }\end{array}$ & $\begin{array}{l}\text { Cylindropuntia } \\
\text { echinocarpus } \\
\text { stem }\end{array}$ & $\begin{array}{l}\text { NCI-H460, MIA } \\
\text { Pa Ca-2, MCF-7, } \\
\text { SF-268, PC-3 M, } \\
\text { MDA-MB-231 } \\
\text { NCI-H460, MIA }\end{array}$ & $\begin{array}{c}1.41,1.66,1.81,2.29 \\
3.0,5.0 \mu \mathrm{M}\end{array}$ & {$[77]$} \\
\hline Bikaverin & Polyketide & $\begin{array}{l}\text { Fusarium o. } \\
\text { CECIS }\end{array}$ & $\begin{array}{c}\text { Cylindropuntia } \\
\text { echinocarpus } \\
\text { stem }\end{array}$ & $\begin{array}{l}\text { Pa Ca-2, MCF-7, } \\
\text { SF-268, EAC, } \\
\text { leukemia L 5178, } \\
\text { sarcoma } 37\end{array}$ & $\begin{array}{c}1.41,1.66,1.81,2.29 \\
0.5,1.4,4.2 \mu \mathrm{g} / \mathrm{mL} \\
\left(\mathrm{ED}_{50}\right)\end{array}$ & {$[77,78]$} \\
\hline $\begin{array}{l}\text { Camptothecin } \\
\text { (CPT) and } \\
\text { 9-methoxy CPT }\end{array}$ & Alkaloids & $\begin{array}{c}\text { Fusarium s. } \\
\text { (MTCC } 9667 \text { and } \\
\text { MTCC 9668) }\end{array}$ & $\begin{array}{l}\text { Apodytes } \\
\text { dimidiata }\end{array}$ & $\begin{array}{l}\text { HCT-116, } \\
\text { SW-480, } \\
\text { MCF-7 }\end{array}$ & $\begin{array}{c}7,8.5,8 \& \\
7,8.5,8 \mu \mathrm{g} / \mathrm{mL}\end{array}$ & {$[10,26]$} \\
\hline Podophyllotoxin & Lignans & Fusariums. & $\begin{array}{c}\text { Podophyllum } \\
\text { hexandrum roots }\end{array}$ & $\#$ & - & [79] \\
\hline $\begin{array}{c}\text { Camptothecine } \\
\text { (CPT), } \\
\text { 9-methoxy CPT, } \\
\text { 10-hydroxy CPT }\end{array}$ & Alkaloids & Fusariums. & $\begin{array}{c}\text { Camptotheca acuminata } \\
\text { inner bark }\end{array}$ & $\begin{array}{c}\text { OVCAR-5, } \\
\text { HCT-116 } \\
\text { SW-480, MCF-7 }\end{array}$ & $\begin{array}{c}7,8.5,8 \& \\
7,8.5,8 \mu \mathrm{g} / \mathrm{mL}\end{array}$ & {$[26,80]$} \\
\hline $\begin{array}{l}\text { Gliocladicillins } \\
\text { A \& B }\end{array}$ & $\begin{array}{l}\text { Epipolythiodi- } \\
\text { oxopiperazines }\end{array}$ & $\begin{array}{l}\text { Gliocladium spp. } \\
\text { XZC04-CC-302 }\end{array}$ & $\begin{array}{l}\text { Cordyceps sinensis } \\
\text { bark. }\end{array}$ & $\begin{array}{l}\text { HeLa, HepG2, } \\
\text { MCF-7 }\end{array}$ & $\begin{array}{c}0.50 \\
0.50,0.20 \mu \mathrm{g} / \mathrm{mL} \\
\left(\mathrm{GI}_{50}\right)\end{array}$ & [81] \\
\hline Guignarenone A & $\begin{array}{l}\text { Tricyclo- } \\
\text { alternarene }\end{array}$ & $\begin{array}{l}\text { Guignardia } b . \\
\text { PSU-G11 }\end{array}$ & $\begin{array}{c}\text { Garcinia hombroniana } \\
\text { leaves }\end{array}$ & KB, Vero & $0.38,2.24 \mu \mathrm{M}$ & [82] \\
\hline $\begin{array}{l}\text { Guignardones } \\
\text { Q \& S }\end{array}$ & Meroterpenoids & $\begin{array}{l}\text { Guignardia } m . \\
\text { A348 }\end{array}$ & $\begin{array}{c}\text { Smilax glabra } \\
\text { leaves }\end{array}$ & MCF-7 & $83.7 \& 92.1 \mu \mathrm{M}$ & [83] \\
\hline $\begin{array}{c}\text { Cajanol } \\
\text { (5-hydroxy-3-(4- } \\
\text { hydroxy-2- } \\
\text { methoxyphenyl)-7- } \\
\text { methoxychroman- } \\
\text { 4-one) }\end{array}$ & Flavonoids & Hypocrea 1. & $\begin{array}{c}\text { Cajanus cajan roots, } \\
\text { stems and leaves }\end{array}$ & $\begin{array}{l}\text { 1. A549 } \\
\text { 2. PC-3, HT-29, } \\
\text { HepG2 }\end{array}$ & $\begin{array}{c}\text { 1. } 20.5 \mu \mathrm{g} / \mathrm{mL} \text { after } \\
72 \mathrm{~h} \text { treatment, } \\
24.6 \mu \mathrm{g} / \mathrm{mL} \text { after } \\
48 \mathrm{~h} \text {; and } \\
32.8 \mu \mathrm{g} / \mathrm{mL} \text { after } \\
24 \mathrm{~h} \\
\text { 2. } 29.8,21.4, \\
\text { 33.6 } \mu \mathrm{g} / \mathrm{mL} \text { (Fungal } \\
\text { crude extract) }\end{array}$ & [84] \\
\hline
\end{tabular}


Table 2. Cont.

\begin{tabular}{|c|c|c|c|c|c|c|}
\hline Compounds & Chemical Class & $\begin{array}{c}\text { Fungal } \\
\text { Endophytes }\end{array}$ & Host Medicinal Plant & $\begin{array}{l}\text { Activity Against } \\
\text { Cell Lines }\end{array}$ & IC50 Values & Ref. \\
\hline Daldinone C \& D & Benzo[j]fluoranthene & $\begin{array}{l}\text { Hypoxylon } t \text {. } \\
\text { IFB-18 }\end{array}$ & $\begin{array}{l}\text { Artemisia annua } \\
\text { surface-sterilized } \\
\text { fresh stems }\end{array}$ & SW1116 & $49.5 \& 41.0 \mu \mathrm{M}$ & [85] \\
\hline $\begin{array}{l}\text { 1. * Brefeldin A, } \\
\text { trichothecolone, } \\
7 \alpha \text {-hydroxy- } \\
\text { scirpene } \\
\text { 2. 8-deoxy- } \\
\text { trichothecin, } \\
7 \alpha- \\
\text { hydroxytrichodermol }\end{array}$ & $\begin{array}{c}\text { * Lactone, } \\
\text { Sesquiterpenes } \\
\text { (trichothecenes) }\end{array}$ & $\begin{array}{c}\text { KLAR } 5 \\
\text { (Hypocreales) }\end{array}$ & $\begin{array}{l}\text { Knema laurina } \\
\text { healthy twig }\end{array}$ & $\begin{array}{l}\text { 1. KB, BC-1, } \\
\text { NCI-H187 } \\
\text { 2. BC-1, } \\
\text { NCI-H187 }\end{array}$ & $\begin{array}{c}\text { 1. } 0.18,0.04,0.1 ; \\
\text { 12.90, 10.06, } 11.31 \& \\
>75.10,2.37 \\
1.73 \mu \mathrm{M} \\
\text { 2. }>62.81,0.88,1.48 \\
\& 8.47,21.53 \\
27.76 \mu \mathrm{M}\end{array}$ & [86] \\
\hline Taxol & Diterpenes & Lasiodiplodia $t$. & $\begin{array}{c}\text { Morinda citrifolia } \\
\text { leaves }\end{array}$ & $\begin{array}{c}\text { 1. MCF-7 } \\
\text { 2. BT220, H116, } \\
\text { INT-407, HL251, } \\
\text { HLK210 }\end{array}$ & $\begin{array}{l}\text { 1. } 300 \mu \mathrm{g} / \mathrm{mL} \\
\text { 2. } 0.005-5.00 \mu \mathrm{M}\end{array}$ & {$[60,87]$} \\
\hline Lasiodiplodin & Macrolide & $\begin{array}{l}\text { Lasiodiplodia } t . \\
\text { (MUB-65) }\end{array}$ & $\begin{array}{c}\text { Myracrodruon } \\
\text { urundeuva } \\
\text { branches }\end{array}$ & HCT-116 & $11.2 \mu \mathrm{g} / \mathrm{mL}$ & [88] \\
\hline Vincristine & Alkaloids & $\begin{array}{c}\text { Mycelia s. 97CY } \\
\text { (3) }\end{array}$ & $\begin{array}{c}\text { Catharanthus roseus } \\
\text { leaves }\end{array}$ & $\begin{array}{c}\text { HeLa, MCF7, } \\
\text { U251, A549, A431 } \\
\text { \& HEK293 }\end{array}$ & $\begin{array}{l}4.2,4.5,5.5,5.5 \\
\quad 5.8 \mu \mathrm{g} / \mathrm{mL}\end{array}$ & {$[74,89]$} \\
\hline Spiromamakone A & $\begin{array}{c}\text { Spirobis } \\
\text { naphthalene }\end{array}$ & Mycelias. & $\begin{array}{c}\text { Knightia excelsa } \\
\text { surface-sterilized } \\
\text { leaves }\end{array}$ & P388 & $0.33 \mu \mathrm{M}$ & [90] \\
\hline Cercosporin & Quinones & $\begin{array}{l}\text { Mycosphaerella } \\
\text { spp. }\end{array}$ & Psychotria horizontalis & MCF7 & $4.68 \mu \mathrm{M}$ & [91] \\
\hline Arundinone B & Coumarins & Microsphaeropsis a. & $\begin{array}{c}\text { Ulmus macrocarpa } \\
\text { stems }\end{array}$ & T24, A549 & $35.4,81.6 \mu \mathrm{M}$ & [92] \\
\hline Mycoleptodiscin B & Alkaloids & $\begin{array}{l}\text { Mycoleptodiscus } \\
\text { spp. F0194 }\end{array}$ & $\begin{array}{c}\text { Desmotes } \\
\text { incomparabilis healthy } \\
\text { mature leaves }\end{array}$ & $\begin{array}{l}\text { H460, A2058, } \\
\text { H522-T1, PC-3, } \\
\text { IMR-90 }\end{array}$ & $\begin{array}{c}0.66,0.78,0.63,0.60 \\
0.41 \mu \mathrm{M}\end{array}$ & [93] \\
\hline Myrotheciumone A & Lactone & Myrothecium r. & Ajuga decumbens & $\begin{array}{c}\text { HepG2, } \\
\text { SMMC-7721, } \\
\text { A549, MCF-7 } \\
\text { cells, QSG-7701, } \\
\text { HL-7702 }\end{array}$ & $\begin{array}{c}5.36,6.56,5.88,7.56 \\
16.30,20.69 \mu \mathrm{M}\end{array}$ & [94] \\
\hline Dihydromyrothecine C & $\begin{array}{l}\text { Trichothecene } \\
\text { Macrolide }\end{array}$ & $\begin{array}{l}\text { Myrothecium r. } \\
\text { IFB-E012 }\end{array}$ & Artemisia annua & $\mathrm{KB}$ & $44.48 \mu \mathrm{M}$ & [95] \\
\hline Camptothecin & Alkaloids & Neurosporac. & $\begin{array}{c}\text { Nothapodytes foetida } \\
\text { seed }\end{array}$ & $\begin{array}{l}\text { A-549, HEP-2, } \\
\text { OVCAR-5 }\end{array}$ & - & {$[11,96]$} \\
\hline $\begin{array}{c}\left(2 R^{*}, 4 R^{*}\right)-3,4- \\
\text { dihydro- } \\
\text { 4-methoxy-2- } \\
\text { methyl-2H-1- } \\
\text { benzopyran-5-ol }\end{array}$ & Pyrans & $\begin{array}{l}\text { Nodulisporium } \\
\text { spp. }\end{array}$ & Aquilaria sinensis stem & SF-268 & - & [97] \\
\hline Brefeldin A & Lactone & Paecilomyces spp. & $\begin{array}{l}\text { 1. Torreya grandis } \\
\text { 2. Taxus mairei } \\
\text { bark }\end{array}$ & $\begin{array}{l}\text { HL-60, KB, Hela, } \\
\text { MCF-7 and } \\
\text { Spc-A-1 }\end{array}$ & $\begin{array}{c}10.0,9.0,1.8,2.0 \& \\
1.0 \mathrm{ng} / \mathrm{mL}\end{array}$ & [31] \\
\hline $\begin{array}{c}(22 E, 24 R)-8,14- \\
\text { epoxyergosta-4,22- } \\
\text { diene-3,6- } \\
\text { dione }\end{array}$ & Steroids & Papulaspora $i$. & $\begin{array}{c}\text { Smallanthus } \\
\text { sonchifolius roots \& } \\
\text { leaves }\end{array}$ & $\begin{array}{l}\text { MDA-MB435, } \\
\text { HCT-8, SF295, } \\
\text { HL-60 }\end{array}$ & $3.3,14.7,5.0,1.6 \mu \mathrm{M}$ & [98] \\
\hline 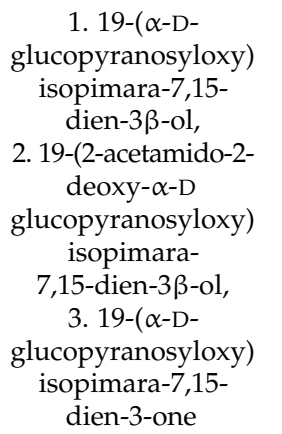 & Diterpenes & $\begin{array}{l}\text { Paraconiothyrium } \\
\text { spp. MY-42 }\end{array}$ & Fagus stem & HL60 & $\begin{array}{l}\text { 1. } 11.2 \mu \mathrm{M} \text {, } \\
\text { 2. } 6.7 \mu \mathrm{M}, \\
\text { 3. } 9.8 \mu \mathrm{M}\end{array}$ & [99] \\
\hline
\end{tabular}


Table 2. Cont.

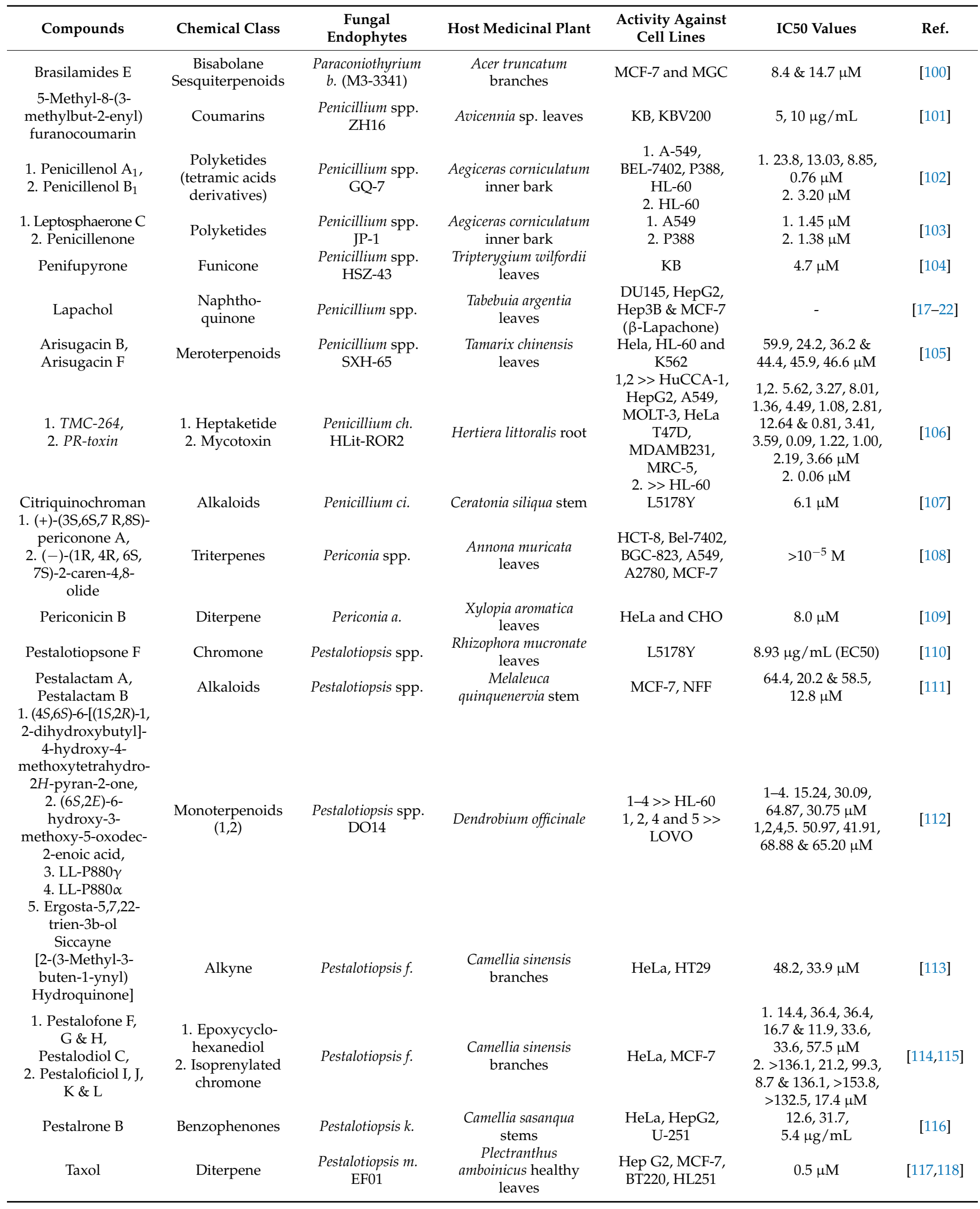


Table 2. Cont.

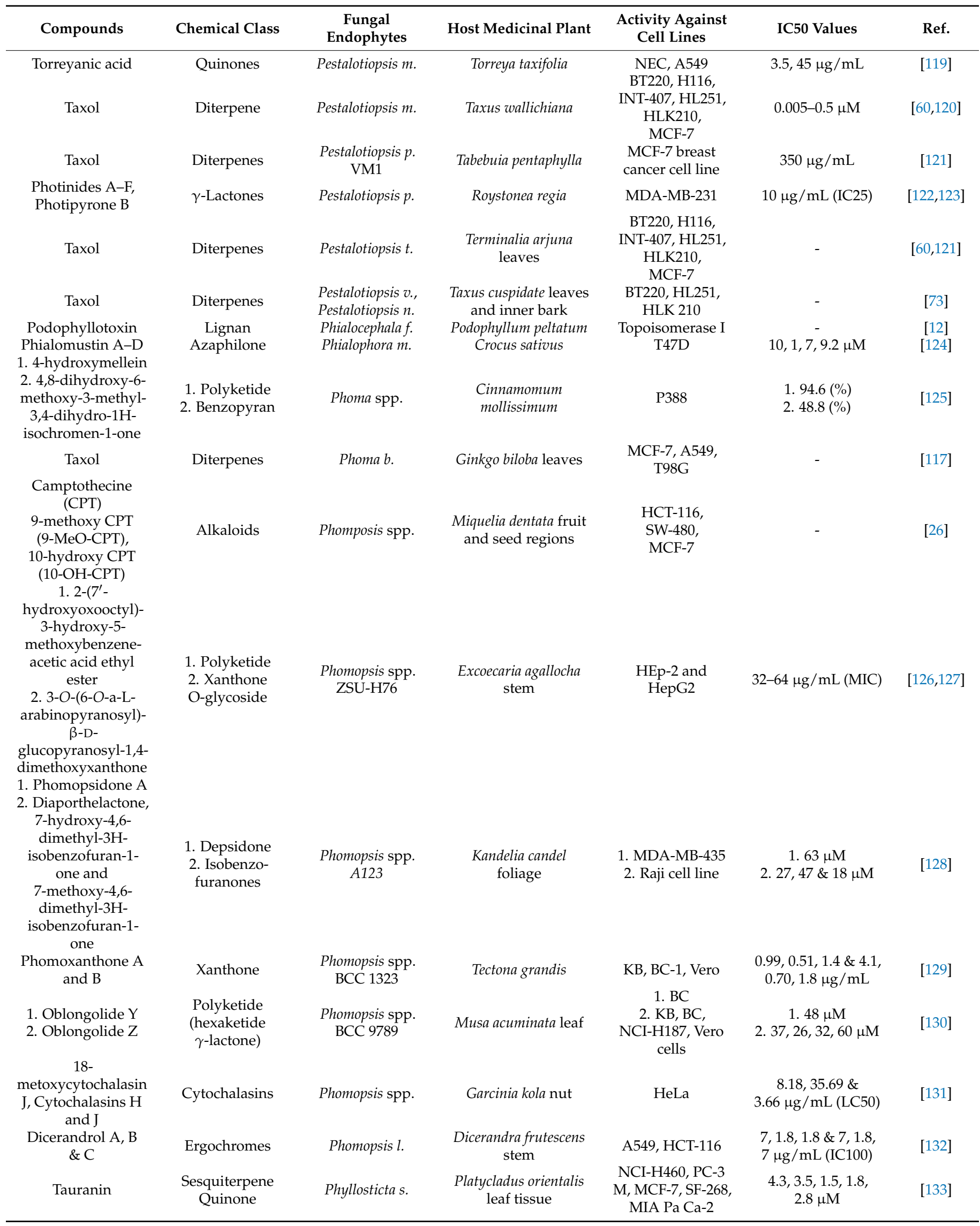


Table 2. Cont.

\begin{tabular}{|c|c|c|c|c|c|c|}
\hline Compounds & Chemical Class & $\begin{array}{c}\text { Fungal } \\
\text { Endophytes }\end{array}$ & Host Medicinal Plant & $\begin{array}{l}\text { Activity Against } \\
\text { Cell Lines }\end{array}$ & IC50 Values & Ref. \\
\hline Ergoflavin & Ergochrome & РM0651480 & Mimusops elengi & $\begin{array}{l}\text { TNF-a, IL-6, } \\
\text { ACHN, H460, } \\
\text { Panc1, HCT116, } \\
\text { and Calu1 }\end{array}$ & $\begin{array}{c}1.9,1.2,1.2,4,2.4,8 \\
\& 1.5 \mu \mathrm{M}\end{array}$ & [134] \\
\hline Spiropreussione A & $\begin{array}{c}\text { Spirobis } \\
\text { naphthalene }\end{array}$ & Preussia spp. & Aquilaria sinensis & A2780, BEL-7404 & $2.4,3.0 \mu \mathrm{M}$ & [135] \\
\hline $\begin{array}{c}\text { Cytochalasin 1, 2, } 3 \\
\text { and E }\end{array}$ & Alkaloids & Rhinocladiella spp. & $\begin{array}{l}\text { Tripterygium wilfordii } \\
\text { dead tree limbs }\end{array}$ & $\begin{array}{c}\text { A2780S, HCT-116, } \\
\text { SW-620 }\end{array}$ & $\begin{array}{c}\text { 3.91, } 15.6,3.91 ; 15.6 \\
62.5,15.6 ; 3.91,- \\
15.6 \&<0.0153 \\
0.977,0.244 \mu \mathrm{g} / \mathrm{mL} \\
(\mathrm{IC} 100)\end{array}$ & [136] \\
\hline $\begin{array}{c}\text { 1. Rhytidones B } \\
\text { 2. Rhytidones C, } \\
\text { MK3018, } \\
\text { Palmarumycin CR1 }\end{array}$ & $\begin{array}{c}\text { Spirobis } \\
\text { naphthalenes }\end{array}$ & $\begin{array}{l}\text { Rhytidhysteron } \\
\text { spp. }\end{array}$ & $\begin{array}{c}\text { Azima sarmentosa } \\
\text { leaves }\end{array}$ & $\begin{array}{l}\text { 1. CaSKi } \\
\text { 2. } \mathrm{MCF}-7 \text { and } \\
\text { CaSki }\end{array}$ & $\begin{array}{c}1.22 .81 \\
\text { 2. } 17.30,20.10,14.47 \\
\& 24.44,25.59 \\
21.95 \mu \mathrm{M}\end{array}$ & [137] \\
\hline TMC-264 & Heptaketide & $\begin{array}{c}\text { Rhizopycnis } v . \\
\text { Nitaf22 }\end{array}$ & Nicotiana tabacum & $\begin{array}{l}\text { HCT-116, HepG2, } \\
\text { BGC-823, } \\
\text { NCIH1650, and } \\
\text { A2780 }\end{array}$ & $\begin{array}{c}4.2,5.9,7.8,3.2 \\
3.6 \mu \mathrm{M}\end{array}$ & [138] \\
\hline Rhytidenone H \& F & Spirobisnaphthalenes & $\begin{array}{c}\text { Rhytidhysteron } r . \\
\text { AS21B }\end{array}$ & Azima sarmentosa & Ramos and H1975 & $\begin{array}{c}0.018,0.252 \& 0.048 \\
1.17 \mu \mathrm{M}\end{array}$ & [139] \\
\hline $\begin{array}{l}\text { 1. Secalonic acid A, } \\
\text { Penicillixanthone A } \\
\text { 2. Hypothemycin }\end{array}$ & $\begin{array}{l}\text { 1. Tetrahydro- } \\
\text { xanthone } \\
\text { 2. RAL }\end{array}$ & Setophomat. & $\begin{array}{l}\text { Unidentified (leaf } \\
\text { litter collected in a } \\
\text { mangrove habitat) }\end{array}$ & $\begin{array}{l}\text { MDA-MB-435 } \\
\text { and SW-620 }\end{array}$ & $\begin{array}{c}\text { 1. } 0.16,0.41 \& 0.18, \\
0.21 \mu \mathrm{M} \\
\text { 2. } 0.58,2.14 \mu \mathrm{M}\end{array}$ & [140] \\
\hline $\begin{array}{l}\text { Sphaeropsidin A, } \\
\text { Sphaeropsidin D }\end{array}$ & Diterpenes & $\begin{array}{l}\text { Smardaea spp. } \\
\quad \text { AZ0432 }\end{array}$ & $\begin{array}{c}\text { Ceratodon purpureus } \\
\text { living photosynthetic } \\
\text { tissue }\end{array}$ & MDA-MB-231 & $1.4,3.7 \mu \mathrm{M}$ & [141] \\
\hline Taxol & Diterpenes & $\begin{array}{l}\text { Stemphylium s. } \\
\text { SBU-16 }\end{array}$ & $\begin{array}{c}\text { Taxus baccata inner } \\
\text { bark }\end{array}$ & $\begin{array}{c}\text { MCF-7, A549, } \\
\text { T98G }\end{array}$ & 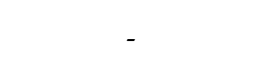 & {$[117,142]$} \\
\hline $\begin{array}{l}\text { 1. Altersolanol A, } \\
\text { 2. Alterporriol G } \\
\text { and } \mathrm{H} \\
\text { 1.3- }\end{array}$ & Quinones & Stemphylium g. & Mentha pulegium stem & $\begin{array}{l}\text { 1. K562, A549, } \\
\text { 2. L5178Y }\end{array}$ & $\begin{array}{l}\text { 1. }>1,>2 \mu \mathrm{M} \\
\text { 2. } 2.7 \mu \mathrm{g} / \mathrm{mL} \\
\quad(\mathrm{EC} 50)\end{array}$ & {$[143,144]$} \\
\hline $\begin{array}{l}\text { Dehydroxymethylbisde- } \\
\text { thio-3,10a- } \\
\text { bis(methylthio)- } \\
\text { gliotoxin } \\
\text { 2. Bisdethiobis } \\
\text { (methylthio)- } \\
\text { Gliotoxin } \\
\text { 3. Didehydrobisde- } \\
\text { thiobis } \\
\text { (methylthio)gliotoxin }\end{array}$ & Alkaloids & $\begin{array}{c}\text { Talaromyces spp. } \\
\text { LGT-2 }\end{array}$ & Tripterygium wilfordi & B16 & $\begin{array}{c}86,82 \& 78 \% \text { at } \\
500 \mu \mathrm{g} / \mathrm{mL}\end{array}$ & [145] \\
\hline $\begin{array}{l}\text { Talaperoxide B, } \\
\text { Talaperoxide D }\end{array}$ & Peroxides & Talaromyces $f$. & $\begin{array}{l}\text { Sonneratia apetala } \\
\text { healthy leaves }\end{array}$ & $\begin{array}{c}\text { MCF-7, } \\
\text { MDA-MB-435, } \\
\text { HepG2, HeLa, } \\
\text { PC-3 }\end{array}$ & $\begin{array}{c}1.33,2.78,1.29,1.73 \\
0.89 \& 1.92,0.91 \\
0.90,1.31 \\
0.70 \mu \mathrm{g} / \mathrm{mL}\end{array}$ & {$[146]$} \\
\hline $\begin{array}{l}\text { Vincristine and } \\
\text { Vinblastine }\end{array}$ & Alkaloids & $\begin{array}{l}\text { Talaromyces } r . \\
\text { CrP20 }\end{array}$ & $\begin{array}{c}\text { Catharanthus roseus } \\
\text { leaf tissues }\end{array}$ & $\begin{array}{c}\text { HeLa, MCF7, } \\
\text { U251, A549, A431 }\end{array}$ & $\begin{array}{c}4.2,4.5,5.5,5.5 \\
5.8 \mu \mathrm{g} / \mathrm{mL}\end{array}$ & {$[74]$} \\
\hline Taxol & Terpenes & Taxomyces $a$. & $\begin{array}{l}\text { Taxus brevifolia } \\
\text { inner bark }\end{array}$ & $\begin{array}{l}\text { BT220, H116, } \\
\text { INT-407, HL251, } \\
\text { MCF-7HLK210 }\end{array}$ & 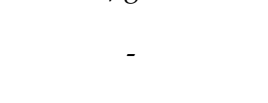 & {$[6,60]$} \\
\hline Hypericin, Emodin & Polyketides & Thielavias. & $\begin{array}{l}\text { Hypericum perforatum } \\
\text { stem }\end{array}$ & THP-1 & - & [147] \\
\hline Podophyllotoxin & Lignan & Trametes $h$. & $\begin{array}{c}\text { Podophyllum } \\
\text { hexandrum }\end{array}$ & Topoisomerase I & - & {$[148]$} \\
\hline $\begin{array}{l}\text { Aspochalasin D, } \\
\text { Aspochalasin J }\end{array}$ & Cytochalasan & Trichoderma g. & Panax notoginseng & HeLa & $5.72,27.4 \mu \mathrm{M}$ & [149] \\
\hline Trichothecinol-A & Mycotoxins & Trichothecium spp. & Phyllanthus amarus & $\begin{array}{l}\text { MDA-MBA-231, } \\
\text { B16F10 }\end{array}$ & $\begin{array}{l}500 \mu \mathrm{M}(\mathrm{LC} 25), \\
500 \mu \mathrm{M}(\mathrm{LC} 50)\end{array}$ & {$[150]$} \\
\hline $\begin{array}{l}\text { Merulin A } \\
\text { Merulin C }\end{array}$ & Sesquiterpenes & $\begin{array}{c}\text { XG8D } \\
\text { (a basidiomycete, } \\
\text { not better } \\
\text { identified) }\end{array}$ & $\begin{array}{c}\text { Xylocarpus granatum } \\
\text { plant }\end{array}$ & BT474, SW620 & $\begin{array}{c}4.98,>10 \& 4.84 \\
>10 \mu \mathrm{g} / \mathrm{mL}\end{array}$ & {$[151]$} \\
\hline $\begin{array}{l}\text { Eremophilanolide } \\
1,2 \& 3\end{array}$ & Sesquiterpenes & $\begin{array}{c}\text { Xylaria spp. BCC } \\
21097\end{array}$ & Licuala spinosa & $\begin{array}{c}\text { KB, MCF-7, } \\
\text { NCI-H187, Vero } \\
\text { cells }\end{array}$ & $3.8-21 \mu \mathrm{M}$ & {$[152]$} \\
\hline
\end{tabular}


Table 2. Cont.

\begin{tabular}{|c|c|c|c|c|c|c|}
\hline Compounds & Chemical Class & $\begin{array}{c}\text { Fungal } \\
\text { Endophytes }\end{array}$ & Host Medicinal Plant & $\begin{array}{l}\text { Activity Against } \\
\text { Cell Lines }\end{array}$ & IC50 Values & Ref. \\
\hline $\begin{array}{l}\text { 1. 2-Chloro-5- } \\
\text { methoxy-3- } \\
\text { methylcyclohexa- } \\
\text { 2,5-diene-1,4-dione } \\
\text { 2. Xylariaquinone A }\end{array}$ & Benzoquinone & Xylaria spp. & Sandoricum koetjape & Vero cells & $1.35,>184 \mu \mathrm{M}$ & [153] \\
\hline $\begin{array}{l}\text { 1. Cytochalasin D } \\
\text { 2. Cytochalasin C } \\
\text { and Q }\end{array}$ & Cytochalasins & $\begin{array}{l}\text { Xylaria spp. } \\
\text { NC1214 }\end{array}$ & Hypnum sp. & $\begin{array}{c}1,2 \text { >> NCI-H460, } \\
\text { PC-3M, SF-268, } \\
\text { MDA-MB-231; } \\
1 . \text { >> MCF-7, }\end{array}$ & $\begin{array}{c}\text { D: } 1.03,0.22,0.43 \\
1.01 \mu \mathrm{M} ; \mathrm{C}: 1.65 \\
1.06,0.96,1.72 \mu \mathrm{M} ; \\
\text { Q: } 1.53,1.51,1.31 \\
1.32 ; 1.44 \mu \mathrm{M}\end{array}$ & [154] \\
\hline Cytochalasin E & Alkaloids & $\begin{array}{c}\text { Xylaria spp. } \\
\text { XC-16 }\end{array}$ & Toona sinensis & brine shrimp & $2.79 \mu \mathrm{M}$ (LC50) & [155] \\
\hline $\begin{array}{l}\text { 1. Cytochalasin D } \\
\text { 2. Ergosterol } \\
\text { peroxide }\end{array}$ & $\begin{array}{l}\text { 1. Cytochalasins } \\
\text { 2. Steroid }\end{array}$ & $\begin{array}{l}\text { Xylaria cf. } c . \\
\text { PK108 }\end{array}$ & Unidentified & $\begin{array}{l}\text { 1. NCI-H187, KB, } \\
\text { Vero cell } \\
\text { 2. NCI-H187, } \\
\text { Vero cell }\end{array}$ & $\begin{array}{c}\text { 1. } 5.95,3.25 \\
0.36 \mu \mathrm{g} / \mathrm{mL} \\
\text { 2. } 5.81 \\
47.95 \mu \mathrm{g} / \mathrm{mL}\end{array}$ & [156] \\
\hline $\begin{array}{l}\text { Xylariacin A } \\
\text { Xylariacin B } \\
\text { Xylariacin C }\end{array}$ & Triterpenes & $\begin{array}{l}\text { Xylarialean spp. } \\
\text { A45 }\end{array}$ & $\begin{array}{c}\text { Annona squamosal } \\
\text { phloem }\end{array}$ & HepG2 & $\begin{array}{c}48,9.7,46.7 \% \text { at } \\
20 \mu \mathrm{g} / \mathrm{mL}\end{array}$ & [157] \\
\hline Secalonic acid D & Ergochrome & $\begin{array}{l}\text { ZSU44 (not better } \\
\text { identified) }\end{array}$ & $\begin{array}{l}\text { (unidentified) } \\
\text { mangrove plant }\end{array}$ & HL-60, K562 & $0.38,0.43 \mu \mathrm{M}$ & [158] \\
\hline
\end{tabular}

* Compounds with IC50 values less than $10 \mu \mathrm{M}$ are reported.

Table 3. Recently (2018-2020) reported potential cytotoxic metabolites isolated from medicinal-plantassociated endophytic fungi.

\begin{tabular}{|c|c|c|c|c|c|}
\hline S1 & Isolated Metabolites * & Fungus Name & $\begin{array}{c}\text { Host Medicinal } \\
\text { Plant }\end{array}$ & Reported Activity & References \\
\hline 1 & Penicolinate A & Bionectria spp. & Raphia taedigera & $\begin{array}{c}\text { Displayed potent cytotoxicity } \\
\text { against cells with an IC50 value of } \\
4.1 \mu \mathrm{M} .\end{array}$ & [159] \\
\hline 2 & Fusarithioamide B & Fusarium c. & $\begin{array}{l}\text { Anvillea arcinia } \\
\text { (Burm.f.) DC. }\end{array}$ & $\begin{array}{c}\text { Showed selective and potent effect } \\
\text { towards BT-549, MCF-7, SKOV-3, } \\
\text { and HCT- } 116 \text { cell lines with IC50s } \\
0.09,0.21,1.23 \text {, and } 0.59 \mu \mathrm{M}, \\
\text { respectively }\end{array}$ & [160] \\
\hline 3 & $\begin{array}{l}\text { 3-(4-nitrophenyl)-5- } \\
\text { phenyl } \\
\text { isoxazole }\end{array}$ & Aspergillus n. spp. & & $\begin{array}{c}\text { Exhibited potent cytotoxic effect on } \\
\text { HepG2 and SMCC-7721 cells with } \\
\text { the IC50 values were } 0.347 \text { and } \\
0.380 \mathrm{mM} \text {, respectively }\end{array}$ & [161] \\
\hline 4 & Spiciferone $\mathbf{F}$ & Phoma $b$. & $\begin{array}{l}\text { Kalidium foliatum } \\
\text { (Pall.) Moq }\end{array}$ & $\begin{array}{l}\text { Exhibited strong biological effect } \\
\text { against MCF7 with a half-maximal } \\
\text { inhibitory concentration value at } \\
7.73 \pm 0.11 \mu \mathrm{M}\end{array}$ & [162] \\
\hline 5 & Xylariphthalide A & Diaporthe spp. & Tylophora ouata & $\begin{array}{c}\text { Displayed cytotoxic activity against } \\
\text { human tumor cell lines BGC-823 } \\
\text { cells with IC } 50 \text { values of } \\
1.5 \mu \mathrm{mol} \cdot \mathrm{L}^{-1}\end{array}$ & [163] \\
\hline 6 & $\begin{array}{l}\text { Cis-4-hydroxy-6- } \\
\text { deoxytalone }\end{array}$ & Diaporthe spp. & Tylophora ouata & $\begin{array}{l}\text { Displayed cytotoxic activity against } \\
\text { human tumor cell lines BGC-823 } \\
\text { cells with IC50 } 8.6 \mu \mathrm{mol} \cdot \mathrm{L}^{-1}\end{array}$ & [163] \\
\hline 7 & Xylarolide A & Diaporthe spp. & Datura inoxia & $\begin{array}{l}\text { Showed promisingly inhibited } \\
\text { growth of MIAPaCa-2 and PC-3 } \\
\text { cells with an IC50 values of } 20 \\
14 \mu \mathrm{M}\end{array}$ & [164] \\
\hline 8 & Jammosporin A & $\begin{array}{c}\text { Rosellinia } \\
\text { sanctae-cruciana }\end{array}$ & Albizia lebbeck & $\begin{array}{l}\text { Exhibited promising cytotoxic } \\
\text { potential against the human } \\
\text { leukemia cancer cell line (MOLT-4) }\end{array}$ & [165] \\
\hline
\end{tabular}


Table 3. Cont.

\begin{tabular}{|c|c|c|c|c|c|}
\hline S1 & Isolated Metabolites * & Fungus Name & $\begin{array}{c}\text { Host Medicinal } \\
\text { Plant }\end{array}$ & Reported Activity & References \\
\hline 9 & $\begin{array}{c}\text { Pyrrocidine A } \\
\text { (Pyridone alkaloid) }\end{array}$ & Cylindrocarpon spp. & Sapium ellipticum & $\begin{array}{l}\text { Showed potent cytotoxicity against } \\
\text { the human ovarian cancer cell line } \\
\text { A2780 with an IC50 value of } 1.7 \mu \mathrm{M}\end{array}$ & [166] \\
\hline $\begin{array}{l}10 \\
11\end{array}$ & $\begin{array}{l}\text { Bostrycoidin } \\
\text { Anhydrofusarubin }\end{array}$ & Fusarium s. & $\begin{array}{l}\text { Cassia alata Linn. } \\
\text { plant }\end{array}$ & $\begin{array}{l}\text { Significant cytotoxicity against vero } \\
\text { cell line }\end{array}$ & [8] \\
\hline 12 & 1-Monolinolein & & & $\begin{array}{l}\text { Exhibited cytotoxicity against } \\
\text { human lung adenocarcinoma } \\
\text { EGFR-TKI-resistant A549 cells with } \\
\text { IC50 values of } 3.6 \mu \mathrm{M}\end{array}$ & \\
\hline 13 & Bafilomycin D & $\begin{array}{l}\text { Streptomyces c. } \\
\text { YBQ59 }\end{array}$ & $\begin{array}{l}\text { Cinnamomum cassia } \\
\text { plant }\end{array}$ & $\begin{array}{l}\text { Showed activity against } \\
\text { EGFR-TKI-resistant A549 cells with } \\
\text { IC50 values } 6.7 \mu \mathrm{M}\end{array}$ & [167] \\
\hline 14 & $3^{\prime}$-Hydroxydaidzein & & & $\begin{array}{l}\text { Showed activity against } \\
\text { EGFR-TKI-resistant A549 cells with } \\
\text { IC50 values } 7.8 \mu \mathrm{M}\end{array}$ & \\
\hline 15 & Colletotricone A & $\begin{array}{l}\text { Colletotrichum } g . \\
\text { A12 }\end{array}$ & Aquilaria sinensis & $\begin{array}{l}\text { Inhibited growth of MCF-7, } \\
\text { NCI-H460, HepG-2, and SF-268 } \\
\text { tumor cells with IC50 values } \\
\text { ranging from } 15.7 \text { to } 46.8 \mu \mathrm{M}\end{array}$ & [168] \\
\hline 16 & Mollicellin G & $\begin{array}{l}\text { Chaetomium spp. } \\
\text { Eef-10 }\end{array}$ & Eucalyptus exserta & $\begin{array}{c}\text { Cytotoxic against two human } \\
\text { cancer cell lines HepG2 and Hela } \\
\text { withIC50 values of } 19.64 \text { and } \\
13.97 \mu \mathrm{g} / \mathrm{mL} \text {, respectively }\end{array}$ & [169] \\
\hline 17 & $\begin{array}{l}\text { Demethylincisterol } \\
\qquad \mathbf{A}_{3}\end{array}$ & Pestalotiopsis spp. & $\begin{array}{l}\text { Rhizophora } \\
\text { mucronata }\end{array}$ & $\begin{array}{l}\text { Showed potent activity against the } \\
\text { Hela, A549 and HepG, with IC50 } \\
\text { values ranging from } 0.17 \text { to } \\
14.16 \mathrm{nM}\end{array}$ & [170] \\
\hline 18 & $\begin{array}{c}\text { Shearilicine (1), } \\
\text { Paspalinine-13-ene (2), } \\
\text { 7-Hydroxypaxilline- } \\
\text { 13-ene (3), Shearinine } \\
\text { O (6), Shearinine P } \\
\text { (7), emindole SB (10), } \\
\text { paspaline (18), } \\
\text { 7-hydroxy-13- } \\
\text { dehydroxypaxilline } \\
(19) \text { * }\end{array}$ & $\begin{array}{l}\text { Penicillium spp. } \\
\text { (strain ZO-R1-1) }\end{array}$ & Zingiber officinale & $\begin{array}{c}\mathbf{1} \text { showed the most pronounced } \\
\text { cytotoxicity against L5178Y (IC50 is } \\
3.6 \mu \mathrm{M} \text { ) whereas } \mathbf{2}, \mathbf{3}, \mathbf{6}, 7 \& \mathbf{1 9} \\
\text { exhibited cytotoxicity with IC50 } \\
\text { values ranging between } 5.3 \text { and } \\
8.1 \mu \mathrm{M} . \mathbf{1}, \mathbf{6}, \mathbf{1 0} \text { and } \mathbf{1 8} \text { displayed } \\
\text { pronounced cytotoxicity with IC50 } \\
\text { values ranging between } 5.3 \text { and } \\
8.7 \mu \mathrm{M} \text { against } \mathrm{A} 2780\end{array}$ & [171] \\
\hline 19 & Flavipin & Chaetomium g. & $\begin{array}{l}\text { Couroupita } \\
\text { guianensis Aubl. } \\
\text { leaves }\end{array}$ & $\begin{array}{c}\text { Exhibited cytotoxicity toward A549, } \\
\text { HT-29, and MCF-7 cancer cells with } \\
\text { an IC50 concentration of } \\
9.89 \mu \mathrm{g} / \mathrm{mL}, 18 \mu \mathrm{g} / \mathrm{mL} \text {, and } \\
54 \mu \mathrm{g} / \mathrm{mL} \text {, respectively }\end{array}$ & [172] \\
\hline 20 & Bellidisin D & Phoma $b$. & $\begin{array}{c}\text { Tricyrtis maculate } \\
\text { leaves }\end{array}$ & $\begin{array}{l}\text { Exhibited significant cytotoxicity } \\
\text { against HL-60, A549, SMMC-7721, } \\
\text { MCF-7, and SW480 cells with IC50 } \\
\text { value ranged from } 3.40 \text { to } 15.25 \mu \mathrm{M}\end{array}$ & [173] \\
\hline 21 & Epicorazine A & Epicoccum $n$. & Salix sp. & $\begin{array}{l}\text { Displayed strong to moderate } \\
\text { cytotoxic activities against L5178Y, } \\
\text { Ramos, and Jurkat J16 cell lines } \\
\text { with IC50 s ranging from } 1.3 \text { to } \\
28 \mathrm{mM}\end{array}$ & [174] \\
\hline
\end{tabular}


Table 3. Cont.

\begin{tabular}{|c|c|c|c|c|c|}
\hline S1 & Isolated Metabolites * & Fungus Name & $\begin{array}{l}\text { Host Medicinal } \\
\text { Plant }\end{array}$ & Reported Activity & References \\
\hline 22 & Cytochalasin E & & & $\begin{array}{l}\text { Exhibited significant cytotoxicity } \\
\text { with an IC50 value of } 7.8 \mu \mathrm{M}\end{array}$ & \\
\hline 23 & $\begin{array}{l}\text { Asperchalasin A-F } \\
\text { (seco-cytochalasins), } \\
\text { Asperlactone G-H } \\
\text { (asperlactones) }\end{array}$ & Aspergillus spp. & Pinellia ternata tubers & $\begin{array}{l}\text { All the compounds showed } \\
\text { cytotoxicity against A- } 549 \text { with } \\
\text { IC50 values ranging from } 23.3 \text { to } \\
70.2 \mu \mathrm{M}\end{array}$ & [175] \\
\hline 24 & $\begin{array}{l}\text { Demethylchaetocochin } \\
\text { C, dethiote- } \\
\text { tra(methylthio)chetomin, } \\
\text { chaetoperazine A, } \\
\text { 4-formyl- } N-(30- \\
\text { hydroxypyridin-20-yl) } \\
\text { benzamide }\end{array}$ & Chaetomium g. 7951 & $\begin{array}{c}\text { Panax notoginseng } \\
\text { root }\end{array}$ & $\begin{array}{c}\text { Showed cytotoxicity against MCF-7, } \\
\text { MDA-MB-231, H460, and HCT-8 } \\
\text { cell lines with IC50 values ranging } \\
\text { from } 4.5 \text { to } 65 \mu \mathrm{M}\end{array}$ & [176] \\
\hline 25 & $\begin{array}{l}\text { Chetoseminudin F (1), } \\
\text { chaetocochin C (6), } \\
\text { ergosterol (8), } \\
\text { chetomin A (9), } \\
\text { chetomin (12) }\end{array}$ & $\begin{array}{l}\text { Chaetomium spp. } \\
\text { SYP-F7950 }\end{array}$ & $\begin{array}{l}\text { Panax notoginseng } \\
\text { Stem }\end{array}$ & $\begin{array}{l}1 \text { displayed more potent cytotoxic } \\
\text { activity against MDA-MB-231 cells } \\
\text { than paclitaxel with IC50 of } \\
26.49 \mu \mathrm{M} .6,8,9 \text { and } 12 \text { exhibited } \\
\text { strong cytotoxicity with IC } 50 \text { values } \\
\text { ranging between } 2.75 \text { and } 8.68 \mu \mathrm{M} \\
\text { against A549 and MDA-MB-231 }\end{array}$ & [177] \\
\hline 26 & $\begin{array}{c}\text { Ascomylactam A to C } \\
(1-3)\end{array}$ & $\begin{array}{l}\text { Didymella spp. } \\
\quad \text { CYSK-4 }\end{array}$ & $\begin{array}{l}\text { Pluchea indica } \\
\text { healthy branch }\end{array}$ & $\begin{array}{c}\mathbf{1} \text { and } 3 \text { exhibited moderate } \\
\text { cytotoxic activities against } \\
\text { MDA-MB-231, MDA-MB-435, } \\
\text { NCI-H460, PC-3 \& HCT116 cell } \\
\text { lines with IC50 values ranging } \\
\text { between } 4.2 \text { and } 7.8 \mu \mathrm{M} \text {. } 2 \text { showed } \\
\text { cytotoxicity towards the } \\
\text { MDA-MB-231 and HCT116 cells } \\
\text { with IC50s of } 6.6 \text { and } 4.5 \mu \mathrm{M}, \\
\text { respectively }\end{array}$ & [178] \\
\hline 27 & Pleosporalin F & $\begin{array}{l}\text { Pleosporales spp. } \\
\text { F46 }\end{array}$ & Mahonia fortunei & $\begin{array}{l}\text { Exhibited moderate cytotoxicity } \\
\text { towards MDA-MB-231 cell line } \\
\text { with an IC50 value of } \\
22.4 \pm 1.1 \mu \mathrm{M} \text {. }\end{array}$ & [179] \\
\hline 28 & $\begin{array}{c}19,20- \\
\text { epoxycytochalasins C } \\
\text { (1) and D (2), and } \\
\text { 18-deoxy-19,20-epoxy- } \\
\text { cytochalasin } \\
\text { C (3) }\end{array}$ & $\begin{array}{l}\text { Nemania spp. } \\
\text { UM10M }\end{array}$ & Torreya taxifolia leaf & $\begin{array}{c}1 \text { and } 3 \text { displayed moderate toxicity } \\
\text { against SK-MEL and BT- } 549 \text { cell } \\
\text { lines. } 2 \text { showed moderate toxicity } \\
\text { against BT-549 and LLC-PK11 cell } \\
\text { lines }\end{array}$ & [180] \\
\hline 29 & $\begin{array}{l}\text { Gartryprostatins A to } \\
\text { C (1-3) }\end{array}$ & $\begin{array}{l}\text { Aspergillus spp. } \\
\text { GZWMJZ-258 }\end{array}$ & $\begin{array}{c}\text { Garcinia multiflora } \\
\text { fruit }\end{array}$ & $\begin{array}{c}\text { 1-3 showed selective cytotoxicity } \\
\text { against the cell line, MV4-11, with } \\
\text { IC50 values of } 7.2,10.0 \text {, and } \\
0.22 \mu \mathrm{M} \text {, respectively }\end{array}$ & [181] \\
\hline 30 & $\begin{array}{c}19,20- \\
\text { epoxycytochalasin C }\end{array}$ & Xylaria cf. c. & $\begin{array}{l}\text { Solanum tuberosum } \\
\text { stem tissues }\end{array}$ & $\begin{array}{l}\text { Displayed significant specific } \\
\text { cytotoxic activity against HL-60 } \\
\text { cells with an IC50 of } 1.11 \mu \mathrm{M} \text {. }\end{array}$ & [182] \\
\hline 31 & Sporulosaldein F & $\begin{array}{l}\text { Paraphaeosphaeria } \\
\text { spp. F03 }\end{array}$ & $\begin{array}{c}\text { Paepalanthus } \\
\text { planifolius leaves }\end{array}$ & $\begin{array}{c}\text { Displayed weak cytotoxic activities } \\
\text { against MCF-7 and LM3 cells, with } \\
\text { IC50 values of } 34.4 \text { and } 39.2 \mu \mathrm{M} \text {, } \\
\text { respectively. }\end{array}$ & [183] \\
\hline 32 & Trichodermic acid & Penicillium o. & Taxus media roots & $\begin{array}{l}\text { Displayed moderate cytotoxicity } \\
\text { towards A549, LN229, MGC, } \\
\text { LOVO, and MDA231 with IC50 } \\
\text { values of } 51.45,23.43,39.16,46.97, \\
\text { and } 42.85 \mu \mathrm{g} / \mathrm{mL} \text {, respectively. }\end{array}$ & [184] \\
\hline
\end{tabular}


Table 3. Cont.

\begin{tabular}{|c|c|c|c|c|c|}
\hline S1 & Isolated Metabolites * & Fungus Name & $\begin{array}{c}\text { Host Medicinal } \\
\text { Plant }\end{array}$ & Reported Activity & References \\
\hline 33 & $\begin{array}{l}\text { Stemphyperylenol } \\
\text { (5), (17R)-4-hydroxy-17- } \\
\text { methylincisterol (10) }\end{array}$ & Alternaria a. & $\begin{array}{l}\text { Psidium littorale } \\
\text { Raddi leaves }\end{array}$ & $\begin{array}{l}5 \text { showed cytotoxicity against } \\
\text { MCF-7 and HepG-4 cell lines (IC50 } \\
\text { values of } 4.2 \pm 0.6 \text { and } \\
7.9 \pm 0.9 \mu \mathrm{M} \text {, respectively); } 10 \\
\text { exhibited cytotoxicity against } \\
\text { HepG- } 4 \text { cell line with an IC50 value } \\
\text { of } 9.73 \pm 1.2 \mu \mathrm{M} \text {. }\end{array}$ & [185] \\
\hline 34 & $\begin{array}{c}\text { Aspergisocoumrins A } \\
\text { \& B }\end{array}$ & $\begin{array}{l}\text { Aspergillus spp. } \\
\text { HN15-5D }\end{array}$ & $\begin{array}{l}\text { Acanthus ilicifolius } \\
\text { fresh leaves }\end{array}$ & $\begin{array}{c}\text { Exhibited cytotoxicity against } \\
\text { MDA-MB- } 435 \text { cells (IC50 values of } \\
5.08 \pm 0.88 \text { and } 4.98 \pm 0.74 \mu \mathrm{M} \\
\text { respectively) }\end{array}$ & [186] \\
\hline 35 & $\begin{array}{l}\text { Phomoxanthone A (1) } \\
\text { and Penialidin A (2) }\end{array}$ & $\begin{array}{l}\text { Coniochaeta spp. } \\
\text { F-8 }\end{array}$ & $\begin{array}{l}\text { Ageratina } \\
\text { adenophora }\end{array}$ & $\begin{array}{c}1 \text { showed a stronger cytotoxicity } \\
\text { than } 2\end{array}$ & [187] \\
\hline 36 & Macrophin & Phoma m. & $\begin{array}{l}\text { Glycyrrhiza glabra } \\
\text { Linn }\end{array}$ & $\begin{array}{c}\text { Exhibited prominent cytotoxic } \\
\text { activity against all the cancer-cell } \\
\text { lines (MDA-MB-231, T47D, MCF-7, } \\
\text { and MIAPaCa-2 with IC50 values } \\
\text { of } 14.8,8.12,13.0 \text {, and } 0.9 \mu \mathrm{M}, \\
\text { respectively). }\end{array}$ & [188] \\
\hline 37 & $\begin{array}{l}\text { Myrothecines D-G } \\
\text { (1-4), } \\
\text { 16-hydroxymytoxin B } \\
\text { (5), and 14'- } \\
\text { dehydrovertisporin (6) }\end{array}$ & $\begin{array}{l}\text { Myrothecium r., } \\
\text { IFB-E008, IFB-E009, } \\
\text { and IFB-E012 } \\
\text { strains }\end{array}$ & $\begin{array}{l}\text { Trachelospermum } \\
\text { jasminoides }\end{array}$ & $\begin{array}{l}\text { Showed cytotoxicity against K562 } \\
\text { and SW1116 cells (IC50 values } \\
\text { ranging between } 56 \mathrm{nM} \text { and } \\
16 \mu \mathrm{M}) \text {. }\end{array}$ & [189] \\
\hline 38 & Giluterrin & Aspergillus t. P63 & $\begin{array}{c}\text { Axonopus } \\
\text { leptostachyus roots }\end{array}$ & $\begin{array}{c}\text { Exhibited cytotoxicity against 786-0 } \\
\text { and PC-3 cell lines (IC50 of } \\
22.93 \mu \mathrm{M} \text { and } 48.55 \mu \mathrm{M}, \\
\text { respectively). }\end{array}$ & [190] \\
\hline 39 & $\begin{array}{l}2^{\prime}- \\
\text { aminodechloromaldoxin } \\
\text { (1) and } 2^{\prime}- \\
\text { aminodechlorogeodoxin (2) }\end{array}$ & Pestalotiopsis $f$. & $\begin{array}{c}\text { Cinnamomum } \\
\text { camphora branches }\end{array}$ & $\begin{array}{c}1 \& 2 \text { displayed moderate } \\
\text { cytotoxicity against NCI-H460, } \\
\text { SF-268, MCF-7 and PC-3cell lines } \\
\text { (IC50 values of } 18.63,20.23,23.53 \\
20.48 \mu \mathrm{M} \text { and } 16.47,17.57,20.79, \\
19.43 \mu \mathrm{M} \text {, respectively). } \\
\text { Showed cytotoxicity against }\end{array}$ & [191] \\
\hline 40 & $\begin{array}{l}\text { Stachybochartins A, } \\
\text { B, C, D and G. }\end{array}$ & $\begin{array}{l}\text { Stachybotrys c. } \\
\text { PT2-12 }\end{array}$ & Pinellia ternata & $\begin{array}{l}\text { MDA-MB-231 and U-2OS cells } \\
\text { (IC50 values ranging between } 4.5 \text { to } \\
21.7 \mu \mathrm{M}) \text {. }\end{array}$ & [192] \\
\hline 41 & $\begin{array}{l}\text { (S)-3,6-dihydroxy-8- } \\
\text { methoxy-3- } \\
\text { methylisochroman-4- } \\
\text { one (1a), } \\
\text { 6-methoxy-3- } \\
\text { methylisochromane-3,8- } \\
\text { diol (2). }\end{array}$ & Aspergillusf. & $\begin{array}{l}\text { Cordyceps sinensis } \\
\text { fruiting body }\end{array}$ & $\begin{array}{c}\text { 1a \& } 2 \text { exhibited moderate growth } \\
\text { inhibition against MV4-11 (IC50 } \\
\text { values of } 38.39 \mu \mathrm{M} \text { and } 30.00 \mu \mathrm{M} \text {, } \\
\text { respectively). }\end{array}$ & [193] \\
\hline 42 & Flavoglaucin & $\begin{array}{l}\text { Aspergillus spp. } \\
\text { AV-2 }\end{array}$ & $\begin{array}{l}\text { Avicennia marina } \\
\text { healthy leaves }\end{array}$ & $\begin{array}{l}\text { Exhibited most potent cytotoxicity } \\
\text { against Caco- } 2 \text { cells (IC50 of } \\
2.87 \mu \mathrm{M})\end{array}$ & [194] \\
\hline 43 & $\begin{array}{l}\text { Peniquinone A (1) \& } \\
\text { peniquinone B (2) }\end{array}$ & $\begin{array}{l}\text { Penicillium spp. } \\
\text { L129 }\end{array}$ & Limonium s. & $\begin{array}{c}1 \text { showed cytotoxicity against the } \\
\text { cell lines, MCF-7, U87, and PC } 3 \\
\text { (IC50 ranging between } 9.01 \text { and } \\
14.59 \mu \mathrm{M}) ; 2 \text { exhibited relatively } \\
\text { weak cytotoxicity against the same } \\
\text { cells (IC50 ranging between } 13.45 \\
\text { and } 25.32 \mu \mathrm{M} \text { ) }\end{array}$ & [195] \\
\hline
\end{tabular}


Table 3. Cont.

\begin{tabular}{|c|c|c|c|c|c|}
\hline S1 & Isolated Metabolites * & Fungus Name & $\begin{array}{l}\text { Host Medicinal } \\
\text { Plant }\end{array}$ & Reported Activity & References \\
\hline 44 & $\begin{array}{l}\text { Pestalolide B (1), } \\
\text { pestalotether F (4) }\end{array}$ & Pestalotiopsis spp. & $\begin{array}{c}\text { Melaleuca } \\
\text { alternifolia leaves }\end{array}$ & $\begin{array}{l}1 \text { displayed remarkable inhibitory } \\
\text { effect against the cell lines, HL60, } \\
\text { U87MG, MDA-MB-231, and } \\
\text { HEP-3B cells (IC50 ranging from } \\
1.42 \text { to } 5.90 \mu \mathrm{M}) ; 4 \text { exhibited } \\
\text { significant inhibitory potency } \\
\text { against HL60 (IC50 5.05 } \mu \mathrm{M})\end{array}$ & [196] \\
\hline 45 & $\begin{array}{l}\text { Emeridone B (2), } \\
\text { Emeridone D (4), } \\
\text { Emeridone F (6) }\end{array}$ & $\begin{array}{l}\text { Emericella spp. } \\
\text { TJ29 }\end{array}$ & $\begin{array}{c}\text { Hypericum } \\
\text { perforatum root }\end{array}$ & $\begin{array}{c}\mathbf{2}, \mathbf{4} \text {, and } \mathbf{6} \text { showed cytotoxicity } \\
\text { against cell lines, SMMC-7721 \& } \\
\text { SW-480 (IC50 values ranging } \\
\text { between } 8.19 \text { and } 18.80 \mu \mathrm{M}) \text {. } \\
\text { Compound } 4 \text { also exhibited } \\
\text { cytotoxicity against A-549 (IC50 of } \\
11.33 \mu \mathrm{M})\end{array}$ & [197] \\
\hline 46 & $\begin{array}{l}\text { Lithocarin B \& C, } \\
\text { Tenellone H }\end{array}$ & Diaporthe l. A740 & $\begin{array}{c}\text { Morinda officinalis } \\
\text { twigs }\end{array}$ & $\begin{array}{c}\text { Displayed weak inhibitory } \\
\text { activities against SF-268, MCF-7, } \\
\text { HepG-2, and A549 cell lines with } \\
\text { IC50 values ranging between } 30 \\
\text { and } 100 \mu \mathrm{M}\end{array}$ & [198] \\
\hline 47 & $\begin{array}{l}\text { Cytosporaquinone } \\
\text { A-D, leucomelone. }\end{array}$ & $\begin{array}{l}\text { Cytospora spp. } \\
\text { CCTU A309 }\end{array}$ & $\begin{array}{c}\text { Juglans (Walnut } \\
\text { tree) }\end{array}$ & $\begin{array}{l}\text { All Showed significant cytotoxicity } \\
\text { against the cell lines, L929 and } \\
\text { KB-3-1 (IC50 values ranging from } \\
2.4 \text { to } 26 \mu \mathrm{g} / \mathrm{mL} \text { ) }\end{array}$ & [199] \\
\hline 48 & $\begin{array}{l}\text { Ilanpyrone (1), } \\
\text { methyl } \\
\text { Asterrate (4) }\end{array}$ & Annulohypoxylon $i$. & Cinnamomum sp. & $\begin{array}{l}1 \text { showed moderate cytotoxicity } \\
\text { against MCF-7 cells (IC50 is } \\
4.79 \mu \mathrm{M}) .4 \text { displayed cytotoxicity } \\
\text { towards MCF-7, NCI-H460, and } \\
\text { SF-268 cells (IC50 values ranging } \\
\text { between } 5.46 \text { to } 8.56 \mu \mathrm{M} \text { ) }\end{array}$ & [200] \\
\hline 49 & $\begin{array}{l}\text { Rhinomilisin A (1), } \\
\text { Rhinomilisin G (7) } \\
\text { and Gliocladic acid } \\
\text { (15) }\end{array}$ & Rhinocladiella s. & Acrostichum aureum & $\begin{array}{c}1,7 \& 15 \text { exhibited cytotoxic } \\
\text { activities against L5178Y (IC50 } \\
\text { values of 5.0, 8.7, and } 24.4 \mu \mathrm{M}, \\
\text { respectively). }\end{array}$ & [201] \\
\hline 50 & $\begin{array}{c}\text { Koninginol B (2), } \\
1 R, 3 S, 6 S, 7 R, 10 S-7- \\
\text { isopropyl-4,10- } \\
\text { dimethylbicyclo[4.4.0]dec- } \\
\text { 4-en-3,10-diol (15), } \\
\text { 1R,3R,6S,7R,10S-7- } \\
\text { isopropyl-4,10- } \\
\text { dimethylbicyclo[4.4.0]dec- } \\
\text { 4-en-3,10-diol (16) }\end{array}$ & Trichoderma k. A729 & $\begin{array}{l}\text { Morinda officinalis } \\
\text { branches }\end{array}$ & $\begin{array}{c}\mathbf{2 , 1 5} \text {, and } \mathbf{1 6} \text { showed } \\
\text { antiproliferative activities against } \\
\text { A549 (IC50 values of } 46.6,31.3 \text {, and } \\
22.2 \mu \mathrm{M} \text {, respectively) }\end{array}$ & [202] \\
\hline 51 & $\begin{array}{c}\text { Cytochalasin D1 (1) } \\
\text { and C1 (2) }\end{array}$ & Xylaria cf. cu. & $\begin{array}{l}\text { Solanum tuberosum } \\
\text { stem tissues }\end{array}$ & $\begin{array}{c}\mathbf{1} \text { and } \mathbf{2} \text { showed moderate } \\
\text { cytotoxicity against HL-60 (IC50 } \\
\text { value of } 12.7 \text { and } 22.3 \mu \mathrm{M}, \\
\text { respectively) }\end{array}$ & [203] \\
\hline 52 & $\begin{array}{l}\text { Bipolahydroquinone } \\
\text { C (3), cochlioquinone } \\
\text { I (4), cochlioquinones } \\
\text { K-M (6-8) }\end{array}$ & Bipolaris spp. L1-2 & $\begin{array}{l}\text { Lycium barbarum } \\
\text { fresh leaves }\end{array}$ & $\begin{array}{c}\text { 3, 4, and } 6-8 \text { exhibited cytotoxic } \\
\text { activities against NCIH226 and/or } \\
\text { MDA-MB-231 (IC50 values ranging } \\
\text { between } 5.5 \text { to } 9.5 \mu \mathrm{M})\end{array}$ & {$[204]$} \\
\hline 53 & Botryosulfuranol A & $\begin{array}{l}\text { Botryosphaeria m. } \\
\text { strain E224 }\end{array}$ & $\begin{array}{c}\text { Bixa orellana fresh } \\
\text { leaves }\end{array}$ & $\begin{array}{c}\text { Exhibited cytotoxicity against } \\
\text { HT-29, HepG2, Caco-2, HeLa, IEC6, } \\
\text { and vero cells (IC50 values ranging } \\
\text { between } 8 \text { to } 23.5 \mu \mathrm{M} \text { ) }\end{array}$ & [205] \\
\hline
\end{tabular}


Table 3. Cont.

\begin{tabular}{|c|c|c|c|c|c|}
\hline S1 & Isolated Metabolites * & Fungus Name & $\begin{array}{l}\text { Host Medicinal } \\
\text { Plant }\end{array}$ & Reported Activity & References \\
\hline 55 & Chloroisosulochrin & $\begin{array}{l}\text { Pestalotiopsis } t . \\
\quad \text { (N635) }\end{array}$ & $\begin{array}{l}\text { Camellia sinensis } \\
\text { (Theaceae) }\end{array}$ & $\begin{array}{c}\text { Exhibited moderate cytotoxicity } \\
\text { towards the HeLa cell line with an } \\
\text { IC50 value of } 35.2 \mu \mathrm{M} \\
\text { Exerted cytotoxicity against HeLa } \\
\text { and MCF-7 cell lines with IC50 } \\
\text { values of } 60.8 \text { and } 22.6 \mathrm{M} \text {, } \\
\text { respectively }\end{array}$ & [206] \\
\hline 56 & Cytosporins W* & $\begin{array}{c}\text { Pseudopestalotiopsis } \\
t .\end{array}$ & $\begin{array}{l}\text { Rhizophora racemosa } \\
\text { mangrove plants }\end{array}$ & $\begin{array}{c}\text { Exhibited potent cytotoxicity } \\
\text { towards mouse lymphoma cell line } \\
\text { L5178Y with an IC50 value of } \\
3.0 \mu \mathrm{M}\end{array}$ & [207] \\
\hline 57 & $\begin{array}{c}\text { Terezine E and } \\
\text { 14-hydroxyterezine D }\end{array}$ & Mucor spp. & Centaurea stoebe & $\begin{array}{l}\text { Showed potent activity against } \\
\text { K-562 and HUVEC cell lines }\end{array}$ & [208] \\
\hline 58 & $\begin{array}{l}\text { Citrinin }(\mathrm{CIT}) \text { and } \\
\text { dicitrinin-A }\end{array}$ & Penicillium ci. & $\begin{array}{l}\text { Dichotomaria } \\
\text { marginata }\end{array}$ & $\begin{array}{l}\text { Showed toxicity in } A \text {. saline, with } \\
\mathrm{LC}_{50}(24 \mathrm{~h}) 1.71 \mu \mathrm{g} / \mathrm{mL} \text { and } \\
2.29 \mu \mathrm{g} / \mathrm{mL} \text {, and } \mathrm{LC}_{50}(48 \mathrm{~h}) \text { of } \\
0.54 \mu \mathrm{g} / \mathrm{mL} \text { and } 0.54 \mu \mathrm{g} / \mathrm{mL}, \\
\text { respectively }\end{array}$ & [209] \\
\hline 59 & Allantopyrone E & Aspergillus v. & $\begin{array}{l}\text { Avicennia marina } \\
\text { mangrove }\end{array}$ & $\begin{array}{l}\text { Showed cytotoxic effect on HeLa } \\
\text { cells with IC50 = 50.97 } \mu \mathrm{M} \\
\text { Both compounds showed }\end{array}$ & [210] \\
\hline 60 & Integracin $A$ and $B$ & Cytospora spp. & $\begin{array}{l}\text { Ceriops tagal } \\
\text { (Chinese } \\
\text { mangrove) }\end{array}$ & $\begin{array}{c}\text { promising cytotoxicity towards } \\
\text { HepG2 Cells with IC50 values of } \\
5.98 \pm 0.12 \mu \mathrm{M} \text { and } 9.97 \pm 0.06 \mu \mathrm{M} \\
\text { respectively }\end{array}$ & [211] \\
\hline 61 & $\begin{array}{c}( \pm) \text {-Asperteretone } F \\
(3 a / 3 b)\end{array}$ & Aspergillus t. & $\begin{array}{l}\text { Hypericum } \\
\text { perforatum }\end{array}$ & $\begin{array}{l}\text { Potent cytotoxic activities against } \\
\text { human pancreatic cancer cells, } \\
\text { including AsPC-1, SW1990 and } \\
\text { PANC-1 cells, with IC50 values } \\
\text { ranging from } 1.2 \text { to } 15.6 \mu \mathrm{M} \\
\text { showed moderate to strong }\end{array}$ & [212] \\
\hline 62 & Sterigmatocystin & $\begin{array}{l}\text { Paecilamyces spp. } \\
\text { TE-540 }\end{array}$ & $\begin{array}{l}\text { Nicotiana tabacum } \\
\text { L. }\end{array}$ & $\begin{array}{l}\text { cytotoxicity towards A549, BT- } 549 \text {, } \\
\text { HepG2, and MCF-7 cells with IC50 } \\
\text { values ranging from } 5.6 \text { to } 14.2 \mu \mathrm{M}\end{array}$ & [213] \\
\hline 63 & $\begin{array}{c}\text { Methyl } \\
\text { 3-chloroasterric acid }\end{array}$ & $\begin{array}{l}\text { Pleosporales spp. } \\
\text { SK7. }\end{array}$ & $\begin{array}{l}\text { Kandelia candel } \\
\text { leaves }\end{array}$ & $\begin{array}{l}\text { Exhibited cytotoxicity against } \\
\text { MDA-MB-435 cell with an IC50 of } \\
25.96 \pm 0.32 \mu \mathrm{M}\end{array}$ & [214] \\
\hline 64 & $\begin{array}{l}\text { Rhizoperemophilane } \\
\text { N }\end{array}$ & Rhizopycnis v. & Nicotiana tabacum & $\begin{array}{c}\text { Exhibited selective cytotoxicity } \\
\text { against NCI-H1650 and BGC823 } \\
\text { tumor cells }\end{array}$ & [215] \\
\hline 65 & Pramanicin A & Aplosporella j. & $\begin{array}{l}\text { Orychophragmus } \\
\text { violaceus (L.) O. E. } \\
\text { Schul }\end{array}$ & $\begin{array}{c}\text { exhibited strong cytotoxic activities } \\
\text { against human lymphoma (Ramos) } \\
\text { and leukemia (Jurkat J16) cells with } \\
\text { IC50 values of } 4.7 \text { and } 4.4 \mu \mathrm{M}, \\
\text { respectively }\end{array}$ & [216] \\
\hline 66 & Myrothecines $\mathrm{H}$ and I & Paramyrothecium $r$. & Morinda officinalis & $\begin{array}{l}\text { Both the compounds exhibited } \\
\text { promising cytotoxicity against } \\
\text { SF-268, NCI-H460, and HepG-2 } \\
\text { tumor cell lines with the IC50 } \\
\text { ranging from } 0.0002-16.2 \mu \mathrm{M} \text { and } \\
\text { induced apoptosis of HepG-2 cells }\end{array}$ & [217] \\
\hline 67 & $\begin{array}{l}\text { Colletotrichalactone A } \\
\text { and } \\
\text { colletotrichalactone } \mathrm{Ca}\end{array}$ & $\begin{array}{l}\text { Colletotrichum spp. } \\
\text { JS-0361 }\end{array}$ & Morus alba & $\begin{array}{l}\text { Exhibited moderate-to-potent } \\
\text { cytotoxic activities against MCF7 } \\
\text { cells with IC50s of } 35.06 \text { and } \\
25.20 \mu \mathrm{M} \text {, respectively }\end{array}$ & [218] \\
\hline
\end{tabular}


Table 3. Cont.

\begin{tabular}{|c|c|c|c|c|c|}
\hline S1 & Isolated Metabolites * & Fungus Name & $\begin{array}{l}\text { Host Medicinal } \\
\text { Plant }\end{array}$ & Reported Activity & References \\
\hline 68 & $\begin{array}{c}\text { Emodin, (an } \\
\text { anthraquinone) }\end{array}$ & Diaporthe l. & $\begin{array}{c}\text { Artocarpus } \\
\text { heterophyllus }\end{array}$ & $\begin{array}{l}\text { exhibited cytotoxicity against } \\
\text { murine leukemia P-388 cells with } \\
\text { an IC50 value of } 0.41 \mu \mathrm{g} / \mathrm{mL}\end{array}$ & [219] \\
\hline 69 & Demethyli cisterol $\mathbf{A}_{3}$ & & & $\begin{array}{l}\text { Showed cytotoxicity against the } \\
\text { A549 and HepG2 cell with IC50 } \\
\text { values of } 5.34 \text { and } 12.03 \mu \mathrm{M} \text {, }\end{array}$ & \\
\hline 70 & Demethylincisterol $A_{5}$ & Aspergillus t. YP-2. & $\begin{array}{c}\text { Taxus yunnanensis } \\
\text { bark }\end{array}$ & $\begin{array}{c}\text { respectively } \\
\text { Showed cytotoxicity against the } \\
\text { A549 and HepG2 cell with IC50 } \\
\text { values of } 11.05 \text { and } 19.15 \mu \mathrm{M} \text {, } \\
\text { respectively }\end{array}$ & [220] \\
\hline
\end{tabular}

${ }^{*}$ Compounds with IC50 values less than $10 \mu \mathrm{M}$ are reported in bold.

\section{Discovery of anticancer agents over years.}

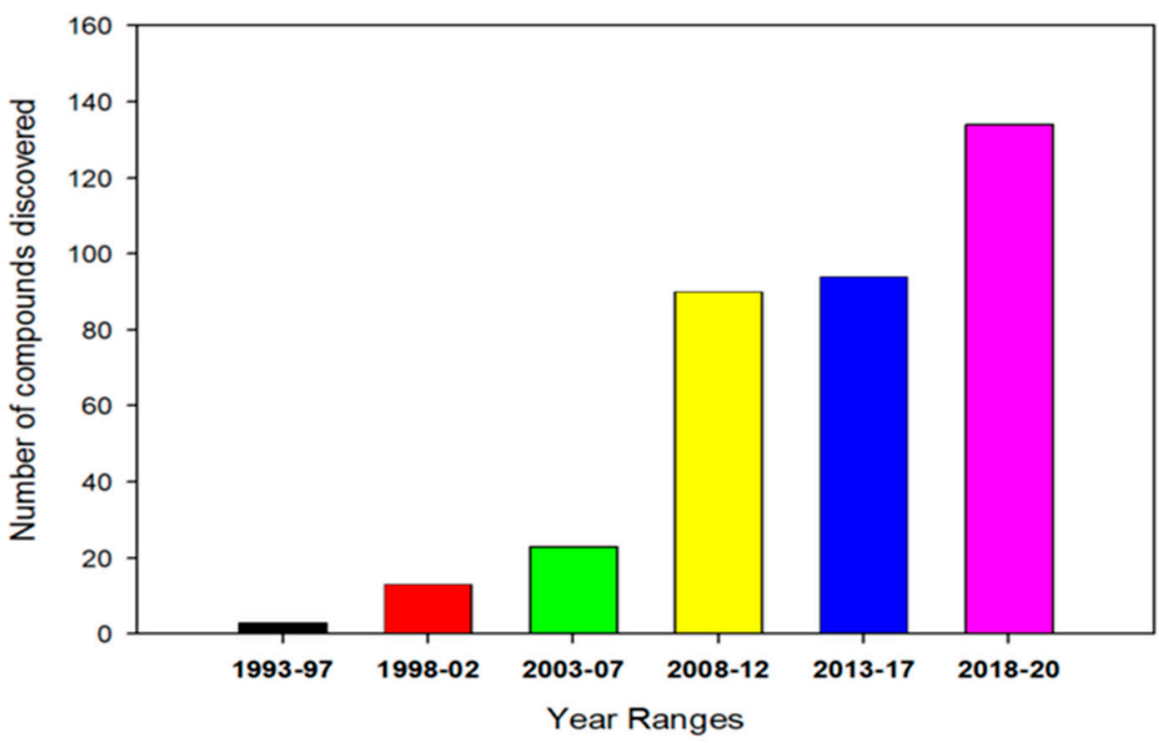

Figure 1. Discovery of anticancer agents from endophytic fungi over time.

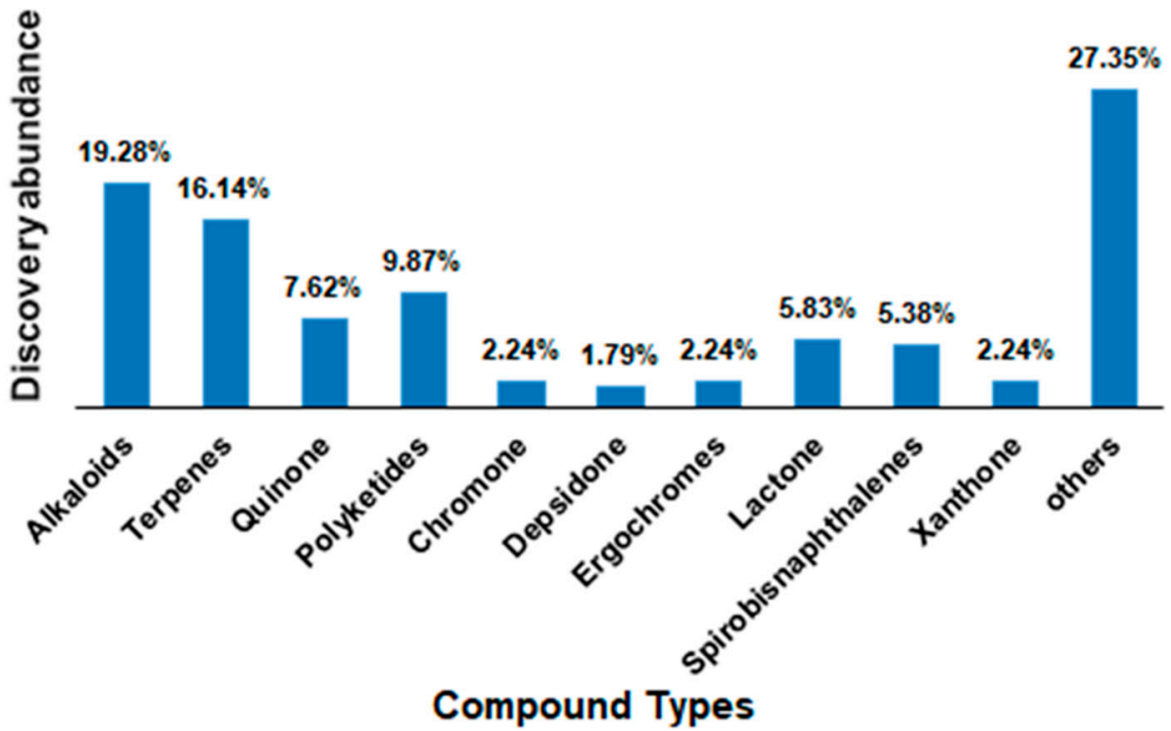

Figure 2. Relative abundance of anticancer agents from endophytic fungi. 
The genera of endophytic fungi containing two or more putative anticancer-agentproducing species are Acremonium, Alternaria, Aspergillus, Ceriporia, Chaetomium, Colletotrichum, Cytospora, Emericella, Eurotium, Eutypella, Fusarium, Guignardia, Hypocrea, Penicillium, Pestalotiopsis, Phomposis, Periconia, Stemphylium, Talaromyces, Thielavia, and Xylaria [4,221]. These endophytic fungi offer an alternative source of bioactive compounds. We may be able to increase their yield of specific anticancer compounds by employing biotechnology and genetic engineering [221].

\subsection{Anti-Cancer Agents in Clinical Use Shared by Plants and Endophytic Fungi}

Plants are prolific sources of anticancer agents. In the area of cancer, of the 175 approved small molecules over the years from the 1940s to 2014,75\% (131) are other than synthetic and 49\% (85) are either natural products or their derivatives [222]. Very recently, it was reported that among the approved 321 anticancer molecules from all sources during the period of 1946 to $2019,35(10.9 \%)$ were unaltered natural products and $65(20.2 \%)$ were natural product derivatives compared to $53(16.5 \%)$ completely synthetic drug molecules. Some of these agents obtained from plants are also found in their corresponding endophytic fungi. The following are some examples of plant/endophytic fungi-derived cancer effective agents [1,6] (Figure 3a,b).

Paclitaxel (Taxol ${ }^{\circledR}$ ) is used in combination with other anti-cancer drugs in ovarian, breast, non-small cell lung cancer (NSCLC), and Kaposi sarcoma. An active paclitaxel analogue, docetaxel is used in breast and non-small cell lung cancer (NSCLC) treatment [223]. Even though camptothecin exerted severe bladder toxicity in its clinical trial in the 1970s and therefore, was dropped, its two water-soluble derivatives, topotecan and irinotecan, have been shown to be more effective anti-cancer agents and are being utilized for these purposes [223]. Topotecan $\left(\right.$ Hycamtin $\left.^{\circledR}\right)$ was the first CPT derivative that was orally available and has been approved for cervical (when used in combination with cisplatin), ovarian, and non-small cell lung cancer treatment. Irinotecan (Camptosar ${ }^{\circledR}$ ) has been approved for colorectal cancer treatment. These agents show cytotoxicity on account of their ability to inhibit a fundamental enzyme, topoisomerase-I, involved in the winding and unwinding process of DNA during replication or protein synthesis [1,223]. The vinca alkaloids, vinblastine and vincristine, and their semi-synthetic analogs, vinorelbine and vindesine, are primarily used in combination with other chemotherapeutic drugs in the treatment of advanced testicular cancer, breast cancer, Kaposi's sarcoma, lung cancer, leukemias, and lymphomas [223]. Etoposide and teniposide are clinically effective semi-synthetic derivatives of a podophyllotoxin isomer, epipodophyllotoxin, which are used in bronchial cancers, lymphomas, and testicular cancer treatments [223].

\subsection{Putative Anticancer Compounds from Endophytic Fungi}

\subsubsection{Alkaloids and Nitrogen-Containing Heterocycles}

Camptothecin (CPT) (1), a pentacyclic quinoline alkaloid, was, at first, isolated from the Camptotheca acuminata (happy tree) woods showing antileukemic and anti-cancer effects in animals [1]. It exerts its cytotoxicity by inhibition and dissociation of the DNAtopoisomerase-I complex during DNA replication [224,225]. However, recently, CPT has been isolated from some endophytic fungi, Entrophospora i., residing in these plants. Since Entrophospora i. also lives inside the inner bark of Nothapodytes foetida [11], in 2008, CPT was isolated from a Nothapodytes foetida seed endophyte, Neurospora c., and both authentic and fungal CPT exhibited comparable cytotoxic effects in human cancer cell lines HEP-2 (liver cancer), A549 (lung cancer), and OVCAR-5 (ovarian cancer) [96]. In 2009, CPT along with its two derivatives, 9-methoxycamptothecin and 10-hydroxycamptothecin, were isolated from a Camptotheca acuminata inner bark endophyte, Fusarium s. (Figure 3a). These derivatives are more water soluble and more potent inhibitors of the topoisomerase-I enzyme [80] (Table 2). 

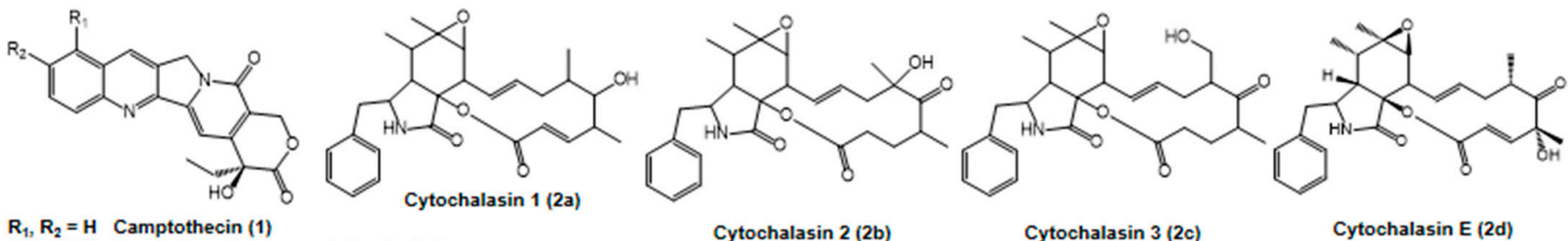

$\mathbf{R}_{1}, \mathbf{R}_{2}=\mathbf{H}$ Camptothecin (1)

$\mathrm{R}_{1}=\mathrm{OCH}_{3}, \mathrm{R}_{2}=\mathrm{H}$ 9-methoxycamptothecin (1a)

Cytochalasin $3(2 \mathrm{c})$

Cytochalasin E (2d)

$R_{1}=H, R_{2}=\mathrm{OH}$ 10-hydroxycamptothecin (1b)
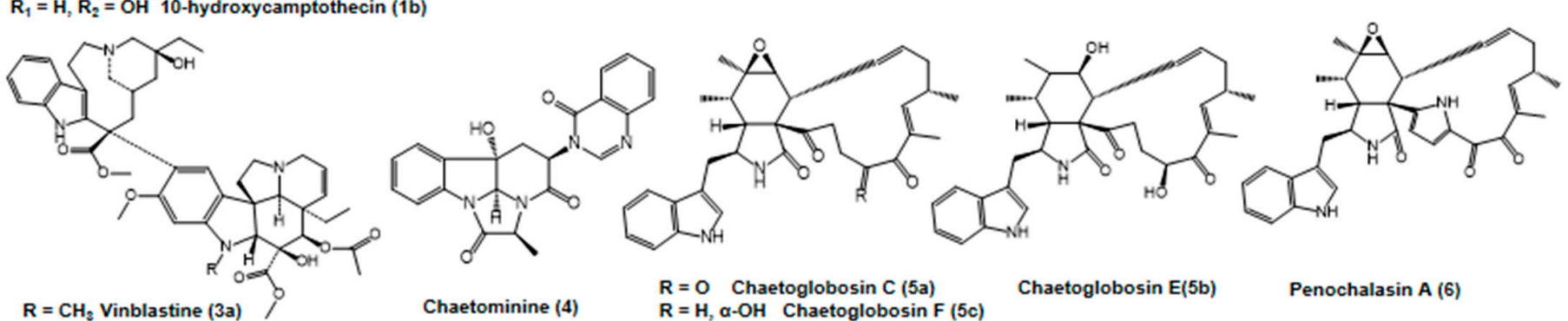

$\mathrm{R}=\mathrm{CHO}$ Vincristine $(3 \mathrm{~b})$

$R=0 \quad$ Chaetoglobosin $C(5 a)$

Chaetoglobosin $\mathrm{E}(5 \mathrm{~b})$

Penochalasin A (6)

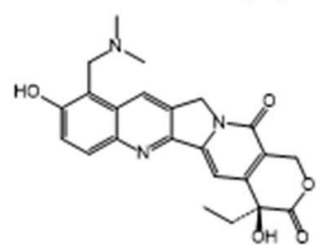

Topotecan (7)<smiles>CCC1CC(C(C)C2CCC(C3CCCCC3)CC2)CCC1C1CCC2C(CC)C3CC(C)C(C)CC3CC12</smiles>

Irinotecan (8)
Daldinone $c(9 a)$
(

Daldinone D (9b)<smiles>CCCCCC1CC(=O)C2C(CC(O)O)CC(O)CC2O1</smiles>

Pestalotiopsone F (10)

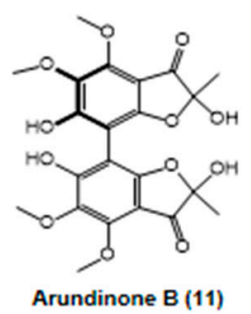

Arundinone B (11)

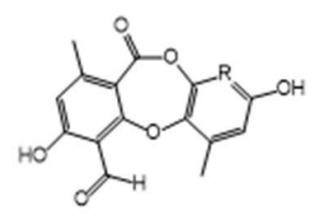

$R=C$ Botryorhodine A (12a) $\mathrm{R}=-\mathrm{CH}_{3}$ Botryorhodine $\mathrm{B}(12 \mathrm{~b})$

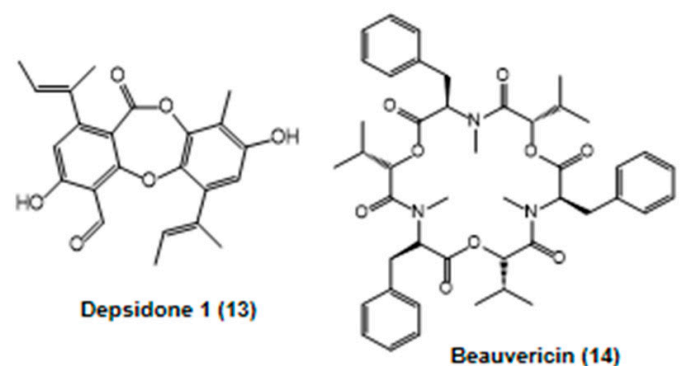

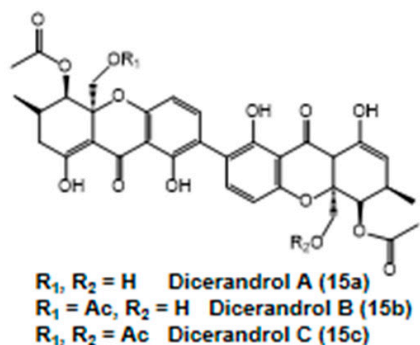
作

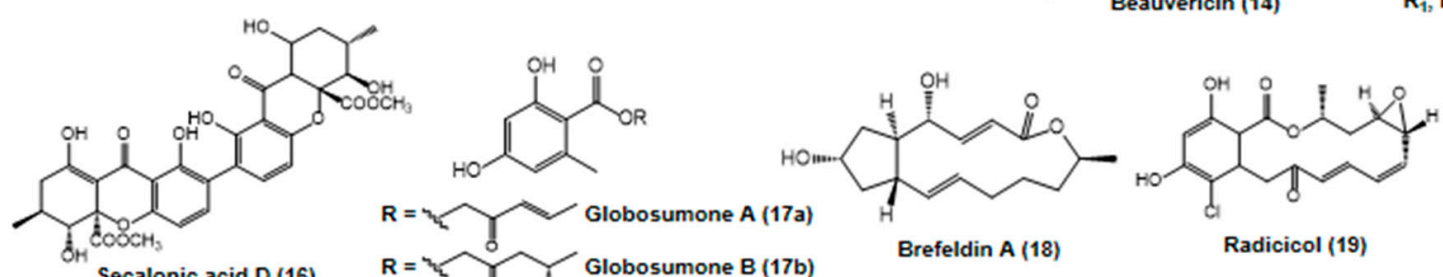

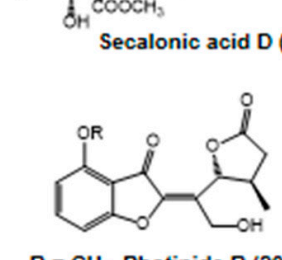

$\mathrm{R}=\mathrm{CH}_{3}$ Photinide $\mathrm{B}(2 \mathrm{~b})$ $\mathbf{R}=\mathbf{H}$ Photinide $\mathrm{D}(\mathbf{2 0 d})$ $R=\overbrace{d}$ Globosumone B (17b)

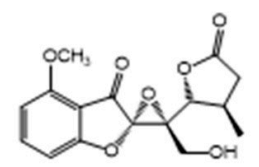

Photinide F (20f)

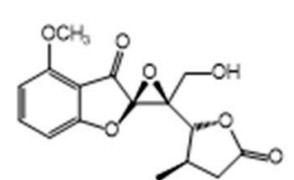

Photinide E (20e)

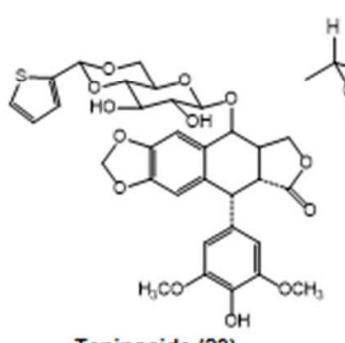

Teniposide (23)

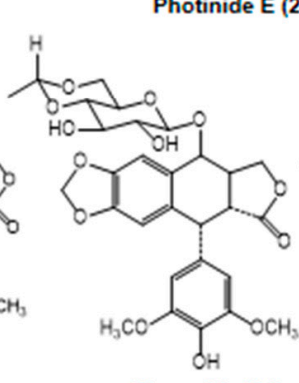

Etoposide (24)<smiles>C=C[C@@H](C)CC</smiles>

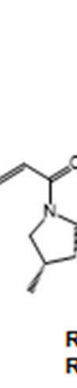

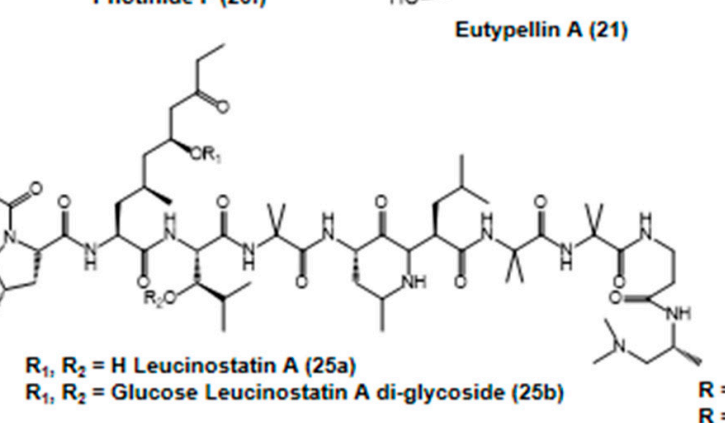
$\mathbf{R}_{1}, \mathbf{R}_{2}=\mathbf{H}$ Leucinostatin $\mathbf{A}(\mathbf{2 5 a})$
$\mathbf{R}_{1}, \mathbf{R}_{2}=$ Glucose Leucinostatin A di-glycoside (25b)<smiles>O=C/C=C/C=C1C(=O)O[C@@H](/C=C/CO)[C@H]1O</smiles>

Eutypellin A (21)

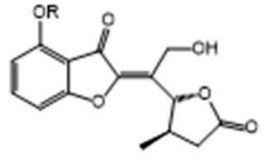

$\mathrm{R}=\mathrm{CH}_{3}$ Photinide $\mathrm{A}$ (20a) $\mathbf{R}=\mathbf{H}$ Photinide $\mathrm{C}(20 \mathrm{c})$

Podophyllotoxin (22)

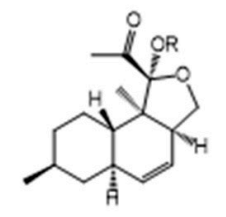

$\mathrm{R}=\mathrm{CH}_{3}$ Oblongolide $\mathrm{Y}$ (26a) $\mathrm{R}=\mathrm{CH}_{2} \mathrm{CH}_{2} \mathrm{Ph}$ Oblongolide $\mathrm{Z}$ (26b)

Figure 3. Cont. 


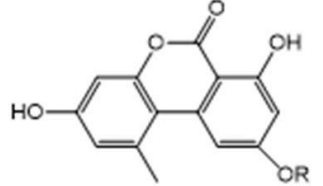

$\mathbf{R}=\mathbf{H} \quad$ Alternariol $(27 \mathrm{a})$

$\mathrm{R}=\mathrm{SO}_{3} \mathrm{H}$ Alternariol 5-O-sulfate (27b)

$\mathrm{R}=\mathrm{CH}_{3}$ Alternariol 5-O-methyl ether (27c)

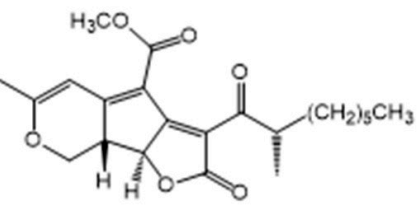

Sequoiatone A (32a)<smiles>COc1c(-c2cc(O)c3c(c2OC)C(=O)c2cc(O)c(C)cc2C3=O)cc(O)c2c1C(=O)C1=C(C[C@@H](O)[C@](C)(O)[C@H]1O)C2=O</smiles>

Alterporriol L (35a) (c)

Isocochliodinol (38)

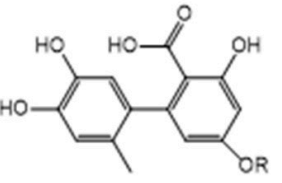

$\mathrm{R}=\mathrm{CH}_{3}$ Altenusin (28a)

$\mathrm{R}=\mathrm{CH}_{3}$ Aitenusin (28a)
$\mathrm{R}=\mathrm{H}$ Desmethyl altenusin (28b)<smiles>CC1=CC(=O)C(C)(C)C(C)C1</smiles>

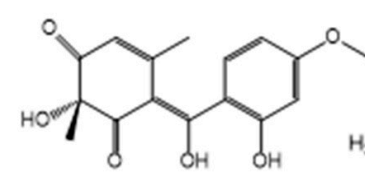

Penicillenone (30)

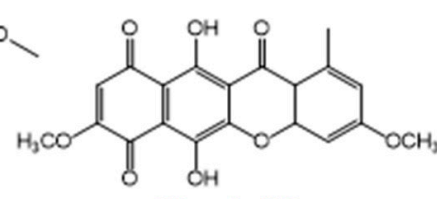

Bikaverin (31)

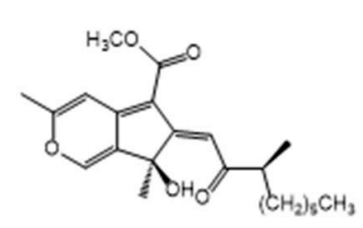

Sequoiatone $B$ (32b)

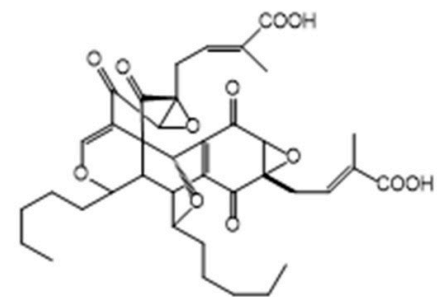

Torreyanic acid (33)<smiles>COC1C(C2CC(O)C3C(O)C4C(O)CCC(O)(O)C4C3C2OC)CC(O)C2C(O)C3CC(C)C(O)CC3C(O)C12</smiles>

Alterporriol K (35b)

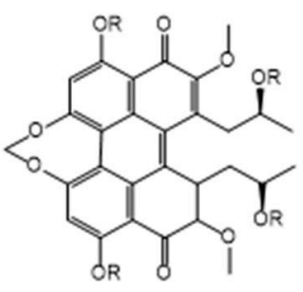

$\mathrm{R}=\mathrm{H} \quad$ Cercosporin 1 (36a) $\mathbf{R}=\mathbf{A c}$ Cercosporin $2(36 b)$<smiles>CC(C)=CCC1=C(O)C(=O)c2ccccc2C1=O</smiles>

Lapachol (34)

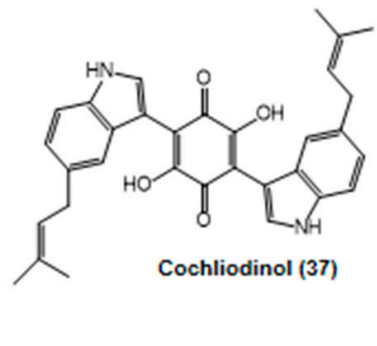<smiles>CO[C@@H]1CC(O)CC2C(O)C3=C(CNC(C)C3)C(=O)C21</smiles>

7-Desmethylscorpinone (39)<smiles>COC1C(O)CC(O)[C@H]2C(=O)C3CN[C@H](C)CC3C(=O)C12</smiles>

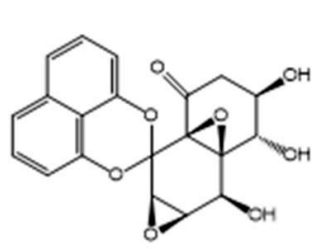

Diepoxin $\delta(43)$

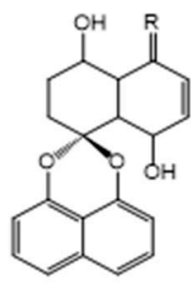

$\mathrm{R}=\mathrm{H}, \mathrm{OH}$ Palmarumycin (44)

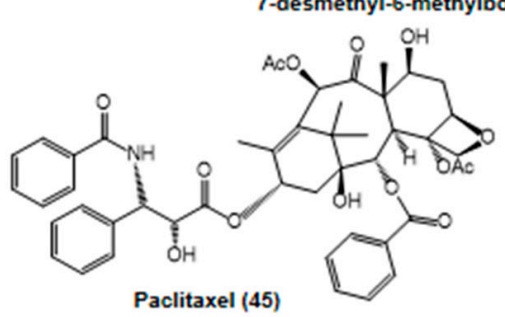

Paclitaxel (45)

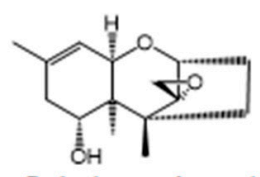

$7 \alpha$-hydroxy scirpene (48)<smiles>CC1(C)C=CC(=O)[C@@]23C[C@@H](CC2(C)C)OO[C@H]3C1(C)CO</smiles>

Merulin C (52b)

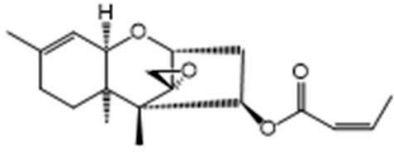

8-deoxy trichothecin (49)

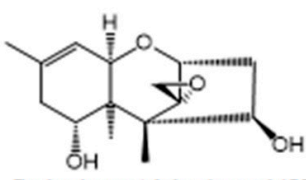

7a-hydroxy trichodermol (50)
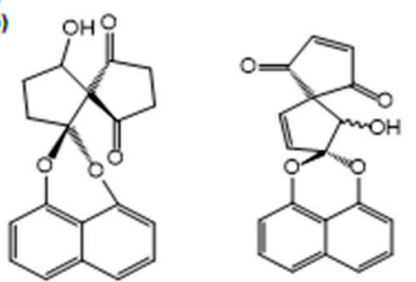

Spiromamakone A (41) Spiropreussione A (42)

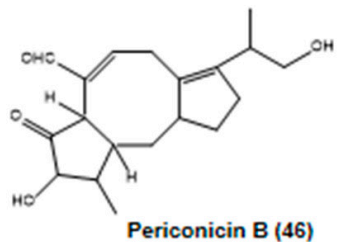

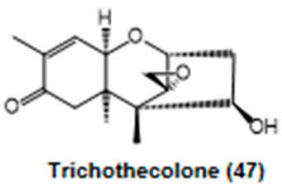<smiles>CCCCCC1CCC(=O)[C@]2(C)CCCCC12CCO</smiles>

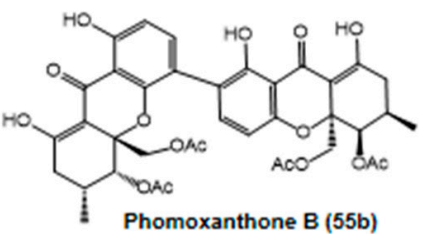<smiles>COC1=CC(=O)c2c(O)c3c(c(O)c2C1=O)CC(C)(O)OC3</smiles>

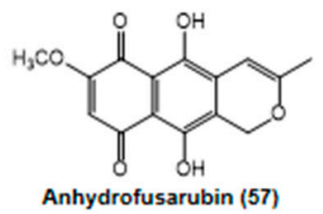

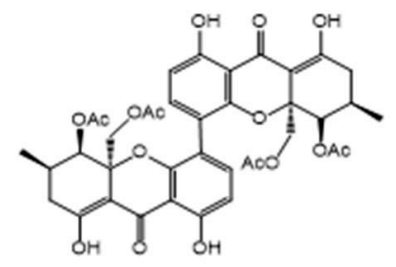

Phomoxanthone A (55a)

b)

Figure 3. Anticancer compounds of different chemical classes from endophytic fungi-alkaloidal compounds and their derivatives: (a) (1-8), benzo[j]fluoranthene (9), Chromone (10), coumarin (11), 
depsidones $(12,13)$, depsideptide (14), ergochromes $(15,16)$, ester $(17)$, lactones (18-22), lignans (23-24), peptide (25), polykedites (26); (b) polyketides (27-32), quinones (33-39), spirobisnaphthalenes (40-42), terpenes (43-54), xanthones (55), naphthoquinones $(56,57)$.

Cytochalasins $(2 \mathrm{a}-2 \mathrm{~d})$ are fungal metabolites that inhibit cell division by means of inhibiting actin filament polymerization [226]. Four cytochalasins (cytochalasin 1, 2, 3 , and E) have been isolated from an endophytic fungus, Rhinocladiella spp. from the Tripterygium wilfordii dead tree limbs and were tested against HCT-116 (colon tumor cell line), A2780S (ovarian tumor cell line), and SW-620 (colon tumor cell line) showing cytotoxic activities [136].

The vinca alkaloid (3a, 3b), vincristine (leurocristine), was isolated from Catharanthus roseus [227]. This alkaloid has also been isolated from some fungal endophytes of Catharanthus roseus such as Fusarium o. (inner bark), Mycelia s. 97CY(3) (Leaves), and Talaromyces r. CrP20 (Leaves) [74,75,89]. Vincristine irreversibly binds to the spindle proteins and microtubules during the S-phase of cell cycle hampering mitotic spindle formation and therefore arresting tumor cell division in the metaphase [1].

Chaetominine (4) was isolated from an endophyte, Chaetomium sp. IFB-E015 from the healthy leaves of Adenophora axilliflora, and it was cytotoxic against K562 (human leukemia cells) and SW1116 (human colon cancer cells) [54].

Cytochalasan-based alkaloids $(5 a-5 c, 6)$, namely chaetoglobosin C, E, F, U, and penochalasin A (6), were obtained from the endophyte Chaetomium g. IFB-E019 residing inside the Imperata cylindrica healthy stem. Chaetoglobosin U was cytotoxically active against the KB cell line (human nasopharyngeal epidermoid tumor) with an IC50 value of $16.0 \mu \mathrm{M}$, whereas chaetoglobosin C (IC50 34.0 $\mu \mathrm{M})$, E (IC50 $40.0 \mu \mathrm{M}), \mathrm{F}$ (IC50 $52.0 \mu \mathrm{M})$, and penochalasin A (IC50 $48.0 \mu \mathrm{M}$ ) were moderately active against the KB cell line [57]. Endophytic fungus Chaetomium $g$. L18 from the plant Curcuma wenyujin produces chaetoglobosin $X$ that exerted cytotoxic activity against $\mathrm{H} 22$ (hepatic cancer cells in mice) and MFC (gastric cancer cells in mice) cell lines [56] (Table 2).

\subsubsection{Benzo[j]fluoranthenes}

Daldinone C (9a) and D (9b) were discovered from an Artemisia Artemisia annua endophyte, Hypoxylon $t$. IFB-18, where both agents exerted strong cytotoxic action against the human colorectal cancer SW1116 cell line at IC50 values of 49.5 and $41.0 \mu \mathrm{M}$, respectively [85] (Table 2, Figure 3a).

\subsubsection{Chromones}

A novel chromone, Pestalotiopsone F (10), was isolated from an endophytic fungus Pestalotiopsis spp. associated with a mangrove plant Rhizophora mucronata. Pestalotiopsone F showed moderate cytotoxicity to L5178Y (murine cancer cell line) at an EC50 value of $8.93 \mu \mathrm{g} / \mathrm{mL}$ [110]. Pestaloficiol I, J, K, and L are new isoprenylated chromone derivatives discovered from a Camellia sinensis endophyte, Pestalotiopsis f., that displayed cytotoxicity against HeLa (Cervical cancer) and MCF-7 (Breast cancer) cell lines [115] (Table 2).

\subsubsection{Coumarins}

Arundinone B (11) was isolated from an endophyte Microsphaeropsis $a$. associated with Ulmus macrocarpa. The compound showed cytotoxicity to T24 (Bladder carcinoma) and A549 (Lung carcinoma epithelial) cell lines [92] (Table 2).

\subsubsection{Depsidones}

Botryorhodines A (12a) and B (12b), two depsidones, were isolated from the endophytic fungus Botryosphaeria $r$. associated with Bidens pilosa. These compounds exhibited weak antitumor activity against the HeLa cell line at a concentration of 96.97 and $36.41 \mu \mathrm{M}$, respectivel [48]. Depsidone 1 was discovered from a fungus of the Pleosporales order (BCC 8616) isolated from an unidentified plant leaf of the Hala-Bala forest origin. Depsidone 1 
displayed weak cytotoxicity to $\mathrm{KB}$ and $\mathrm{BC}$ cell lines with IC50 values 6.5 and $4.1 \mu \mathrm{g} / \mathrm{mL}$, respectively [43] (Table 2).

\subsubsection{Depsipeptides}

Beauvericin (14), a depsipeptide, was isolated from two fungi, Fusarium o. EPH2RAA and Fusarium o., associated with the plants Cylindropuntia echinocarpus and Ephedra fasciculate, respectively. Beauvericin displayed cytotoxicity to NCI-H460 (human non-small cell lung cancer), MIA Pa Ca-2 (human pancreatic carcinoma), MCF-7 (human breast cancer), and SF-268 (human CNS cancer) cell lines with IC50 values of 1.41, 1.66, 1.81, and $2.29 \mu \mathrm{M}$, respectively, showing selective cytotoxicity toward MIA PaCa-2 and NCI-H460 (Table 2). Beauvericin also inhibited the metastasis of MDA-MB-231 (Breast cancer) and PC-3M (metastatic prostate cancer) cells at concentrations ranging between 3.0-4.0 and 2.0-2.5 $\mu \mathrm{M}$, respectively [77]. According to other studies, beauvericin displayed cytotoxicity against A549 (Lung carcinoma epithelial), PC-3 (Prostate cancer), and PANC-1 (human pancreatic carcinoma) cell lines with IC50 values of $10.4 \pm 1.6,49.5 \pm 3.8$, and $47.2 \pm 2.9 \mu \mathrm{M}$, respectively [71]. Additionally, in 2006, Ivanova et al. demonstrated the cytotoxicity of beauvericin against Hep-G2 (hepatocellular carcinoma) and MRC-5 (fibroblast-like fetal lung cell line) cells as well [76].

\subsubsection{Ergochromes}

Phomopsis l., an endophytic fungus of Dicerandra frutescens, produced three compounds dicerandrols $A, B$, and C (15a-15c), structurally related to the ergochromes and secalonic acids as they also have the same tricyclic $\mathrm{C} 15$ system with a similar arrangement of substituents. These compounds displayed modest antitumor activities toward A549 (lung adenocarcinoma epithelial cell line) and HCT-116 (colon tumor cell line) cell lines [132] (Table 2).

Secalonic acid D (16), isolated from mangrove plant endophytic fungus no. ZSU44, displayed potent cytotoxicity against HL60 (the human promyelocytic leukemia cell line) and K562 (human leukemia cells) cells with IC50 values of 0.38 and $0.43 \mu \mathrm{M}$, respectively. It caused apoptosis in those cell lines and cell cycle arrest in the G(1) phase as well [158].

\subsubsection{Esters}

Globosumones A (17a) and B (17b), isolated from the endophyte Chaetomium g. associated with Ephedra fasciculate, were shown to have cytotoxicity to MCF-7 (breast cancer), MIA PaCa-2 (pancreatic carcinoma), NCI-H460 (non-small cell lung cancer), SF-268 (CNS glioma), and WI-38 (normal human fibroblast cells) cell lines [58].

\subsubsection{Lactones}

The lactone compound Brefeldin A (18) was obtained from two endophytic fungi, Aspergillus $\mathrm{c}$. and Paecilomyces spp., isolated from the plants Taxus mairei and Torreya grandis. Brefeldin A exhibited antitumor activities to Hela, HL-60, KB, MCF-7, and Spc-A-1 with IC50 values of 1.8, 10.0, 9.0, 2.0, and $1.0 \mathrm{ng} / \mathrm{mL}$ [31]. Brefeldin A was also obtained from the endophyte Acremonium spp. isolated from the healthy Knema laurina twig. It showed cytotoxicity to BC-1 (breast cancer), KB (epidermoid cancer of the mouth), and NCIH187 (human small-cell lung cancer), with IC50 values of $0.04,0.18$, and $0.11 \mu \mathrm{M}$, respectively [86] (Table 2).

Radicicol (19) was obtained from Chaetomium c. associated with Ephedra fasciculate and it is a HSP90 (heat shock protein) inhibitor, which is frequently expressed highly in cancer cells. It also showed cytotoxicity to the MCF-7 (breast cancer) cell line at an IC50 value $0.03 \mu \mathrm{M}[55]$.

Photinides A-F (20a-20f) were obtained from the endophyte Pestalotiopsis $p$. associated with Roystonea regia, and all of these $\gamma$-lactones at $10 \mu \mathrm{g} / \mathrm{mL}$ exerted cytotoxicity against the MDA-MB-231 (breast cancer) cell line with inhibitory rates of 24.4, 24.2, 23.1, 24.4, and $24.6 \%$, respectively [123] (Table 2). 
Eutypellin A (21), isolated from the endophyte Eutypella spp. BCC 13199 associated with Etlingera littoralis, showed cytotoxicity to KB, MCF-7NCI-H187 (human small-cell lung cancer cells), and nonmalignant Vero cells with IC50 values of 38, 84, 12, and $88 \mu \mathrm{M}$, respectively [70].

\subsubsection{Lignans}

Podophyllotoxin (22), a precursor to the topoisomerase-I-inhibiting anticancer drugs teniposide (23), etoposide (24), and etoposide phosphate, were isolated from the endophyte Phialocephala f. associated with Podophyllum peltatum [12]. This was also obtained from the endophyte Trametes $h$. associated with Podophyllum hexandrum and from the endophyte Fusarium s. associated with Podophyllum hexandrum [1,79,148] (Table 2).

\subsubsection{Peptides}

Leucinostatin A was isolated from the endophyte Acremonium spp. associated with Taxus baccata and was shown to be effective against BT-20 (breast cancer) cell line with an LD50 value of $2 \mathrm{nM}$ [14]. It inhibits the growth of prostate cancer cells through the suppression of IGF-I (Insulin-Like Growth Factor-I) expression in PrSC (prostate stromal cells) [228] (Table 2).

\subsubsection{Polyketides}

Two novel oblongolides, Y (26a) and Z (26b) (Figure 3a), are produced by the endophyte Phomopsis spp. BCC 9789 housed in Musa acuminate (a wild banana). Oblongolide Y exhibited cytotoxicity against BC (human breast cancer) cell line (IC50 $48 \mu \mathrm{M}$ ) and Oblongolide Z showed cytotoxicity against BC (human breast cancer), KB (human oral epidermoid cancer), NCI-H187 (small-cell lung cancer), and nonmalignant (Vero) cell lines with IC50 values of $26 \mu \mathrm{M}, 37 \mu \mathrm{M}, 32 \mu \mathrm{M}$, and $60 \mu \mathrm{M}$, respectively [130] (Table 2).

Five tricyclic lactone polyketides, alternariol (27a), alternariol 5-O-sulfate (27b), alternariol 5-O-methyl ether (27c), altenusin (28a), and desmethylaltenusin (28b) (Figure 3b), were isolated from the endophyte Alternaria spp. housed in the leaves of Polygonum senegalense. All these compounds manifested significant cytotoxicity against L5178Y (mouse lymphoma cells) with EC50 values of 1.7, 4.5, 7.8, 6.8, and $6.2 \mu \mathrm{g} / \mathrm{mL}$, respectively [16]. According to another study conducted by Devari et al. in 2014, alternariol 5-O-methyl ether showed antiproliferative activity against HL-60 (human promyelocytic leukemia), A549 (lung cancer), PC-3 (prostate cancer), HeLa (cervical cancer), A431 (skin carcinoma), MiaPaka-2 (pancreatic cancer), and T47D (breast cancer) cell lines. Among all these cell lines, HL-60 (human promyelocytic leukemia) cells were most sensitive (IC50 $85 \mu \mathrm{M}$ ) to alternariol 5-O-methyl ether [25].

Two novel polyketides, leptosphaerone C (29) and penicillenone (30), are produced by an endophytic fungus Penicillium spp. JP-1, isolated from Aegiceras corniculatum. Leptosphaerone $\mathrm{C}$ showed cytotoxicity to A549 (lung carcinoma epithelial) with an IC50 value of $1.45 \mu \mathrm{M}$, and penicillenone exhibited activity against P388 (leukemia cells) with an IC50 value of $1.38 \mu \mathrm{M}$ [103].

Bikaverin (31) was isolated from an endophytic fungus Fusarium o. strain CECIS associated with Cylindropuntia echinocarpa [77]. It exerted cytotoxic activities against cancer cell lines, MIA PaCa-2 (pancreatic carcinoma), NCI-H460 (non-small cell lung cancer), MCF-7 (human breast cancer), and SF-268 (human CNS cancer) with IC50 values of 0.26, $0.43,0.42$, and $0.38 \mu \mathrm{M}$, respectively, showing selective cytotoxicity toward MIA PaCa-2 and NCI-H460. Bikaverin was also proven to be cytotoxic against EAC (Erlich ascites carcinoma), leukemia L5178, and sarcoma 37 cell lines affecting precursor utilization of nucleic acid and protein synthesis [78].

Sequoiatone A (32a) and B (32b), two novel polyketides (Figure 3b), were isolated from a Sequoia sempervirens bark endophyte, Aspergillus $p$. These polyketide compounds were tested against 60 diverse human tumor cell lines, and among them, breast cancer cell lines showed the greatest sensitivity [37] (Table 2). 


\subsubsection{Quinones}

Torreyanic acid (33) (Figure 3b), a dimeric quinine, was isolated from an endophyte of Torreya taxifolia, Pestalotiopsis $m$. It causes cytotoxicity by apoptosis against A549 (lung carcinoma epithelial) and NEC (human colorectal neuroendocrine cell carcinoma) cell lines with IC50 values of $3.5 \mu \mathrm{g} / \mathrm{mL}$ and $45 \mu \mathrm{g} / \mathrm{mL}$, respectively [119] (Table 2).

Four endophytes, Alternaria spp., Alternaria a., Aspergillus n., and Penicillium spp., associated with Tabebuia argentea, produced the antitumor and anti-metastatic agent lapachol (34) $[17,20-22]$. It acts by interfering with the bioactivities of the topoisomerase enzymes, which are crucial for DNA replication [22]. $\beta$-Lapachone showed activity on DU145 (human prostate carcinoma) and MCF-7 (breast cancer cell line) cell lines [20,22]. Additionally, its antitumor and anti-metastatic activities were evident in HepG2 (human hepatocellular liver carcinoma) and Hep3B (human hepatoma cell line) cell lines [19]. Notably, Aspergillus $n$. can be used to produce lapachol in a large scale within a short time [18].

Two bianthraquinone derivatives, Alterporriol K (35a) and L (35b), are produced by the endophytic fungus Alternaria spp. ZJ9-6B associated with the mangrove Aegiceras corniculatum. Alterporriol $\mathrm{K}$ and L exerted moderate cytotoxicity against MDA-MB-435 and MCF-7 (breast cancer cell line) cell lines with IC50 values between 13.1 and $29.1 \mu \mathrm{M}$ [24].

Cercosporin (36) was isolated from the endophytic fungus Mycosphaerella spp., associated with Psychotria horizontalis, and exhibited cytotoxicity against MCF-7 [91].

Another endophytic fungus, isolated from the Salvia officinalis stem, was Chaetomium spp., which produced the cytotoxically active agents, cochliodinol (37) and isocochliodinol (38) (Figure 3b). These compounds were tested against the L5178Y (mouse lymphoma cells) cell line where cochliodinol showed higher cytotoxicity (EC50 $7.0 \mu \mathrm{g} / \mathrm{mL}$ ) than isocochliodinol (EC50 $71.5 \mu \mathrm{g} / \mathrm{mL}$ ) [51] (Table 2).

Azaanthraquinones, 7-desmethylscorpinone (39), and 7-desmethyl-6-methylbostrycoidin (40) (Figure 3b) isolated form Fusarium s. showed cytotoxic activity against four human tumor cell lines, MDA MB 231, MIA PaCa2, HeLa, and NCI H1975 [229].

\subsubsection{Spirobisnaphthalenes}

Mycelia s., an endophytic fungus isolated from the leaves of Knightia excelsa, was shown to produce Spiromamakone A (41) (Figure 3b) that exhibited cytotoxicity to P388 (murine leukemia cell line) at an IC50 value $0.33 \mu \mathrm{M}$ [90] (Table 2).

A novel spirobisnaphthalene, spiropreussione A (42), was isolated from the endophyte Preussia spp. associated with Aquilaria sinensis. It displayed cytotoxicity to A2780 (human ovarian carcinoma) and BEL-7404 (human liver carcinoma) cell lines with IC50 values of 2.4 and $3.0 \mu \mathrm{M}$, respectively [135].

Diepoxin $\delta(43)$, palmarumycin C8 (44), and diepoxins $k$ and $\zeta$ were isolated from the endophytic fungus Berkleasmium spp. associated with Dioscorea zingiberensis. Diepoxin $\delta$ and palmarumycin C8 displayed pronounced cytotoxicity to A-549, A-2780, Bel-7402, BGC-823, and HCT-8 cell lines with IC50 values between 1.28 and $5.83 \mu \mathrm{M}$, while diepoxins $\kappa$ and $\zeta$ selectively inhibited A-549 and Bel-7402 cells' growth showing moderate to weak cytotoxicity [44] (Table 2).

\subsubsection{Terpenes (Diterpenes, Sesquiterpenes, Triterpenes)}

Several terpenes of plant and fungal origin have been established as potential anticancer drugs (Figure 3b, structures 45-54). Among these, paclitaxel (Taxol) (45) was isolated from Taxus brevifolia (Pacific yew tree) $[230,231]$. However, due to less availability of the pacific yew tree and insignificant yield of this metabolite, scientist have set up other approaches, including tissue culture, chemical synthesis, and semi-synthesis [230,232]. However, this diterpenoid was also reported to be produced by an endophytic fungus, Taxomyces a., isolated from the Taxus brevifolia [6]. Following this report, a number of paclitaxel producing other endophytes were reported. Some of them are Bartalinia $r$. from the leaves of Aegle marmelos [42] and Pestalotiopsis $n$. and Pestalotiopsis $v$. from the plant 
Taxus cuspidate [73]. This metabolite has been found to induce apoptosis when screened against INT-407, BT220, H116, HL251, and HLK210 cell lines [42] (Table 2).

A fusicoccane diterpene, periconicin B (46), was isolated from a Xylopia aromatica endophyte, Periconia $a$. It exerted potent cytotoxicity against HeLa (cervical cancer) and $\mathrm{CHO}$ (Chinese hamster ovary) cell lines [109].

Four sesquiterpens, trichothecolone (47), $7 \alpha$-hydroxy-scirpene (48), 8-deoxy-trichothecin (49), and $7 \alpha$-hydroxytrichodermol (50), were isolated from an endophyte, KLAR 5, housed in the healthy twig of Knema laurina. Compounds 47 and 48 were moderately active against BC-1 (human breast cancer cells), KB (Human nasopharyngeal epidermoid tumor), and NCI-H187 (human small-cell lung cancer cells), whereas compounds 49 and 50 showed selective cytotoxic activity against BC-1 and NCI-H187 [86].

Ent-4(15)-eudesmen-11-ol-1-one (51), an eudesmane sesquiterpene, isolated from an Etlingera littoralis endophyte, Eutypella spp. BCC 13199, showed weak cytotoxicity against KB, MCF7, NCI-H187, and Vero cells with IC50 values of 32, 20, 11, and $32 \mu \mathrm{M}$, respectively [70].

Two sesquiterpenes, Merulin A (52a) and Merulin C (52b), are produced by a Xylocarpus granatum endophytic fungi, XG8D, where both of them showed significant cytotoxic activity against SW620 (colon cancer) and BT474 (breast cancer) cell lines with IC50 values of 4.84 and $4.11 \mu \mathrm{g} / \mathrm{mL}$ for SW620 and 4.98 and $1.57 \mu \mathrm{g} / \mathrm{mL}$ for BT474, respectively [151].

Three novel eremophilane-type sesquiterpenes (Figure 3b), eremophilanolides 1, 2, and 3 (53a-53c), were isolated from the endophytic fungi Xylaria spp. BCC 21097 of the Licuala spinose plant and were moderately cytotoxic against KB, MCF-7, and NCI-H187 cell lines [152].

Tauranin (54) is produced by a Platycladus orientalis endophyte, Phyllosticta s., exhibiting cytotoxicity against MCF-7 (breast cancer), MIA Pa Ca-2 (pancreatic carcinoma), NCI-H460 (non-small cell lung cancer), PC-3 M (metastatic prostate cancer), and SF-268 (CNS cancer- glioma) cell lines with IC50 values of $1.5,2.8,4.3,3.5$, and $1.8 \mu \mathrm{M}$, respectively [133] (Table 2).

\subsubsection{Xanthones}

Phomoxanthone A (55a) and B (55b) (Figure 3b), isolated from the endophyte Phomopsis spp. BCC 1323 associated with Tectona grandis, exerted significant cytotoxicity against KB, BC-1, and nonmalignant Vero cells with IC50 values of $0.99,0.51$, and $1.4 \mu \mathrm{g} / \mathrm{mL}$, respectively, for phomoxanthone A and $4.1,0.70$, and $1.8 \mu \mathrm{g} / \mathrm{mL}$, respectively, for phomoxanthone B [129] (Table 2).

\subsection{Recently Reported Metabolites with Potential Cytotoxicity and the Case of Fusarubin}

More than one hundred metabolites have been isolated and evaluated for putative anticancer activities in the years 2018 to 2020. Cytotoxic activities of these endophytic metabolites have been summarized in Table 3. Among the reported metabolites, penicolinate A isolated form Bionectria spp. [159] and pyrrocidine A isolated from Cylindrocarpon spp. [166] exhibited potent cytotoxicity against against the human ovarian cancer cell line A2780. Fusarithioamide B, a new type benzamide, isolated form Fusarium c., showed potent activity against several cell lines [160]. 3-(4-nitrophenyl)-5-phenyl isoxazole was reported to have a potent effect against HepG2 and SMCC-7721 cells [161], while spiciferone F was reported to have a strong effect against MCF7 [162]. Liu et al. isolated two metabolies, namely xylariphthalide A and cis-4-hydroxy-6-deoxytalone, and Sharma V. et al. isolated Xylarolide A from Diaporthe spp. [163,164]. All these metabolites showed activity towards cancer cells. Three naphthaquinones, anhydrofusarubin, fusarubin, and 3-deoxyfusarubin, and one aza-anthraquinone, bostrycoidin, have potentiality as bioactive compounds against cytotoxicity on vero cells. These metabolites were isolated from a Fusarium s. strain isolated from Casia alata. [8]. Monolinolein, bafilomycin D, and 3'-hydroxydaidzein displayed a strong effect against A549 cells. These metabolites were isolated from actinomycete strain 
YBQ59 residing in Cinnamomum cassia [167]. Colletotrichum g. A12 produced colletotricone A, which showed moderate activity against MCF-7, NCI-H460, HepG-2m and SF-268 tumor cell lines [168]. Mollicellin G, a depsidone, was reported as a moderately active cytotoxic metabolite towards HepG2 and Hela cells [169]. A metabolite of Pestalotiopsis spp., named demethylincisterol A3, showed potential cytotoxicity against human cancer cell lines Hela, A549, and HepG [170].

A new type of cytochalasin, named jammosporin A, isolated from endophytic fungi Rosellinia s.-c., exhibited cytotoxic potential towards MOLT-4 cells [165]. Prenylated diphenyl ethers, namely diorcinol $\mathrm{N}$ and analogues isolated from Arthrinium a. TE-3, showed moderate cytotoxicity against the human monocytic cell line (THP-1 cell line), with IC50 values of 40.2, 28.3, and $25.9 \mu \mathrm{M}$, respectively [233].

An indole diterpenoid, shearilicine, isolated form Penicillium spp. (strain ZO-R1-1) of Zingiber officinale, showed potent cytotoxicity towards L5178Y cells and A2780 cells [171]. Flavipin from Chaetomium g. displayed activity against A549, HT-29, and MCF-7 cells [172]. Emodin, an anthraquinone from Diaporthe l., significantly inhibited the growth of murine leukemia P-388 cells [219].

Recently reported metabolites, namely chloroisosulochrin from Pestalotiopsis t. (N635) [206], cytosporin W from Pseudopestalotiopsis t. [207], terezine E and 14-hydroxyterezine D from Mucor spp. [208], citrinin (CIT) and dicitrinin-A from Penicillium c. [209], allantopyrone E from Aspergillus v. [210], integracin A and B from Cytospora spp. [211], ( \pm )-asperteretone F $(3 a / 3 b)$, and compound 6 (name not established in the paper) Aspergillus t. [212], sterigmatocystin, a xanthone, from Paecilamyces spp. TE-540 [213], mutolide [234] and pramanicin A from Aplosporella j. [216], myrothecines H and I from Paramyrothecium r. A697 [217], and colletotrichalactone A and colletotrichalactone Ca from Colletotrichum spp. JS-0361, exhibited promising activity against different cancer cells [218]. A summary of the putative cytotoxic effects of recently reported endophytic fungal metabolites are summarized in Table 3.

Fusarubin and anhydrofusarubin have been isolated from the endophytic fungi Cladosporium residing inside Rauwolfia leaves. These compounds inhibited the cell growth of different leukemia cell lines (OCI-AML3, HL-60, U937, and Jurkat) by arresting the cell cycle and augmenting apoptosis. Whereas fusarubin exerted an antiproliferative effect on OCI-AML3 cells by up-regulating p21 in a p53-dependent manner, apoptosis was induced only in a small sub-population of leukemic cells by inducing the production of the Fas ligand (Figure 4) [9].

A<smiles>COC1=CC(=O)c2c(O)c3c(c(O)c2C(=O)C1=O)[C@@H]1COC(C)(O)O[C@H]1C[C@H]3O</smiles>
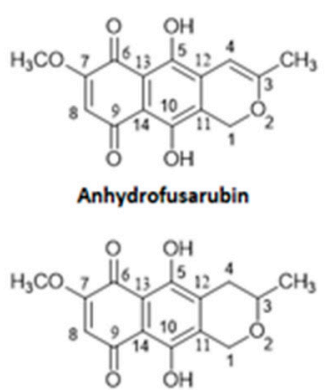

3-deoxy fusarubin
B

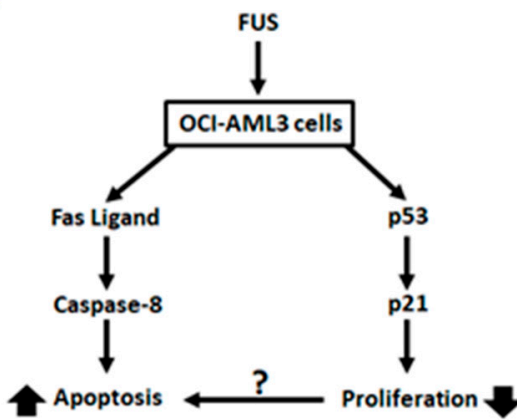

Figure 4. Fusarubin (FUS) and FUS analogues with proposed mechanism of action. (A) Structures of FUS derivatives and (B) Proposed mechanism of action of FUS on OCI-AML3 cells.

\section{Conclusions}

Several hundred endophytic fugal metabolites have been isolated to have cytotoxic and antimicrobial effects. Many metabolites are currently available as drugs on the market. Given that plants host endophytes as part of a symbiotic relationship, some plant metabolites might have an endophytic fungal origin. In fact, increasing evidence indicates that some of these plant metabolites are also produced by fungi. Many of the isolated 
metabolites of endophytic fungi inhabitant medicinal plants have been proved to have cytotoxic effects in vitro. Several of these compounds have been investigated at the molecular level to elucidate the mechanism, since these metabolites are produced in very small quantities by endophytes of plant origin. Due to very insignificant yields and isolation difficulties, these secondary metabolites may not be available to carry out in vivo studies in animal models. Some laboratories applied synthetic approaches to produce natural product derivatives, and one group also tried to synthesize some of these compounds. Optimizing derivatization and synthetic approaches is critical to attain higher yields for animal studies. These approaches will be key for investigating and developing these putative anticancer compounds into treatments.

Funding: This research received no external funding.

Institutional Review Board Statement: Not applicable.

Informed Consent Statement: Not applicable.

Data Availability Statement: Not applicable.

Conflicts of Interest: The authors declare no conflict of interest.

\section{Abbreviations}

\section{Fungus Name}

Allantophomopsis lycopodina

Alternaria alternata

Alternaria tenuissima

Aspergillus clavatus

Aspergillus fumigatus

Aspergillus glaucus

Aspergillus niger

Aspergillus parasiticus

Aspergillus terreus

Aspergillus violaceofuscus

Bartalinia robillardoides

Bionectria ochroleuca

Bipolaris setariae

Botryosphaeria dothidea

Botryosphaeria rhodina

Ceriporia lacerate

Chaetomium chiversii

Chaetomium globosum

Cladosporium cladosporioides

Cladosporium oxysporum

Colletotrichum capsici

Colletotrichum gloeosporioides

Cordyceps taii

Diaporthe terebinthifolii

Entrophospora infrequens

Fusarium oxysporum

Fusarium solani

Guignardia bidwellii

Guignardia mangiferae

Hypocrea lixii

Hypoxylon truncatum

Lasiodiplodia theobromae

Mycelia sterilia

Microsphaeropsis arundinis

Myrothecium roridum

\author{
Abbreviation \\ Allantophomopsis 1 . \\ Alternaria a. \\ Alternaria $t$. \\ Aspergillus c. \\ Aspergillus $f$. \\ Aspergillus g. \\ Aspergillus n. \\ Aspergillus $p$. \\ Aspergillus $t$. \\ Aspergillus v. \\ Bartalinia r. \\ Bionectria o. \\ Bipolaris s. \\ Botryosphaeriad. \\ Botryosphaeria $r$. \\ Ceriporia l. \\ Chaetomium c. \\ Chaetomium g. \\ Cladosporium c. \\ Cladosporium o. \\ Colletotrichum c. \\ Colletotrichum g. \\ Cordyceps $t$. \\ Diaporthe t. \\ Entrophospora i. \\ Fusarium o. \\ Fusarium s. \\ Guignardia $b$. \\ Guignardia m. \\ Hypocrea $l$. \\ Hypoxylon $t$. \\ Lasiodiplodia $t$. \\ Mycelias. \\ Microsphaeropsis a. \\ Myrothecium $r$.
}




\begin{tabular}{|c|c|}
\hline Neurospora crassa & Neurospora c. \\
\hline Papulaspora immersa & Papulaspora i. \\
\hline Paraconiothyrium brasiliense & Paraconiothyrium $b$. \\
\hline Penicillium chermesinum & Penicillium ch. \\
\hline Penicillium citrinum & Penicillium ci. \\
\hline Periconia atropurpurea & Periconia a. \\
\hline Pestalotiopsis fici & Pestalotiopsis $f$. \\
\hline Pestalotiopsis karstenii & Pestalotiopsis $k$. \\
\hline Pestalotiopsis microspora & Pestalotiopsis m. \\
\hline Pestalotiopsis pauciseta & Pestalotiopsis pa. \\
\hline Pestalotiopsis photiniae & Pestalotiopsis ph. \\
\hline Pestalotiopsis terminaliae & Pestalotiopsis t. \\
\hline Pestalotiopsis versicolor & Pestalotiopsis v. \\
\hline Pestalotiopsis neglecta & Pestalotiopsis $n$. \\
\hline Phialocephala fortinii & Phialocephalaf. \\
\hline Phialophora mustea & Phialophora m. \\
\hline Phoma betae & Phoma b. \\
\hline Phomopsis longicolla & Phomopsis l. \\
\hline Phyllosticta spinarum & Phyllosticta s. \\
\hline Rhizopycnis vagum & Rhizopycnis $v$. \\
\hline Rhytidhysteron rufulum & Rhytidhysteron $r$. \\
\hline Setophoma terrestris & Setophoma t. \\
\hline Stemphylium sedicola & Stemphylium s. \\
\hline Stemphylium globuliferum & Stemphylium g. \\
\hline Talaromyces flavus & Talaromyces $f$. \\
\hline Talaromyces radicus & Talaromyces $r$. \\
\hline Taxomyces andreanae & Taxomyces $a$. \\
\hline Thielavia subthermophila & Thielavias. \\
\hline Trametes hirsuta & Trametes $h$. \\
\hline Trichoderma gamsii & Trichoderma g. \\
\hline Xylaria cf. cubensis & Xylaria cf. c. \\
\hline
\end{tabular}

\section{References}

1. Kumar, V.; Rai, S.; Gaur, P.; Fatima, T. Endophytic Fungi: Novel Sources of Anticancer Molecules. In Advances in Endophytic Research; Verma, V.C., Gange, A.C., Eds.; Springer: New Delhi, India, 2014; pp. 389-422; ISBN 978-81-322-1574-5.

2. Gunatilaka, A.A.L. Natural Products from Plant-Associated Microorganisms: Distribution, Structural Diversity, Bioactivity, and Implications of Their Occurrence. J. Nat. Prod. 2006, 69, 509-526. [CrossRef]

3. Zhang, H.W.; Song, Y.C.; Tan, R.X. Biology and Chemistry of Endophytes. Nat. Prod. Rep. 2006, 23, 753-771. [CrossRef]

4. Aly, A.H.; Debbab, A.; Kjer, J.; Proksch, P. Fungal Endophytes from Higher Plants: A Prolific Source of Phytochemicals and Other Bioactive Natural Products. Fungal Divers. 2010, 41, 1-16. [CrossRef]

5. Staniek, A.; Woerdenbag, H.J.; Kayser, O. Endophytes: Exploiting Biodiversity for the Improvement of Natural Product-Based Drug Discovery. J. Plant Interact. 2008, 3, 75-93. [CrossRef]

6. Stierle, A.; Strobel, G.; Stierle, D. Taxol and Taxane Production by Taxomyces Andreanae, an Endophytic Fungus of Pacific Yew. Sci.-N. Y. THEN Wash. 1993, 260, 214. [CrossRef]

7. Khan, M.I.H.; Sohrab, M.H.; Rony, S.R.; Tareq, F.S.; Hasan, C.M.; Mazid, M.A. Cytotoxic and Antibacterial Naphthoquinones from an Endophytic Fungus, Cladosporium sp. Toxicol. Rep. 2016, 3, 861-865. [CrossRef]

8. Khan, N.; Afroz, F.; Begum, N.; Roy Rony, S.; Sharmin, S.; Moni, F.; Mahmood Hasan, C.; Shaha, K.; Sohrab, H. Endophytic Fusarium Solani: A Rich Source of Cytotoxic and Antimicrobial Napthaquinone and Aza-Anthraquinone Derivatives. Toxicol. Rep. 2018, 5, 970-976. [CrossRef]

9. Adorisio, S.; Fierabracci, A.; Muscari, I.; Liberati, A.M.; Cannarile, L.; Thuy, T.T.; Sung, T.V.; Sohrab, H.; Hasan, C.M.; Ayroldi, E.; et al. Fusarubin and Anhydrofusarubin Isolated from a Cladosporium Species Inhibit Cell Growth in Human Cancer Cell Lines. Toxins 2019, 11, 503. [CrossRef]

10. Shweta, S.; Zuehlke, S.; Ramesha, B.T.; Priti, V.; Mohana Kumar, P.; Ravikanth, G.; Spiteller, M.; Vasudeva, R.; Uma Shaanker, R. Endophytic Fungal Strains of Fusarium Solani, from Apodytes Dimidiata E. Mey. Ex Arn (Icacinaceae) Produce Camptothecin, 10-Hydroxycamptothecin and 9-Methoxycamptothecin. Phytochemistry 2010, 71, 117-122. [CrossRef]

11. Puri, S.C.; Verma, V.; Amna, T.; Qazi, G.N.; Spiteller, M. An Endophytic Fungus from Nothapodytes Foetida That Produces Camptothecin. J. Nat. Prod. 2005, 68, 1717-1719. [CrossRef]

12. Eyberger, A.L.; Dondapati, R.; Porter, J.R. Endophyte Fungal Isolates from Podophyllum Peltatum Produce Podophyllotoxin. J. Nat. Prod. 2006, 69, 1121-1124. [CrossRef] 
13. Kusari, S.; Lamshöft, M.; Spiteller, M. Aspergillus Fumigatus Fresenius, an Endophytic Fungus from Juniperus Communis L. Horstmann as a Novel Source of the Anticancer pro-Drug Deoxypodophyllotoxin. J. Appl. Microbiol. 2009, 107, 1019-1030. [CrossRef]

14. Strobel, G.A.; Hess, W.M. Glucosylation of the Peptide Leucinostatin A, Produced by an Endophytic Fungus of European Yew, May Protect the Host from Leucinostatin Toxicity. Chem. Biol. 1997, 4, 529-536. [CrossRef]

15. Yokoigawa, J.; Morimoto, K.; Shiono, Y.; Uesugi, S.; Kimura, K.; Kataoka, T. Allantopyrone A, an $\alpha$-Pyrone Metabolite from an Endophytic Fungus, Inhibits the Tumor Necrosis Factor $\alpha$-Induced Nuclear Factor KB Signaling Pathway. J. Antibiot. 2015, 68, 71-75. [CrossRef]

16. Aly, A.H.; Edrada-Ebel, R.; Indriani, I.D.; Wray, V.; Müller, W.E.; Totzke, F.; Zirrgiebel, U.; Schächtele, C.; Kubbutat, M.H.; Lin, W.H.; et al. Cytotoxic Metabolites from the Fungal Endophyte Alternaria sp. and Their Subsequent Detection in Its Host Plant Polygonum Senegalense. J. Nat. Prod. 2008, 71, 972-980. [CrossRef]

17. Balassiano, I.T.; De Paulo, S.A.; Henriques Silva, N.; Cabral, M.C.; da Gloria da Costa Carvalho, M. Demonstration of the Lapachol as a Potential Drug for Reducing Cancer Metastasis. Oncol. Rep. 2005, 13, 329-333.

18. Govindappa, M. First Report of Anticancer Agent, Lapachol Producing Endophyte, Aspergillus Niger of Tabebuia Argentea and Its in Vitro Cytotoxicity Assays. Bangladesh J. Pharmacol. 2014, 9, 129-139. [CrossRef]

19. KIM, S.O.; KWON, J.I.; JEONG, Y.K.; KIM, G.Y.; KIM, N.D.; CHOI, Y.H. Induction of Egr-1 Is Associated with Anti-Metastatic and Anti-Invasive Ability of $\beta$-Lapachone in Human Hepatocarcinoma Cells. Biosci. Biotechnol. Biochem. 2007, 71, $2169-2176$. [CrossRef]

20. Lee, J.H.; Cheong, J.; Park, Y.M.; Choi, Y.H. Down-Regulation of Cyclooxygenase-2 and Telomerase Activity by $\beta$-Lapachone in Human Prostate Carcinoma Cells. Pharmacol. Res. 2005, 51, 553-560. [CrossRef]

21. Sadananda, T.S.; Nirupama, R.; Chaithra, K.; Govindappa, M.; Chandrappa, C.P.; Vinay Raghavendra, B. Antimicrobial and Antioxidant Activities of Endophytes from Tabebuia Argentea and Identification of Anticancer Agent (Lapachol). J. Med. Plants Res. 2011, 5, 3643-3652.

22. Wuerzberger, S.M.; Pink, J.J.; Planchon, S.M.; Byers, K.L.; Bornmann, W.G.; Boothman, D.A. Induction of Apoptosis in MCF-7:WS8 Breast Cancer Cells by $\beta$-Lapachone. Cancer Res. 1998, 58, 1876-1885.

23. Wang, J.; Cox, D.G.; Ding, W.; Huang, G.; Lin, Y.; Li, C. Three New Resveratrol Derivatives from the Mangrove Endophytic Fungus Alternaria sp. Mar. Drugs 2014, 12, 2840-2850. [CrossRef]

24. Huang, C.-H.; Pan, J.-H.; Chen, B.; Yu, M.; Huang, H.-B.; Zhu, X.; Lu, Y.-J.; She, Z.-G.; Lin, Y.-C. Three Bianthraquinone Derivatives from the Mangrove Endophytic Fungus Alternaria sp. ZJ9-6B from the South China Sea. Mar. Drugs 2011, 9, 832-843. [CrossRef]

25. Devari, S.; Jaglan, S.; Kumar, M.; Deshidi, R.; Guru, S.; Bhushan, S.; Kushwaha, M.; Gupta, A.P.; Gandhi, S.G.; Sharma, J.P.; et al. Capsaicin Production by Alternaria Alternata, an Endophytic Fungus from Capsicum Annum; LC-ESI-MS/MS Analysis. Phytochemistry 2014, 98, 183-189. [CrossRef]

26. Shweta, S.; Gurumurthy, B.R.; Ravikanth, G.; Ramanan, U.S.; Shivanna, M.B. Endophytic Fungi from Miquelia Dentata Bedd., Produce the Anti-Cancer Alkaloid, Camptothecine. Phytomed. Int. J. Phytother. Phytopharm. 2013, 20, 337-342. [CrossRef]

27. Seetharaman, P.; Gnanasekar, S.; Chandrasekaran, R.; Chandrakasan, G.; Kadarkarai, M.; Sivaperumal, S. Isolation and Characterization of Anticancer Flavone Chrysin (5,7-Dihydroxy Flavone)-Producing Endophytic Fungi from Passiflora Incarnata L. Leaves. Ann. Microbiol. 2017, 67, 321-331. [CrossRef]

28. Wang, Y.; Yang, M.-H.; Wang, X.-B.; Li, T.-X.; Kong, L.-Y. Bioactive Metabolites from the Endophytic Fungus Alternaria Alternata. Fitoterapia 2014, 99, 153-158. [CrossRef]

29. Fang, Z.F.; Yu, S.S.; Zhou, W.Q.; Chen, X.G.; Ma, S.G.; Li, Y.; Qu, J. A New Isocoumarin from Metabolites of the Endophytic Fungus Alternaria Tenuissima (Nees \& T. Nees: Fr.) Wiltshire. Chin. Chem. Lett. 2012, 23, 317-320. [CrossRef]

30. Siriwardane, A.M.D.A.; Kumar, N.S.; Jayasinghe, L.; Fujimoto, Y. Chemical Investigation of Metabolites Produced by an Endophytic Aspergillus sp. Isolated from Limonia Acidissima. Nat. Prod. Res. 2015, 29, 1384-1387. [CrossRef]

31. Wang, J.; Huang, Y.; Fang, M.; Zhang, Y.; Zheng, Z.; Zhao, Y.; Su, W. Brefeldin A, a Cytotoxin Produced by Paecilomyces sp. and Aspergillus Clavatus Isolated from Taxus Mairei and Torreya Grandis. FEMS Immunol. Med. Microbiol. 2002, 34, 51-57. [CrossRef]

32. Ge, H.M.; Yu, Z.G.; Zhang, J.; Wu, J.H.; Tan, R.X. Bioactive Alkaloids from Endophytic Aspergillus Fumigatus. J. Nat. Prod. 2009, 72, 753-755. [CrossRef]

33. Liang, Z.; Zhang, T.; Zhang, X.; Zhang, J.; Zhao, C. An Alkaloid and a Steroid from the Endophytic Fungus Aspergillus Fumigatus. Molecules 2015, 20, 1424-1433. [CrossRef]

34. Asker, M.; Mohamed, S.F.; Mahmoud, M.G.; Sayed, O.H.E. Antioxidant and Antitumor Activity of a New Sesquiterpene Isolated from Endophytic Fungus Aspergillus Glaucus. Int. J. PharmTech Res. 2013, 5.2, 391-397.

35. Liu, D.; Li, X.-M.; Meng, L.; Li, C.-S.; Gao, S.-S.; Shang, Z.; Proksch, P.; Huang, C.-G.; Wang, B.-G. Nigerapyrones A-H, $\alpha$-Pyrone Derivatives from the Marine Mangrove-Derived Endophytic Fungus Aspergillus Niger MA-132. J. Nat. Prod. 2011, 74, $1787-1791$. [CrossRef]

36. Song, Y.C.; Li, H.; Ye, Y.H.; Shan, C.Y.; Yang, Y.M.; Tan, R.X. Endophytic Naphthopyrone Metabolites Are Co-Inhibitors of Xanthine Oxidase, SW1116 Cell and Some Microbial Growths. FEMS Microbiol. Lett. 2004, 241, 67-72. [CrossRef]

37. Stierle, A.A.; Stierle, D.B.; Bugni, T. Sequoiatones A and B: Novel Antitumor Metabolites Isolated from a Redwood Endophyte. J. Org. Chem. 1999, 64, 5479-5484. [CrossRef] 
38. Stierle, D.B.; Stierle, A.A.; Bugni, T. Sequoiamonascins A-D: Novel Anticancer Metabolites Isolated from a Redwood Endophyte. J. Org. Chem. 2003, 68, 4966-4969. [CrossRef]

39. Da Silva, I.P.; Brissow, E.; Filho, L.C.K.; Senabio, J.; de Siqueira, K.A.; Filho, S.V.; Damasceno, J.L.; Mendes, S.A.; Tavares, D.C.; Magalhães, L.G.; et al. Bioactive Compounds of Aspergillus Terreus-F7, an Endophytic Fungus from Hyptis Suaveolens (L.) Poit. World J. Microbiol. Biotechnol. 2017, 33, 62. [CrossRef]

40. Goutam, J.; Sharma, G.; Tiwari, V.K.; Mishra, A.; Kharwar, R.N.; Ramaraj, V.; Koch, B. Isolation and Characterization of "Terrein" an Antimicrobial and Antitumor Compound from Endophytic Fungus Aspergillus Terreus (JAS-2) Associated from Achyranthus Aspera Varanasi, India. Front. Microbiol. 2017, 8, 1334. [CrossRef]

41. Myobatake, Y.; Takemoto, K.; Kamisuki, S.; Inoue, N.; Takasaki, A.; Takeuchi, T.; Mizushina, Y.; Sugawara, F. Cytotoxic Alkylated Hydroquinone, Phenol, and Cyclohexenone Derivatives from Aspergillus Violaceofuscus Gasperini. J. Nat. Prod. 2014, 77, 1236-1240. [CrossRef]

42. Gangadevi, V.; Muthumary, J. Taxol, an Anticancer Drug Produced by an Endophytic Fungus Bartalinia Robillardoides Tassi, Isolated from a Medicinal Plant, Aegle Marmelos Correa Ex Roxb. World J. Microbiol. Biotechnol. 2008, 24, 717. [CrossRef]

43. Pittayakhajonwut, P.; Dramae, A.; Madla, S.; Lartpornmatulee, N.; Boonyuen, N.; Tanticharoen, M. Depsidones from the Endophytic Fungus BCC 8616. J. Nat. Prod. 2006, 69, 1361-1363. [CrossRef]

44. Shan, T.; Tian, J.; Wang, X.; Mou, Y.; Mao, Z.; Lai, D.; Dai, J.; Peng, Y.; Zhou, L.; Wang, M. Bioactive Spirobisnaphthalenes from the Endophytic Fungus Berkleasmium sp. J. Nat. Prod. 2014, 77, 2151-2160. [CrossRef]

45. Ebrahim, W.; Kjer, J.; El Amrani, M.; Wray, V.; Lin, W.; Ebel, R.; Lai, D.; Proksch, P. Pullularins E and F, Two New Peptides from the Endophytic Fungus Bionectria Ochroleuca Isolated from the Mangrove Plant Sonneratia Caseolaris. Mar. Drugs 2012, 10, $1081-1091$. [CrossRef]

46. Bhatia, D.R.; Dhar, P.; Mutalik, V.; Deshmukh, S.K.; Verekar, S.A.; Desai, D.C.; Kshirsagar, R.; Thiagarajan, P.; Agarwal, V. Anticancer Activity of Ophiobolin A, Isolated from the Endophytic Fungus Bipolaris Setariae. Nat. Prod. Res. 2016, 30, 1455-1458. [CrossRef]

47. Xiao, J.; Zhang, Q.; Gao, Y.-Q.; Tang, J.-J.; Zhang, A.-L.; Gao, J.-M. Secondary Metabolites from the Endophytic Botryosphaeria Dothidea of Melia Azedarach and Their Antifungal, Antibacterial, Antioxidant, and Cytotoxic Activities. J. Agric. Food Chem. 2014, 62, 3584-3590. [CrossRef]

48. Abdou, R.; Scherlach, K.; Dahse, H.-M.; Sattler, I.; Hertweck, C. Botryorhodines A-D, Antifungal and Cytotoxic Depsidones from Botryosphaeria Rhodina, an Endophyte of the Medicinal Plant Bidens Pilosa. Phytochemistry 2010, 71, 110-116. [CrossRef]

49. Feng, Y.; Ren, F.; Niu, S.; Wang, L.; Li, L.; Liu, X.; Che, Y. Guanacastane Diterpenoids from the Plant Endophytic Fungus Cercospora sp. J. Nat. Prod. 2014, 77, 873-881. [CrossRef]

50. Ying, Y.-M.; Shan, W.-G.; Zhang, L.-W.; Zhan, Z.-J. Ceriponols A-K, Tremulane Sesquitepenes from Ceriporia Lacerate HS-ZJUTC13A, a Fungal Endophyte of Huperzia Serrata. Phytochemistry 2013, 95, 360-367. [CrossRef]

51. Debbab, A.; Aly, H.A.; Edrada-Ebel, R.A.; Müller, W.E.; Mosaddak, M.; Hakiki, A.; Ebel, R.; Proksch, P. Bioactive Secondary Metabolites from the Endophytic Fungus Chaetomium sp. Isolated from Salvia Officinalis Growing in Morocco. Biotechnol. Agron. Soc. Environ. 2009, 13, 229-234.

52. Wang, F.; Jiang, J.; Hu, S.; Ma, H.; Zhu, H.; Tong, Q.; Cheng, L.; Hao, X.; Zhang, G.; Zhang, Y. Secondary Metabolites from Endophytic Fungus Chaetomium sp. Induce Colon Cancer Cell Apoptotic Death. Fitoterapia 2017, 121, 86-93. [CrossRef]

53. Wang, F.; Tong, Q.; Ma, H.; Xu, H.; Hu, S.; Ma, W.; Xue, Y.; Liu, J.; Wang, J.; Song, H.; et al. Indole Diketopiperazines from Endophytic Chaetomium Sp 88194 Induce Breast Cancer Cell Apoptotic Death. Sci. Rep. 2015, 5, 9294. [CrossRef]

54. Jiao, R.H.; Xu, S.; Liu, J.Y.; Ge, H.M.; Ding, H.; Xu, C.; Zhu, H.L.; Tan, R.X. Chaetominine, a Cytotoxic Alkaloid Produced by Endophytic Chaetomium sp. IFB-E015. Org. Lett. 2006, 8, 5709-5712. [CrossRef]

55. Turbyville, T.J.; Wijeratne, E.K.; Liu, M.X.; Burns, A.M.; Seliga, C.J.; Luevano, L.A.; David, C.L.; Faeth, S.H.; Whitesell, L.; Gunatilaka, A.L. Search for Hsp90 Inhibitors with Potential Anticancer Activity: Isolation and SAR Studies of Radicicol and Monocillin I from Two Plant-Associated Fungi of the Sonoran Desert. J. Nat. Prod. 2006, 69, 178. [CrossRef]

56. Wang, Y.; Xu, L.; Ren, W.; Zhao, D.; Zhu, Y.; Wu, X. Bioactive Metabolites from Chaetomium Globosum L18, an Endophytic Fungus in the Medicinal Plant Curcuma Wenyujin. Phytomed. Int. J. Phytother. Phytopharm. 2012, 19, 364-368. [CrossRef]

57. Ding, G.; Song, Y.C.; Chen, J.R.; Xu, C.; Ge, H.M.; Wang, X.T.; Tan, R.X. Chaetoglobosin U, a Cytochalasan Alkaloid from Endophytic Chaetomium Globosum IFB-E019. J. Nat. Prod. 2006, 69, 302-304. [CrossRef]

58. Bashyal, B.P.; Wijeratne, E.K.; Faeth, S.H.; Gunatilaka, A.L. Globosumones A- C, Cytotoxic Orsellinic Acid Esters from the Sonoran Desert Endophytic Fungus Chaetomium Globosum 1. J. Nat. Prod. 2005, 68, 724-728. [CrossRef]

59. Li, H.; Xiao, J.; Gao, Y.-Q.; Tang, J.; Zhang, A.-L.; Gao, J.-M. Chaetoglobosins from Chaetomium Globosum, an Endophytic Fungus in Ginkgo Biloba, and Their Phytotoxic and Cytotoxic Activities. J. Agric. Food Chem. 2014, 62, 3734-3741. [CrossRef]

60. Gangadevi, V.; Muthumary, J. Taxol Production by Pestalotiopsis Terminaliae, an Endophytic Fungus of Terminalia Arjuna (Arjun Tree). Biotechnol. Appl. Biochem. 2009, 52, 9-15. [CrossRef]

61. Zhang, P.; Zhou, P.-P.; Yu, L.-J. An Endophytic Taxol-Producing Fungus from Taxus Media, Cladosporium Cladosporioides MD2. Curr. Microbiol. 2009, 59, 227. [CrossRef]

62. Gokul Raj, K.; Manikandan, R.; Arulvasu, C.; Pandi, M. Anti-Proliferative Effect of Fungal Taxol Extracted from Cladosporium Oxysporum against Human Pathogenic Bacteria and Human Colon Cancer Cell Line HCT 15. Spectrochim. Acta A Mol. Biomol. Spectrosc. 2015, 138, 667-674. [CrossRef] 
63. Raj, K.G.; Sambantham, S.; Manikanadan, R.; Arulvasu, C.; Pandi, M. Fungal Taxol Extracted from Cladosporium Oxysporum Induces Apoptosis in T47D Human Breast Cancer Cell Line. Asian Pac. J. Cancer Prev. 2014, 15, 6627-6632. [CrossRef]

64. Kumaran, R.S.; Jung, H.; Kim, H.J. In Vitro Screening of Taxol, an Anticancer Drug Produced by the Fungus, Colletotrichum Capsici. Eng. Life Sci. 2011, 11, 264-271. [CrossRef]

65. Wang, Y.; Tang, K. A New Endophytic Taxol-and Baccatin III-Producing Fungus Isolated from Taxus Chinensis Var. Mairei. Afr. J. Biotechnol. 2011, 10, 16379-16386.

66. Bungihan, M.; Tan, A.M.; Takayama, H.; Cruz, D.E.; Nonato, G.M. A New Macrolide Isolated from the Endophytic Fungus Colletotrichum sp. Philipp. Sci. Lett. 2013, 6, 57-73.

67. Li, X.-G.; Pan, W.-D.; Lou, H.-Y.; Liu, R.-M.; Xiao, J.-H.; Zhong, J.-J. New Cytochalasins from Medicinal Macrofungus Crodyceps Taii and Their Inhibitory Activities against Human Cancer Cells. Bioorg. Med. Chem. Lett. 2015, 25, 1823-1826. [CrossRef]

68. Lu, S.; Sun, P.; Li, T.; Kurtán, T.; Mándi, A.; Antus, S.; Krohn, K.; Draeger, S.; Schulz, B.; Yi, Y.; et al. Bioactive Nonanolide Derivatives Isolated from the Endophytic Fungus Cytospora sp. J. Org. Chem. 2011, 76, 9699-9710. [CrossRef]

69. Yedukondalu, N.; Arora, P.; Wadhwa, B.; Malik, F.A.; Vishwakarma, R.A.; Gupta, V.K.; Riyaz-Ul-Hassan, S.; Ali, A. Diapolic Acid A-B from an Endophytic Fungus, Diaporthe Terebinthifolii Depicting Antimicrobial and Cytotoxic Activity. J. Antibiot. 2017, 70, 212-215. [CrossRef]

70. Isaka, M.; Palasarn, S.; Lapanun, S.; Chanthaket, R.; Boonyuen, N.; Lumyong, S. $\gamma$-Lactones and Ent-Eudesmane Sesquiterpenes from the Endophytic Fungus Eutypella sp. BCC 13199. J. Nat. Prod. 2009, 72, 1720-1722. [CrossRef]

71. Wang, Q.-X.; Li, S.-F.; Zhao, F.; Dai, H.-Q.; Bao, L.; Ding, R.; Gao, H.; Zhang, L.-X.; Wen, H.-A.; Liu, H.-W. Chemical Constituents from Endophytic Fungus Fusarium Oxysporum. Fitoterapia 2011, 82, 777-781. [CrossRef]

72. Elavarasi, A.; Rathna, G.S.; Kalaiselvam, M. Taxol Producing Mangrove Endophytic Fungi Fusarium Oxysporum from Rhizophora Annamalayana. Asian Pac. J. Trop. Biomed. 2012, 2, S1081-S1085. [CrossRef]

73. Kumaran, R.S.; Kim, H.J.; Hur, B.-K. Taxol Promising Fungal Endophyte, Pestalotiopsis Species Isolated from Taxus Cuspidata. J. Biosci. Bioeng. 2010, 110, 541-546. [CrossRef]

74. Palem, P.P.C.; Kuriakose, G.C.; Jayabaskaran, C. An Endophytic Fungus, Talaromyces Radicus, Isolated from Catharanthus Roseus, Produces Vincristine and Vinblastine, Which Induce Apoptotic Cell Death. PLoS ONE 2015, 10, e0144476. [CrossRef]

75. Zhang, L.; Guo, B.; Li, H.; Zeng, S.; Shao, H.; Gu, S.; Wei, R. Preliminary Study on the Isolation of Endophytic Fungus of Catharanthus Roseus and Its Fermentation to Produce Products of Therapeutic Value. Chin. Tradit. Herb. Drugs 2000, 31, 805-807.

76. Ivanova, L.; Skjerve, E.; Eriksen, G.S.; Uhlig, S. Cytotoxicity of Enniatins A, A1, B, B1, B2 and B3 from Fusarium Avenaceum. Toxicon Off. J. Int. Soc. Toxinology 2006, 47, 868-876. [CrossRef]

77. Zhan, J.; Burns, A.M.; Liu, M.X.; Faeth, S.H.; Gunatilaka, A.A.L. Search for Cell Motility and Angiogenesis Inhibitors with Potential Anticancer Activity: Beauvericin and Other Constituents of Two Endophytic Strains of Fusarium Oxysporum. J. Nat. Prod. 2007, 70, 227-232. [CrossRef]

78. Fuska, J.; Proksa, B.; Fusková, A. New Potential Cytotoxic and Antitumor Substances I. In Vitro Effect of Bikaverin and Its Derivatives on Cells of Certain Tumors. Neoplasma 1975, 22, 335-338.

79. Nadeem, M.; Ram, M.; Alam, P.; Ahmad, M.M.; Mohammad, A.; Al-Qurainy, F.; Khan, S.; Abdin, M.Z. Fusarium Solani, P1, a New Endophytic Podophyllotoxin-Producing Fungus from Roots of Podophyllum Hexandrum. Afr. J. Microbiol. Res. 2012, 6 , 2493-2499.

80. Kusari, S.; Zühlke, S.; Spiteller, M. An Endophytic Fungus from Camptotheca Acuminata That Produces Camptothecin and Analogues. J. Nat. Prod. 2009, 72, 2-7. [CrossRef]

81. Chen, Y.; Gou, H.; Du, Z.; Liu, X.-Z.; Che, Y.; Ye, X. Ecology-Based Screen Identifies New Metabolites from a Cordyceps-Colonizing Fungus as Cancer Cell Proliferation Inhibitors and Apoptosis Inducers. Cell Prolif. 2009, 42, 838-847. [CrossRef]

82. Sommart, U.; Rukachaisirikul, V.; Trisuwan, K.; Tadpetch, K.; Phongpaichit, S.; Preedanon, S.; Sakayaroj, J. Tricycloalternarene Derivatives from the Endophytic Fungus Guignardia Bidwellii PSU-G11. Phytochem. Lett. 2012, 5, 139-143. [CrossRef]

83. Sun, Z.-H.; Liang, F.-L.; Wu, W.; Chen, Y.-C.; Pan, Q.-L.; Li, H.-H.; Ye, W.; Liu, H.-X.; Li, S.-N.; Tan, G.-H.; et al. Guignardones P-S, New Meroterpenoids from the Endophytic Fungus Guignardia Mangiferae A348 Derived from the Medicinal Plant Smilax Glabra. Molecules 2015, 20, 22900-22907. [CrossRef]

84. Zhao, J.; Li, C.; Wang, W.; Zhao, C.; Luo, M.; Mu, F.; Fu, Y.; Zu, Y.; Yao, M. Hypocrea Lixii, Novel Endophytic Fungi Producing Anticancer Agent Cajanol, Isolated from Pigeon Pea (Cajanus Cajan [L.] Millsp.). J. Appl. Microbiol. 2013, 115, 102-113. [CrossRef]

85. Gu, W.; Ge, H.M.; Song, Y.C.; Ding, H.; Zhu, H.L.; Zhao, X.A.; Tan, R.X. Cytotoxic Benzo [j] Fluoranthene Metabolites from Hypoxylon Truncatum IFB-18, an Endophyte of Artemisia Annua. J. Nat. Prod. 2007, 70, 114-117. [CrossRef]

86. Chinworrungsee, M.; Wiyakrutta, S.; Sriubolmas, N.; Chuailua, P.; Suksamrarn, A. Cytotoxic Activities of Trichothecenes Isolated from an Endophytic Fungus Belonging to Order Hypocreales. Arch. Pharm. Res. 2008, 31, 611. [CrossRef]

87. Pandi, M.; Kumaran, R.S.; Choi, Y.-K.; Kim, H.J.; Muthumary, J. Isolation and Detection of Taxol, an Anticancer Drug Produced from Lasiodiplodia Theobromae, an Endophytic Fungus of the Medicinal Plant Morinda Citrifolia. Afr. J. Biotechnol. 2011, 10, $1428-1435$.

88. Sobreira, A.C.M.; Pessoa, O.D.L.; Florêncio, K.G.D.; Wilke, D.V.; Freire, F.C.O.; Gonçalves, F.J.T.; Ribeiro, P.R.V.; Silva, L.M.A.; Brito, E.S.; Canuto, K.M. Resorcylic Lactones from Lasiodiplodia Theobromae (MUB65), a Fungal Endophyte Isolated from Myracrodruon Urundeuva. Planta Med. 2016, 82, P671. [CrossRef] 
89. Yang, X.; Zhang, L.; Guo, B.; Guo, S. Preliminary Study of a Vincristine-Proudcing Endophytic Fungus Isolated from Leaves of Catharanthus Roseus. Chin. Tradit. Herb. Drugs 2004, 35, 79-81.

90. Van der Sar, S.A.; Blunt, J.W.; Munro, M.H.G. Spiro-Mamakone A: A Unique Relative of the Spirobisnaphthalene Class of Compounds. Org. Lett. 2006, 8, 2059-2061. [CrossRef]

91. Moreno, E.; Varughese, T.; Spadafora, C.; Arnold, A.E.; Coley, P.D.; Kursar, T.A.; Gerwick, W.H.; Cubilla-Rios, L. Chemical Constituents of the New Endophytic Fungus Mycosphaerella sp. Nov. and Their Anti-Parasitic Activity. Nat. Prod. Commun. 2011, 6, 835-840. [CrossRef]

92. Luo, J.; Liu, X.; Li, E.; Guo, L.; Che, Y. Arundinols A-C and Arundinones A and B from the Plant Endophytic Fungus Microsphaeropsis Arundinis. J. Nat. Prod. 2013, 76, 107-112. [CrossRef]

93. Ortega, H.E.; Graupner, P.R.; Asai, Y.; TenDyke, K.; Qiu, D.; Shen, Y.Y.; Rios, N.; Arnold, A.E.; Coley, P.D.; Kursar, T.A.; et al. Mycoleptodiscins A and B, Cytotoxic Alkaloids from the Endophytic Fungus Mycoleptodiscus sp. F0194. J. Nat. Prod. 2013, 76, 741-744. [CrossRef]

94. Lin, T.; Wang, G.; Shan, W.; Zeng, D.; Ding, R.; Jiang, X.; Zhu, D.; Liu, X.; Yang, S.; Chen, H. Myrotheciumones: Bicyclic Cytotoxic Lactones Isolated from an Endophytic Fungus of Ajuga Decumbens. Bioorg. Med. Chem. Lett. 2014, 24, 2504-2507. [CrossRef]

95. Shen, L.; Zhu, L.; Tan, Q.; Wan, D.; Xie, J.; Peng, J. New Cytotoxic Trichothecene Macrolide Epimers from Endophytic Myrothecium Roridum IFB-E012. J. Antibiot. 2016, 69, 652-655. [CrossRef]

96. Rehman, S.; Shawl, A.S.; Kour, A.; Andrabi, R.; Sudan, P.; Sultan, P.; Verma, V.; Qazi, G.N. An Endophytic Neurospora sp. from Nothapodytes Foetida Producing Camptothecin. Appl. Biochem. Microbiol. 2008, 44, 203-209. [CrossRef]

97. Wu, Z.-C.; Li, D.-L.; Chen, Y.-C.; Zhang, W.-M. A New Isofuranonaphthalenone and Benzopyrans from the Endophytic Fungus Nodulisporium sp. A4 from Aquilaria Sinensis. Helv. Chim. Acta 2010, 93, 920-924. [CrossRef]

98. Borges Coutinho Gallo, M.; Coêlho Cavalcanti, B.; Washington Araújo Barros, F.; Odorico de Moraes, M.; Veras Costa-Lotufo, L.; Pessoa, C.; Kenupp Bastos, J.; Tallarico Pupo, M. Chemical Constituents of Papulaspora Immersa, an Endophyte from Smallanthus Sonchifolius (Asteraceae), and Their Cytotoxic Activity. Chem. Biodivers. 2010, 7, 2941-2950. [CrossRef]

99. Shiono, Y.; Kikuchi, M.; Koseki, T.; Murayama, T.; Kwon, E.; Aburai, N.; Kimura, K. Isopimarane Diterpene Glycosides, Isolated from Endophytic Fungus Paraconiothyrium sp. MY-42. Phytochemistry 2011, 72, 1400-1405. [CrossRef]

100. Liu, L.; Chen, X.; Li, D.; Zhang, Y.; Li, L.; Guo, L.; Cao, Y.; Che, Y. Bisabolane Sesquiterpenoids from the Plant Endophytic Fungus Paraconiothyrium Brasiliense. J. Nat. Prod. 2015, 78, 746-753. [CrossRef]

101. Huang, Z.; Yang, J.; Cai, X.; She, Z.; Lin, Y. A New Furanocoumarin from the Mangrove Endophytic Fungus Penicillium sp. (ZH16). Nat. Prod. Res. 2012, 26, 1291-1295. [CrossRef]

102. Lin, Z.-J.; Lu, Z.-Y.; Zhu, T.-J.; Fang, Y.-C.; Gu, Q.-Q.; Zhu, W.-M. Penicillenols from Penicillium sp. GQ-7, an Endophytic Fungus Associated with Aegiceras Corniculatum. Chem. Pharm. Bull. 2008, 56, 217-221. [CrossRef]

103. Lin, Z.; Zhu, T.; Fang, Y.; Gu, Q.; Zhu, W. Polyketides from Penicillium sp. JP-1, an Endophytic Fungus Associated with the Mangrove Plant Aegiceras Corniculatum. Phytochemistry 2008, 69, 1273-1278. [CrossRef]

104. Chen, M.-J.; Fu, Y.-W.; Zhou, Q.-Y. Penifupyrone, a New Cytotoxic Funicone Derivative from the Endophytic Fungus Penicillium sp. HSZ-43. Nat. Prod. Res. 2014, 28, 1544-1548. [CrossRef]

105. Sun, X.; Kong, X.; Gao, H.; Zhu, T.; Wu, G.; Gu, Q.; Li, D. Two New Meroterpenoids Produced by the Endophytic Fungus Penicillium sp. SXH-65. Arch. Pharm. Res. 2014, 37, 978-982. [CrossRef]

106. Darsih, C.; Prachyawarakorn, V.; Wiyakrutta, S.; Mahidol, C.; Ruchirawat, S.; Kittakoop, P. Cytotoxic Metabolites from the Endophytic Fungus Penicillium Chermesinum: Discovery of a Cysteine-Targeted Michael Acceptor as a Pharmacophore for Fragment-Based Drug Discovery, Bioconjugation and Click Reactions. RSC Adv. 2015, 5, 70595-70603. [CrossRef]

107. El-Neketi, M.; Ebrahim, W.; Lin, W.; Gedara, S.; Badria, F.; Saad, H.-E.A.; Lai, D.; Proksch, P. Alkaloids and Polyketides from Penicillium Citrinum, an Endophyte Isolated from the Moroccan Plant Ceratonia Siliqua. J. Nat. Prod. 2013, 76, 1099-1104. [CrossRef]

108. Ge, H.-L.; Zhang, D.-W.; Li, L.; Xie, D.; Zou, J.-H.; Si, Y.-K.; Dai, J. Two New Terpenoids from Endophytic Fungus Periconia sp. F-31. Chem. Pharm. Bull. 2011, 59, 1541-1544. [CrossRef]

109. Teles, H.L.; Sordi, R.; Silva, G.H.; Castro-Gamboa, I.; da Silva Bolzani, V.; Pfenning, L.H.; de Abreu, L.M.; Costa-Neto, C.M.; Young, M.C.M.; Araújo, Â.R. Aromatic Compounds Produced by Periconia Atropurpurea, an Endophytic Fungus Associated with Xylopia Aromatica. Phytochemistry 2006, 67, 2686-2690. [CrossRef]

110. Xu, J.; Kjer, J.; Sendker, J.; Wray, V.; Guan, H.; Edrada, R.; Lin, W.; Wu, J.; Proksch, P. Chromones from the Endophytic Fungus Pestalotiopsis sp. Isolated from the Chinese Mangrove Plant Rhizophora Mucronata. J. Nat. Prod. 2009, 72, 662-665. [CrossRef]

111. Davis, R.A.; Carroll, A.R.; Andrews, K.T.; Boyle, G.M.; Tran, T.L.; Healy, P.C.; Kalaitzis, J.A.; Shivas, R.G. Pestalactams A-C: Novel Caprolactams from the Endophytic Fungus Pestalotiopsis sp. Org. Biomol. Chem. 2010, 8, 1785-1790. [CrossRef]

112. Wu, L.-S.; Jia, M.; Chen, L.; Zhu, B.; Dong, H.-X.; Si, J.-P.; Peng, W.; Han, T. Cytotoxic and Antifungal Constituents Isolated from the Metabolites of Endophytic Fungus DO14 from Dendrobium Officinale. Molecules 2015, 21, 14. [CrossRef]

113. Liu, S.; Guo, L.; Che, Y.; Liu, L. Pestaloficiols Q-S from the Plant Endophytic Fungus Pestalotiopsis Fici. Fitoterapia 2013, 85, 114-118. [CrossRef]

114. LIU, S.-C.; YE, X.; GUO, L.-D.; LIU, L. Cytotoxic Isoprenylated Epoxycyclohexanediols from the Plant Endophyte Pestalotiopsis Fici. Chin. J. Nat. Med. 2011, 9, 374-379. [CrossRef] 
115. Liu, L.; Liu, S.; Niu, S.; Guo, L.; Chen, X.; Che, Y. Isoprenylated Chromone Derivatives from the Plant Endophytic Fungus Pestalotiopsis Fici. J. Nat. Prod. 2009, 72, 1482-1486. [CrossRef]

116. Luo, D.Q.; Zhang, L.; Shi, B.Z.; Song, X.M. Two New Oxysporone Derivatives from the Fermentation Broth of the Endophytic Plant Fungus Pestalotiopsis Karstenii Isolated from Stems of Camellia Sasanqua. Molecules 2012, 17, 8554-8560. [CrossRef]

117. Kumaran, R.S.; Choi, Y.-K.; Lee, S.; Jeon, H.J.; Jung, H.; Kim, H.J. Isolation of Taxol, an Anticancer Drug Produced by the Endophytic Fungus, Phoma Betae. Afr. J. Biotechnol. 2012, 11, 950-960.

118. Rajendran, L.; Rajagopal, K.; Subbarayan, K.; Ulagappan, K.; Sampath, A.; Karthik, G. Efficiency of Fungal Taxol on Human Liver Carcinoma Cell Lines. Am. J. Res. Commun. 2013, 1, 112-121.

119. Lee, J.C.; Strobel, G.A.; Lobkovsky, E.; Clardy, J. Torreyanic Acid: A Selectively Cytotoxic Quinone Dimer from the Endophytic Fungus Pestalotiopsis Microspora. J. Org. Chem. 1996, 61, 3232-3233. [CrossRef]

120. Metz, A.M.; Haddad, A.; Worapong, J.; Long, D.M.; Ford, E.J.; Hess, W.M.; Strobel, G.A. Induction of the Sexual Stage of Pestalotiopsis Microspora, a Taxol-Producing Fungus. Microbiology 2000, 146, 2079-2089. [CrossRef]

121. Vennila, R.; Kamalraj, S.; Muthumary, J. In Vitro Studies on Anticancer Activity of Fungal Taxol against Human Breast Cancer Cell Line MCF-7 Cells. Asian Pac. J. Trop. Biomed. 2012, 2, S1159-S1161. [CrossRef]

122. Ding, G.; Qi, Y.; Liu, S.; Guo, L.; Chen, X. Photipyrones A and B, New Pyrone Derivatives from the Plant Endophytic Fungus Pestalotiopsis Photiniae. J. Antibiot. 2012, 65, 271. [CrossRef]

123. Ding, G.; Zheng, Z.; Liu, S.; Zhang, H.; Guo, L.; Che, Y. Photinides A-F, Cytotoxic Benzofuranone-Derived $\gamma$-Lactones from the Plant Endophytic Fungus Pestalotiopsis Photiniae. J. Nat. Prod. 2009, 72, 942-945. [CrossRef]

124. Nalli, Y.; Mirza, D.N.; Wani, Z.A.; Wadhwa, B.; Mallik, F.A.; Raina, C.; Chaubey, A.; Riyaz-Ul-Hassan, S.; Ali, A. Phialomustin A-D, New Antimicrobial and Cytotoxic Metabolites from an Endophytic Fungus, Phialophora Mustea. RSC Adv. 2015, 5, 95307-95312. [CrossRef]

125. Santiago, C.; Sun, L.; Munro, M.H.G.; Santhanam, J. Polyketide and Benzopyran Compounds of an Endophytic Fungus Isolated from C Innamomum Mollissimum: Biological Activity and Structure. Asian Pac. J. Trop. Biomed. 2014, 4, 627-632. [CrossRef]

126. Huang, Z.; Guo, Z.; Yang, R.; Yin, X.; Li, X.; Luo, W.; She, Z.; Lin, Y. Chemistry and Cytotoxic Activities of Polyketides Produced by the Mangrove Endophytic Fungus Phomopsis SP. ZSU-H76. Chem. Nat. Compd. 2009, 45, 625. [CrossRef]

127. Huang, Z.; Yang, J.; Lei, F.; She, Z.; Lin, Y. A New Xanthone O-Glycoside from the Mangrove Endophytic Fungus Phomopsis sp. Chem. Nat. Compd. 2013, 49, 27-30. [CrossRef]

128. Zhang, W.; Xu, L.; Yang, L.; Huang, Y.; Li, S.; Shen, Y. Phomopsidone A, a Novel Depsidone Metabolite from the Mangrove Endophytic Fungus Phomopsis sp. A123. Fitoterapia 2014, 96, 146-151. [CrossRef]

129. Isaka, M.; Jaturapat, A.; Rukseree, K.; Danwisetkanjana, K.; Tanticharoen, M.; Thebtaranonth, Y. Phomoxanthones A and B, Novel Xanthone Dimers from the Endophytic Fungus Phomopsis Species. J. Nat. Prod. 2001, 64, 1015-1018. [CrossRef]

130. Bunyapaiboonsri, T.; Yoiprommarat, S.; Srikitikulchai, P.; Srichomthong, K.; Lumyong, S. Oblongolides from the Endophytic Fungus Phomopsis sp. BCC 9789. J. Nat. Prod. 2010, 73, 55-59. [CrossRef]

131. Jouda, J.-B.; Tamokou, J.-D.; Mbazoa, C.D.; Douala-Meli, C.; Sarkar, P.; Bag, P.K.; Wandji, J. Antibacterial and Cytotoxic Cytochalasins from the Endophytic Fungus Phomopsis sp. Harbored in Garcinia Kola (Heckel) Nut. BMC Complement. Altern. Med. 2016, 16, 462. [CrossRef]

132. Wagenaar, M.M.; Clardy, J. Dicerandrols, New Antibiotic and Cytotoxic Dimers Produced by the Fungus Phomopsis Longicolla Isolated from an Endangered Mint. J. Nat. Prod. 2001, 64, 1006-1009. [CrossRef]

133. Wijeratne, E.K.; Paranagama, P.A.; Marron, M.T.; Gunatilaka, M.K.; Arnold, A.E.; Gunatilaka, A.L. Sesquiterpene Quinones and Related Metabolites from Phyllosticta Spinarum, a Fungal Strain Endophytic in Platycladus Orientalis of the Sonoran Desert (1). J. Nat. Prod. 2008, 71, 218-222. [CrossRef]

134. Deshmukh, S.K.; Mishra, P.D.; Kulkarni-Almeida, A.; Verekar, S.; Sahoo, M.R.; Periyasamy, G.; Goswami, H.; Khanna, A.; Balakrishnan, A.; Vishwakarma, R. Anti-Inflammatory and Anticancer Activity of Ergoflavin Isolated from an Endophytic Fungus. Chem. Biodivers. 2009, 6, 784-789. [CrossRef]

135. Chen, X.; Shi, Q.; Lin, G.; Guo, S.; Yang, J. Spirobisnaphthalene Analogues from the Endophytic Fungus Preussia sp. J. Nat. Prod. 2009, 72, 1712-1715. [CrossRef]

136. Wagenaar, M.M.; Corwin, J.; Strobel, G.; Clardy, J. Three New Cytochalasins Produced by an Endophytic Fungus in the Genus Rhinocladiella. J. Nat. Prod. 2000, 63, 1692-1695. [CrossRef]

137. Pudhom, K.; Teerawatananond, T.; Chookpaiboon, S. Spirobisnaphthalenes from the Mangrove-Derived Fungus Rhytidhysteron sp. AS21B. Mar. Drugs 2014, 12, 1271-1280. [CrossRef]

138. Lai, D.; Wang, A.; Cao, Y.; Zhou, K.; Mao, Z.; Dong, X.; Tian, J.; Xu, D.; Dai, J.; Peng, Y.; et al. Bioactive Dibenzo- $\alpha$-Pyrone Derivatives from the Endophytic Fungus Rhizopycnis Vagum Nitaf22. J. Nat. Prod. 2016, 79, 2022-2031. [CrossRef]

139. Siridechakorn, I.; Yue, Z.; Mittraphab, Y.; Lei, X.; Pudhom, K. Identification of Spirobisnaphthalene Derivatives with Anti-Tumor Activities from the Endophytic Fungus Rhytidhysteron Rufulum AS21B. Bioorg. Med. Chem. 2017, 25, 2878-2882. [CrossRef]

140. El-Elimat, T.; Figueroa, M.; Raja, H.A.; Graf, T.N.; Swanson, S.M.; Falkinham, J.O.; Wani, M.C.; Pearce, C.J.; Oberlies, N.H. Biosynthetically Distinct Cytotoxic Polyketides from Setophoma Terrestris. Eur. J. Org. Chem. 2015, 2015, 109-121. [CrossRef]

141. Wang, X.-N.; Bashyal, B.P.; Wijeratne, E.M.K.; U’Ren, J.M.; Liu, M.X.; Gunatilaka, M.K.; Arnold, A.E.; Gunatilaka, A.A.L. Smardaesidins A-G, Isopimarane and 20-Nor-Isopimarane Diterpenoids from Smardaea Sp., a Fungal Endophyte of the Moss Ceratodon Purpureus. J. Nat. Prod. 2011, 74, 2052-2061. [CrossRef] 
142. Mirjalili, M.H.; Farzaneh, M.; Bonfill, M.; Rezadoost, H.; Ghassempour, A. Isolation and Characterization of Stemphylium Sedicola SBU-16 as a New Endophytic Taxol-Producing Fungus from Taxus Baccata Grown in Iran. FEMS Microbiol. Lett. 2012, 328, 122-129. [CrossRef]

143. Debbab, A.; Aly, A.H.; Edrada-Ebel, R.; Wray, V.; Müller, W.E.G.; Totzke, F.; Zirrgiebel, U.; Schächtele, C.; Kubbutat, M.H.G.; Lin, W.H.; et al. Bioactive Metabolites from the Endophytic Fungus Stemphylium Globuliferum Isolated from Mentha Pulegium. J. Nat. Prod. 2009, 72, 626-631. [CrossRef]

144. Teiten, M.-H.; Mack, F.; Debbab, A.; Aly, A.H.; Dicato, M.; Proksch, P.; Diederich, M. Anticancer Effect of Altersolanol A, a Metabolite Produced by the Endophytic Fungus Stemphylium Globuliferum, Mediated by Its pro-Apoptotic and Anti-Invasive Potential via the Inhibition of NF-KB Activity. Bioorg. Med. Chem. 2013, 21, 3850-3858. [CrossRef]

145. Zhao, Q.-H.; Yang, Z.-D.; Shu, Z.-M.; Wang, Y.-G.; Wang, M.-G. Secondary Metabolites and Biological Activities of Talaromyces sp. LGT-2, an Endophytic Fungus from Tripterygium Wilfordii. Iran. J. Pharm. Res. IJPR 2016, 15, 453-457.

146. Li, H.; Huang, H.; Shao, C.; Huang, H.; Jiang, J.; Zhu, X.; Liu, Y.; Liu, L.; Lu, Y.; Li, M.; et al. Cytotoxic Norsesquiterpene Peroxides from the Endophytic Fungus Talaromyces Flavus Isolated from the Mangrove Plant Sonneratia Apetala. J. Nat. Prod. 2011, 74, 1230-1235. [CrossRef]

147. Kusari, S.; Zühlke, S.; Košuth, J.; Čellárová, E.; Spiteller, M. Light-Independent Metabolomics of Endophytic Thielavia Subthermophila Provides Insight into Microbial Hypericin Biosynthesis. J. Nat. Prod. 2009, 72, 1825-1835. [CrossRef]

148. Puri, S.C.; Nazir, A.; Chawla, R.; Arora, R.; Riyaz-ul-Hasan, S.; Amna, T.; Ahmed, B.; Verma, V.; Singh, S.; Sagar, R.; et al. The Endophytic Fungus Trametes Hirsuta as a Novel Alternative Source of Podophyllotoxin and Related Aryl Tetralin Lignans. J. Biotechnol. 2006, 122, 494-510. [CrossRef]

149. Ding, G.; Wang, H.; Li, L.; Chen, A.J.; Chen, L.; Chen, H.; Zhang, H.; Liu, X.; Zou, Z. Trichoderones A and B: Two Pentacyclic Cytochalasans from the Plant Endophytic Fungus Trichoderma Gamsii. Eur. J. Org. Chem. 2012, 2012, 2516-2519. [CrossRef]

150. Taware, R.; Abnave, P.; Patil, D.; Rajamohananan, P.R.; Raja, R.; Soundararajan, G.; Kundu, G.C.; Ahmad, A. Isolation, Purification and Characterization of Trichothecinol-A Produced by Endophytic Fungus Trichothecium sp. and Its Antifungal, Anticancer and Antimetastatic Activities. Sustain. Chem. Process. 2014, 2, 8. [CrossRef]

151. Chokpaiboon, S.; Sommit, D.; Teerawatananond, T.; Muangsin, N.; Bunyapaiboonsri, T.; Pudhom, K. Cytotoxic Nor-Chamigrane and Chamigrane Endoperoxides from a Basidiomycetous Fungus. J. Nat. Prod. 2010, 73, 1005-1007. [CrossRef]

152. Isaka, M.; Chinthanom, P.; Boonruangprapa, T.; Rungjindamai, N.; Pinruan, U. Eremophilane-Type Sesquiterpenes from the Fungus Xylaria sp. BCC 21097. J. Nat. Prod. 2010, 73, 683-687. [CrossRef]

153. Tansuwan, S.; Pornpakakul, S.; Roengsumran, S.; Petsom, A.; Muangsin, N.; Sihanonta, P.; Chaichit, N. Antimalarial Benzoquinones from an Endophytic Fungus, Xylaria sp. J. Nat. Prod. 2007, 70, 1620-1623. [CrossRef]

154. Wei, H.; Xu, Y.; Espinosa-Artiles, P.; Liu, M.X.; Luo, J.-G.; U’Ren, J.M.; Elizabeth Arnold, A.; Leslie Gunatilaka, A.A. Sesquiterpenes and Other Constituents of Xylaria sp. NC1214, a Fungal Endophyte of the Moss Hypnum sp. Phytochemistry 2015, 118, 102-108. [CrossRef]

155. Zhang, Q.; Xiao, J.; Sun, Q.-Q.; Qin, J.-C.; Pescitelli, G.; Gao, J.-M. Characterization of Cytochalasins from the Endophytic Xylaria sp. and Their Biological Functions. J. Agric. Food Chem. 2014, 62, 10962-10969. [CrossRef]

156. Sawadsitang, S.; Mongkolthanaruk, W.; Suwannasai, N.; Sodngam, S. Antimalarial and Cytotoxic Constituents of Xylaria Cf. Cubensis PK108. Nat. Prod. Res. 2015, 29, 2033-2036. [CrossRef]

157. Lin, T.; Lin, X.; Lu, C.-H.; Shen, Y.-M. Three New Triterpenes from Xylarialean sp. A45, an Endophytic Fungus from Annona Squamosa L. Helv. Chim. Acta 2011, 94, 301-305. [CrossRef]

158. Zhang, J.; Tao, L.; Liang, Y.; Yan, Y.; Dai, C.; Xia, X.; She, Z.; Lin, Y.; Fu, L. Secalonic Acid D Induced Leukemia Cell Apoptosis and Cell Cycle Arrest of G(1) with Involvement of GSK-3beta/Beta-Catenin/c-Myc Pathway. Cell Cycle Georget. Tex 2009, 8, 2444-2450. [CrossRef]

159. Kamdem, R.S.T.; Wang, H.; Wafo, P.; Ebrahim, W.; Özkaya, F.C.; Makhloufi, G.; Janiak, C.; Sureechatchaiyan, P.; Kassack, M.U.; Lin, W.; et al. Induction of New Metabolites from the Endophytic Fungus Bionectria sp. through Bacterial Co-Culture. Fitoterapia 2018, 124, 132-136. [CrossRef]

160. Ibrahim, S.R.M.; Mohamed, G.A.; Al Haidari, R.A.; Zayed, M.F.; El-Kholy, A.A.; Elkhayat, E.S.; Ross, S.A. Fusarithioamide B, a New Benzamide Derivative from the Endophytic Fungus Fusarium Chlamydosporium with Potent Cytotoxic and Antimicrobial Activities. Bioorg. Med. Chem. 2018, 26, 786-790. [CrossRef]

161. Zhang, X.; Liu, J.; Tang, P.; Liu, Z.; Guo, G.-J.; Sun, Q.-Y.; Yin, J. Identification of a New Uncompetitive Inhibitor of Adenosine Deaminase from Endophyte Aspergillus Niger sp. Curr. Microbiol. 2018, 75, 565-573. [CrossRef]

162. Tan, X.-M.; Li, L.-Y.; Sun, L.-Y.; Sun, B.-D.; Niu, S.-B.; Wang, M.-H.; Zhang, X.-Y.; Sun, W.-S.; Zhang, G.-S.; Deng, H.; et al Spiciferone Analogs from an Endophytic Fungus Phoma Betae Collected from Desert Plants in West China. J. Antibiot. 2018, 71, 613-617. [CrossRef]

163. Liu, Z.; Zhao, J.-Y.; Li, Y.; Lyu, X.-X.; Liu, Y.-B. Investigations on secondary metabolites of endophyte Diaporthe sp. hosted in Tylophora ovata. Zhongguo Zhong Yao Za Zhi Zhongguo Zhongyao Zazhi China J. Chin. Mater. Medica 2018, 43, 2944-2949. [CrossRef]

164. Sharma, V.; Singamaneni, V.; Sharma, N.; Kumar, A.; Arora, D.; Kushwaha, M.; Bhushan, S.; Jaglan, S.; Gupta, P. Valproic Acid Induces Three Novel Cytotoxic Secondary Metabolites in Diaporthe Sp., an Endophytic Fungus from Datura Inoxia Mill. Bioorg. Med. Chem. Lett. 2018, 28, 2217-2221. [CrossRef] 
165. Sharma, N.; Kushwaha, M.; Arora, D.; Jain, S.; Singamaneni, V.; Sharma, S.; Shankar, R.; Bhushan, S.; Gupta, P.; Jaglan, S. New Cytochalasin from Rosellinia Sanctae-Cruciana, an Endophytic Fungus of Albizia Lebbeck. J. Appl. Microbiol. 2018, 125, 111-120. [CrossRef]

166. Kamdem, R.S.T.; Pascal, W.; Rehberg, N.; van Geelen, L.; Höfert, S.-P.; Knedel, T.-O.; Janiak, C.; Sureechatchaiyan, P.; Kassack, M.U.; Lin, W.; et al. Metabolites from the Endophytic Fungus Cylindrocarpon sp. Isolated from Tropical Plant Sapium Ellipticum. Fitoterapia 2018, 128, 175-179. [CrossRef]

167. Vu, H.-N.T.; Nguyen, D.T.; Nguyen, H.Q.; Chu, H.H.; Chu, S.K.; Chau, M.V.; Phi, Q.-T. Antimicrobial and Cytotoxic Properties of Bioactive Metabolites Produced by Streptomyces Cavourensis YBQ59 Isolated from Cinnamomum Cassia Prels in Yen Bai Province of Vietnam. Curr. Microbiol. 2018, 75, 1247-1255. [CrossRef]

168. Liu, H.-X.; Tan, H.-B.; Chen, Y.-C.; Li, S.-N.; Li, H.-H.; Zhang, W.-M. Secondary Metabolites from the Colletotrichum Gloeosporioides A12, an Endophytic Fungus Derived from Aquilaria Sinensis. Nat. Prod. Res. 2018, 32, 2360-2365. [CrossRef]

169. Ouyang, J.; Mao, Z.; Guo, H.; Xie, Y.; Cui, Z.; Sun, J.; Wu, H.; Wen, X.; Wang, J.; Shan, T. Mollicellins O-R, Four New Depsidones Isolated from the Endophytic Fungus Chaetomium sp. Eef-10. Molecules 2018, 23, 3218. [CrossRef]

170. Zhou, J.; Li, G.; Deng, Q.; Zheng, D.; Yang, X.; Xu, J. Cytotoxic Constituents from the Mangrove Endophytic Pestalotiopsis sp. Induce G0/G1 Cell Cycle Arrest and Apoptosis in Human Cancer Cells. Nat. Prod. Res. 2018, 32, 2968-2972. [CrossRef]

171. Ariantari, N.P.; Ancheeva, E.; Wang, C.; Mándi, A.; Knedel, T.-O.; Kurtán, T.; Chaidir, C.; Müller, W.E.G.; Kassack, M.U.; Janiak, C.; et al. Indole Diterpenoids from an Endophytic Penicillium sp. J. Nat. Prod. 2019, 82, 1412-1423. [CrossRef]

172. Senthil Kumar, V.; Kumaresan, S.; Tamizh, M.M.; Hairul Islam, M.I.; Thirugnanasambantham, K. Anticancer Potential of NFKB Targeting Apoptotic Molecule "Flavipin" Isolated from Endophytic Chaetomium Globosum. Phytomedicine 2019, 61, 152830. [CrossRef]

173. Wang, W.-X.; Zheng, M.-J.; Li, J.; Feng, T.; Li, Z.-H.; Huang, R.; Zheng, Y.-S.; Sun, H.; Ai, H.-L.; Liu, J.-K. Cytotoxic Polyketides from Endophytic Fungus Phoma Bellidis Harbored in Ttricyrtis Maculate. Phytochem. Lett. 2019, 29, 41-46. [CrossRef]

174. Harwoko, H.; Daletos, G.; Stuhldreier, F.; Lee, J.; Wesselborg, S.; Feldbrügge, M.; Müller, W.E.G.; Kalscheuer, R.; Ancheeva, E.; Proksch, P. Dithiodiketopiperazine Derivatives from Endophytic Fungi Trichoderma Harzianum and Epicoccum Nigrum. Nat. Prod. Res. 2021, 35, 257-265. [CrossRef]

175. Xin, X.-Q.; Chen, Y.; Zhang, H.; Li, Y.; Yang, M.-H.; Kong, L.-Y. Cytotoxic Seco-Cytochalasins from an Endophytic Aspergillus sp. Harbored in Pinellia Ternata Tubers. Fitoterapia 2019, 132, 53-59. [CrossRef]

176. Wang, F.; Zhao, W.; Zhang, C.; Chang, S.; Shao, R.; Xing, J.; Chen, M.; Zhang, Y.; Si, S. Cytotoxic Metabolites from the Endophytic Fungus Chaetomium Globosum 7951. RSC Adv. 2019, 9, 16035-16039. [CrossRef]

177. Peng, F.; Hou, S.-Y.; Zhang, T.-Y.; Wu, Y.-Y.; Zhang, M.-Y.; Yan, X.-M.; Xia, M.-Y.; Zhang, Y.-X. Cytotoxic and Antimicrobial Indole Alkaloids from an Endophytic Fungus Chaetomium sp. SYP-F7950 of Panax Notoginseng. RSC Adv. 2019, 9, $28754-28763$. [CrossRef]

178. Chen, Y.; Liu, Z.; Huang, Y.; Liu, L.; He, J.; Wang, L.; Yuan, J.; She, Z. Ascomylactams A-C, Cytotoxic 12- or 13-Membered-Ring Macrocyclic Alkaloids Isolated from the Mangrove Endophytic Fungus Didymella sp. CYSK-4, and Structure Revisions of Phomapyrrolidones A and C. J. Nat. Prod. 2019, 82, 1752-1758. [CrossRef]

179. Li, G.; Xu, K.; Chen, W.-Q.; Guo, Z.-H.; Liu, Y.-T.; Qiao, Y.-N.; Sun, Y.; Sun, G.; Peng, X.-P.; Lou, H.-X. Heptaketides from the Endophytic Fungus Pleosporales sp. F46 and Their Antifungal and Cytotoxic Activities. RSC Adv. 2019, 9, 12913-12920. [CrossRef]

180. Kumarihamy, M.; Ferreira, D.; Croom, E.M.; Sahu, R.; Tekwani, B.L.; Duke, S.O.; Khan, S.; Techen, N.; Nanayakkara, N.P.D Antiplasmodial and Cytotoxic Cytochalasins from an Endophytic Fungus, Nemania sp. UM10M, Isolated from a Diseased Torreya Taxifolia Leaf. Molecules 2019, 24, 777. [CrossRef]

181. He, W.; Xu, Y.; Fu, P.; Zuo, M.; Liu, W.; Jiang, Y.; Wang, L.; Zhu, W. Cytotoxic Indolyl Diketopiperazines from the Aspergillus sp. GZWMJZ-258, Endophytic with the Medicinal and Edible Plant Garcinia Multiflora. J. Agric. Food Chem. 2019, 67, 10660-10666. [CrossRef]

182. Wang, W.-X.; Li, Z.-H.; Ai, H.-L.; Li, J.; He, J.; Zheng, Y.-S.; Feng, T.; Liu, J.-K. Cytotoxic 19,20-Epoxycytochalasans from Endophytic Fungus Xylaria Cf. Curta. Fitoterapia 2019, 137, 104253. [CrossRef]

183. De Amorim, M.R.; Hilário, F.; Junior, F.M. dos S.; Junior, J.M.B.; Bauab, T.M.; Araújo, A.R.; Carlos, I.Z.; Vilegas, W.; Santos, L.C. dos New Benzaldehyde and Benzopyran Compounds from the Endophytic Fungus Paraphaeosphaeria sp. F03 and Their Antimicrobial and Cytotoxic Activities. Planta Med. 2019, 85, 957-964. [CrossRef]

184. Zhao, T.; Xu, L.-L.; Zhang, Y.; Lin, Z.-H.; Xia, T.; Yang, D.-F.; Chen, Y.-M.; Yang, X.-L. Three New $\alpha$-Pyrone Derivatives from the Plant Endophytic Fungus Penicillium Ochrochloronthe and Their Antibacterial, Antifungal, and Cytotoxic Activities. J. Asian Nat. Prod. Res. 2019, 21, 851-858. [CrossRef]

185. Xu, J.; Hu, Y.-W.; Qu, W.; Chen, M.-H.; Zhou, L.-S.; Bi, Q.-R.; Luo, J.-G.; Liu, W.-Y.; Feng, F.; Zhang, J. Cytotoxic and Neuroprotective Activities of Constituents from Alternaria Alternate, a Fungal Endophyte of Psidium Littorale. Bioorg. Chem. 2019, 90, 103046. [CrossRef]

186. Wu, Y.; Chen, S.; Liu, H.; Huang, X.; Liu, Y.; Tao, Y.; She, Z. Cytotoxic Isocoumarin Derivatives from the Mangrove Endophytic Fungus Aspergillus sp. HN15-5D. Arch. Pharm. Res. 2019, 42, 326-331. [CrossRef]

187. Fu, J.; Hu, L.; Shi, Z.; Sun, W.; Yue, D.; Wang, Y.; Ma, X.; Ren, Z.; Zuo, Z.; Peng, G.; et al. Two Metabolites Isolated from Endophytic Fungus Coniochaeta sp. F-8 in Ageratina Adenophora Exhibit Antioxidative Activity and Cytotoxicity. Nat. Prod. Res. 2021, 35, 2840-2848. [CrossRef] 
188. Nalli, Y.; Arora, P.; Khan, S.; Malik, F.; Riyaz-Ul-Hassan, S.; Gupta, V.; Ali, A. Isolation, Structural Modification of Macrophin from Endophytic Fungus Phoma Macrostoma and Their Cytotoxic Potential. Med. Chem. Res. 2019, 28, 260-266. [CrossRef]

189. Shen, L.; Ai, C.-Z.; Song, Y.-C.; Wang, F.-W.; Jiao, R.-H.; Zhang, A.-H.; Man, H.-Z.; Tan, R.-X. Cytotoxic Trichothecene Macrolides Produced by the Endophytic Myrothecium Roridum. J. Nat. Prod. 2019, 82, 1503-1509. [CrossRef]

190. Gubiani, J.R.; Oliveira, M.C.S.; Neponuceno, R.A.R.; Camargo, M.J.; Garcez, W.S.; Biz, A.R.; Soares, M.A.; Araujo, A.R.; da Bolzani, V.S.; Lisboa, H.C.F.; et al. Cytotoxic Prenylated Indole Alkaloid Produced by the Endophytic Fungus Aspergillus Terreus P63. Phytochem. Lett. 2019, 32, 162-167. [CrossRef]

191. Rao, L.; You, Y.-X.; Su, Y.; Liu, Y.; He, Q.; Fan, Y.; Hu, F.; Xu, Y.-K.; Zhang, C.-R. Two Spiroketal Derivatives with an Unprecedented Amino Group and Their Cytotoxicity Evaluation from the Endophytic Fungus Pestalotiopsis Flavidula. Fitoterapia 2019, 135, 5-8. [CrossRef]

192. Zhang, H.; Yang, M.-H.; Zhuo, F.; Gao, N.; Cheng, X.-B.; Wang, X.-B.; Pei, Y.-H.; Kong, L.-Y. Seven New Cytotoxic Phenylspirodrimane Derivatives from the Endophytic Fungus Stachybotrys Chartarum. RSC Adv. 2019, 9, 3520-3531. [CrossRef]

193. Li, X.-H.; Han, X.-H.; Qin, L.-L.; He, J.-L.; Cao, Z.-X.; Gu, Y.-C.; Guo, D.-L.; Deng, Y. Isochromanes from Aspergillus Fumigatus, an Endophytic Fungus from Cordyceps Sinensis. Nat. Prod. Res. 2019, 33, 1870-1875. [CrossRef]

194. Elissawy, A.M.; Ebada, S.S.; Ashour, M.L.; El-Neketi, M.; Ebrahim, W.; Singab, A.B. New Secondary Metabolites from the Mangrove-Derived Fungus Aspergillus sp. AV-2. Phytochem. Lett. 2019, 29, 1-5. [CrossRef]

195. Zhang, H.-M.; Ju, C.-X.; Li, G.; Sun, Y.; Peng, Y.; Li, Y.-X.; Peng, X.-P.; Lou, H.-X. Dimeric 1,4-Benzoquinone Derivatives with Cytotoxic Activities from the Marine-Derived Fungus Penicillium sp. L129. Mar. Drugs 2019, 17, 383. [CrossRef]

196. Yang, B.; Tong, Q.; Lin, S.; Guo, J.; Zhang, J.; Liu, J.; Wang, J.; Zhu, H.; Hu, Z.; Zhang, Y. Cytotoxic Butenolides and Diphenyl Ethers from the Endophytic Fungus Pestalotiopsis sp. Phytochem. Lett. 2019, 29, 186-189. [CrossRef]

197. Li, Q.; Chen, C.; Cheng, L.; Wei, M.; Dai, C.; He, Y.; Gong, J.; Zhu, R.; Li, X.-N.; Liu, J.; et al. Emeridones A-F, a Series of 3,5-Demethylorsellinic Acid-Based Meroterpenoids with Rearranged Skeletons from an Endophytic Fungus Emericella sp. TJ29. J. Org. Chem. 2019, 84, 1534-1541. [CrossRef]

198. Liu, H.; Chen, Y.; Li, H.; Li, S.; Tan, H.; Liu, Z.; Li, D.; Liu, H.; Zhang, W. Four New Metabolites from the Endophytic Fungus Diaporthe Lithocarpus A740. Fitoterapia 2019, 137, 104260. [CrossRef]

199. Narmani, A.; Teponno, R.B.; Arzanlou, M.; Surup, F.; Helaly, S.E.; Wittstein, K.; Praditya, D.F.; Babai-Ahari, A.; Steinmann, E.; Stadler, M. Cytotoxic, Antimicrobial and Antiviral Secondary Metabolites Produced by the Plant Pathogenic Fungus Cytospora sp. CCTU A309. Fitoterapia 2019, 134, 314-322. [CrossRef]

200. Cheng, M.-J.; Yang, S.-S.; Wu, M.-D.; Chang, H.-H.; Kuo, Y.-H.; Hsieh, S.-Y.; Chen, J.-J.; Wu, H.-C. Isolation and Structure Elucidation of Secondary Metabolites From an Endophytic Fungus Annulohypoxylon Ilanense. Nat. Prod. Commun. 2019, 14, 9. [CrossRef]

201. Liu, S.; Zhao, Y.; Heering, C.; Janiak, C.; Müller, W.E.G.; Akoné, S.H.; Liu, Z.; Proksch, P. Sesquiterpenoids from the Endophytic Fungus Rhinocladiella Similis. J. Nat. Prod. 2019, 82, 1055-1062. [CrossRef]

202. Chen, S.; Li, H.; Chen, Y.; Li, S.; Xu, J.; Guo, H.; Liu, Z.; Zhu, S.; Liu, H.; Zhang, W. Three New Diterpenes and Two New Sesquiterpenoids from the Endophytic Fungus Trichoderma Koningiopsis A729. Bioorg. Chem. 2019, 86, 368-374. [CrossRef]

203. Wang, W.-X.; Feng, T.; Li, Z.-H.; Li, J.; Ai, H.-L.; Liu, J.-K. Cytochalasins D1 and C1, Unique Cytochalasans from Endophytic Fungus Xylaria Cf. Curta. Tetrahedron Lett. 2019, 60, 150952. [CrossRef]

204. Long, Y.; Tang, T.; Wang, L.-Y.; He, B.; Gao, K. Absolute Configuration and Biological Activities of Meroterpenoids from an Endophytic Fungus of Lycium Barbarum. J. Nat. Prod. 2019, 82, 2229-2237. [CrossRef]

205. Barakat, F.; Vansteelandt, M.; Triastuti, A.; Jargeat, P.; Jacquemin, D.; Graton, J.; Mejia, K.; Cabanillas, B.; Vendier, L.; Stigliani, J.-L.; et al Thiodiketopiperazines with Two Spirocyclic Centers Extracted from Botryosphaeria Mamane, an Endophytic Fungus Isolated from Bixa Orellana L. Phytochemistry 2019, 158, 142-148. [CrossRef]

206. Guo, L.; Lin, J.; Niu, S.; Liu, S.; Liu, L. Pestalotiones A-D: Four New Secondary Metabolites from the Plant Endophytic Fungus Pestalotiopsis Theae. Molecules 2020, 25, 470. [CrossRef]

207. Yu, X.; Müller, W.E.G.; Meier, D.; Kalscheuer, R.; Guo, Z.; Zou, K.; Umeokoli, B.O.; Liu, Z.; Proksch, P. Polyketide Derivatives from Mangrove Derived Endophytic Fungus Pseudopestalotiopsis Theae. Mar. Drugs 2020, 18, 129. [CrossRef]

208. Abdou, R.; Shabana, S.; Rateb, M.E. Terezine E, Bioactive Prenylated Tryptophan Analogue from an Endophyte of Centaurea Stoebe. Nat. Prod. Res. 2020, 34, 503-510. [CrossRef]

209. de Oliveira Filho, J.W.G.; Andrade, T.d.J.A.d.S.; de Lima, R.M.T.; Silva, D.H.S.; dos Reis, A.C.; Santos, J.V.d.O.; de Meneses, A.-A.P.M.; de Carvalho, R.M.; da Mata, A.M.O.; de Alencar, M.V.O.B.; et al. Cytogenotoxic Evaluation of the Acetonitrile Extract, Citrinin and Dicitrinin-A from Penicillium Citrinum. Drug Chem. Toxicol. 2020, 1-10. [CrossRef]

210. Elsbaey, M.; Tanaka, C.; Miyamoto, T. Allantopyrone E, a Rare $\alpha$-Pyrone Metabolite from the Mangrove Derived Fungus Aspergillus Versicolor. Nat. Prod. Res. 2020, 1-5. [CrossRef]

211. Wei, C.; Deng, Q.; Sun, M.; Xu, J. Cytospyrone and Cytospomarin: Two New Polyketides Isolated from Mangrove Endophytic Fungus, Cytospora sp. Molecules 2020, 25, 4224. [CrossRef]

212. Deng, M.; Tao, L.; Qiao, Y.; Sun, W.; Xie, S.; Shi, Z.; Qi, C.; Zhang, Y. New Cytotoxic Secondary Metabolites against Human Pancreatic Cancer Cells from the Hypericum Perforatum Endophytic Fungus Aspergillus Terreus. Fitoterapia 2020, 146, 104685. [CrossRef] 
213. Li, X.-Q.; Dong, Q.-J.; Xu, K.; Yuan, X.-L.; Liu, X.-M.; Zhang, P. Cytotoxic Xanthones from the Plant Endophytic Fungus Paecilamyces sp. TE-540. Nat. Prod. Res. 2020, 35, 6134-6140. [CrossRef]

214. Wen, S.; Fan, W.; Guo, H.; Huang, C.; Yan, Z.; Long, Y. Two New Secondary Metabolites from the Mangrove Endophytic Fungus Pleosporales sp. SK7. Nat. Prod. Res. 2020, 34, 2919-2925. [CrossRef]

215. Wang, A.; Yin, R.; Zhou, Z.; Gu, G.; Dai, J.; Lai, D.; Zhou, L. Eremophilane-Type Sesquiterpenoids From the Endophytic Fungus Rhizopycnis Vagum and Their Antibacterial, Cytotoxic, and Phytotoxic Activities. Front. Chem. 2020, 8, 596889. [CrossRef]

216. Gao, Y.; Stuhldreier, F.; Schmitt, L.; Wesselborg, S.; Guo, Z.; Zou, K.; Mándi, A.; Kurtán, T.; Liu, Z.; Proksch, P. Induction of New Lactam Derivatives From the Endophytic Fungus Aplosporella Javeedii Through an OSMAC Approach. Front. Microbiol. 2020, 11, 2796. [CrossRef]

217. Liu, H.; Chen, Y.; Li, S.; Zhang, W.; Liu, Z.; Tan, H.; Zhang, W. Trichothecene Macrolides from the Endophytic Fungus Paramyrothecium Roridum and Their Cytotoxic Activity. Fitoterapia 2020, 147, 104768. [CrossRef]

218. Bang, S.; Kwon, H.E.; Baek, J.Y.; Jang, D.S.; Kim, S.; Nam, S.-J.; Lee, D.; Kang, K.S.; Shim, S.H. Colletotrichalactones A-Ca, Unusual 5/6/10-Fused Tricyclic Polyketides Produced by an Endophytic Fungus, Colletotrichum sp. JS-0361. Bioorganic Chem. 2020, 105, 104449. [CrossRef]

219. Riga, R.; Happyana, N.; Quentmeier, A.; Zammarelli, C.; Kayser, O.; Hakim, E.H. Secondary Metabolites from Diaporthe Lithocarpus Isolated from Artocarpus Heterophyllus. Nat. Prod. Res. 2021, 35, 2324-2328. [CrossRef]

220. Yu, S.; Zhu, Y.-X.; Peng, C.; Li, J. Two New Sterol Derivatives Isolated from the Endophytic Fungus Aspergillus Tubingensis YP-2. Nat. Prod. Res. 2021, 35, 3277-3284. [CrossRef]

221. Chen, L.; Zhang, Q.-Y.; Jia, M.; Ming, Q.-L.; Yue, W.; Rahman, K.; Qin, L.-P.; Han, T. Endophytic Fungi with Antitumor Activities: Their Occurrence and Anticancer Compounds. Crit. Rev. Microbiol. 2014, 42, 454-473. [CrossRef]

222. Newman, D.J.; Cragg, G.M. Natural Products as Sources of New Drugs from 1981 to 2014. J. Nat. Prod. 2016, $79,629-661$. [CrossRef]

223. Cragg, G.M.; Newman, D.J. Plants as a Source of Anti-Cancer Agents. J. Ethnopharmacol. 2005, 100, 72-79. [CrossRef]

224. Ling-hua, M.; Zhi-yong, L.; Pommier, Y. Non-Camptothecin DNA Topoisomerase I Inhibitors in Cancer Therapy. Curr. Top. Med. Chem. 2003, 3, 305-320. [CrossRef]

225. Pommier, Y. Topoisomerase I Inhibitors: Camptothecins and Beyond. Nat. Rev. Cancer 2006, 6, 789-802. [CrossRef]

226. Haidle, A.M.; Myers, A.G. An Enantioselective, Modular, and General Route to the Cytochalasins: Synthesis of L-696,474 and Cytochalasin B. Proc. Natl. Acad. Sci. USA 2004, 101, 12048-12053. [CrossRef]

227. Svoboda, G. Alkaloids of Vinca Rosea (Catharanthus Roseus). IX. Extraction and Characterization of Leurosidine and Leurocristine. Subj. Strain Bibliogr. 1961, 24, 173-178.

228. Kawada, M.; Inoue, H.; Ohba, S.-I.; Masuda, T.; Momose, I.; Ikeda, D. Leucinostatin A Inhibits Prostate Cancer Growth through Reduction of Insulin-like Growth Factor-I Expression in Prostate Stromal Cells. Int. J. Cancer 2010, 126, 810-818. [CrossRef]

229. Chowdhury, N.S.; Sohrab, H.; Rana, S.; Hasan, C.M.; Jamshidi, S.; Rahman, K.M. Cytotoxic Naphthoquinone and Azaanthraquinone Derivatives from an Endophytic Fusarium Solani. J. Nat. Prod. 2017, 80, 1173-1177. [CrossRef]

230. Kharwar, R.N.; Mishra, A.; Gond, S.K.; Stierle, A.; Stierle, D. Anticancer Compounds Derived from Fungal Endophytes; Their Importance and Future Challenges. Nat. Prod. Rep. 2011, 28, 1208-1228. [CrossRef]

231. Wani, M.C.; Taylor, H.L.; Wall, M.E.; Coggon, P.; McPhail, A.T. Plant Antitumor Agents. VI. Isolation and Structure of Taxol, a Novel Antileukemic and Antitumor Agent from Taxus Brevifolia. J. Am. Chem. Soc. 1971, 93, 2325-2327. [CrossRef]

232. Cragg, G.M.; Kingston, D.G.I.; Newman, D.J. (Eds.) Anticancer Agents from Natural Products, 2nd ed.; CRC Press: Boca Raton, FL, USA, 2012; ISBN 978-0-429-13085-4.

233. Zhang, P.; Li, X.; Yuan, X.-L.; Du, Y.-M.; Wang, B.-G.; Zhang, Z.-F. Antifungal Prenylated Diphenyl Ethers from Arthrinium Arundinis, an Endophytic Fungus Isolated from the Leaves of Tobacco (Nicotiana Tabacum L.). Molecules 2018, 23, 3179. [CrossRef]

234. Gao, Y.; Stuhldreier, F.; Schmitt, L.; Wesselborg, S.; Wang, L.; Müller, W.E.G.; Kalscheuer, R.; Guo, Z.; Zou, K.; Liu, Z.; et al. Sesterterpenes and Macrolide Derivatives from the Endophytic Fungus Aplosporella Javeedii. Fitoterapia 2020, $146,104652$. [CrossRef] 